\title{
Perda dentária em adultos e idosos no Brasil: a influência de aspectos individuais, contextuais e geográficos
}

\author{
Rafael da Silveira Moreira
}

Tese apresentada ao Programa de Pós-Graduação em Saúde Pública da Faculdade de Saúde Pública da Universidade de São Paulo - USP, para obtenção do título de Doutor em Saúde Pública.

Área de Concentração: Epidemiologia

Orientador: Prof. Dr. Júlio César Rodrigues Pereira Co-orientadora: Prof ${ }^{a}$. Drª ${ }^{\text {a }}$ Lígia Vizeu Barrozo 
É expressamente proibida a comercialização deste documento, tanto na sua forma impressa como eletrônica. Sua reprodução total ou parcial é permitida exclusivamente para fins acadêmicos e científicos, desde que na reprodução figure a identificação do autor, título, instituição e ano da tese. 


\section{DedicATÓRIA}

DEDICO ESTE TRABALHO A TODOS AQUELES QUE LUTAM PELA MELHORIA DAS CONDIÇÕES DE VIDA E SAÚDE DA POPULAÇÃO BRASILEIRA, EM ESPECIAL AQUELES QUE VERDADEIRAMENTE COMBATEM A INIQUIDADE HERDADA PELO NOSSO SISTEMA PÚBLICO DE SAÚDE E QUE BUSCAM POR MEIO DE PRÁTICAS CONTRA-HEGEMÔNICAS PROMOVEREM A SAÚDE BUCAL EM NOSSO PAÍS.

DEDICO ESTE TRABALHO TAMBÉM AOS ADULTOS E IDOSOS QUE PARTICIPARAM DO LEVANTAMENTO EPIDEMIOLÓGICO ANALISADO NESTE ESTUDO E AOS PESQUISADORES QUE TRABALHARAM PARA A SUA REALIZAÇÃO, UTILIZANDO FERRAMENTAS METODOLÓGICAS E REFERENCIAIS TEÓRICOS DA EPIDEMIOLOGIA, PILAR DA SAÚDE COLETIVA, PERMITINDO CONHECER E ANALISAR OS FENÔMENOS E RELAÇÕES PRESENTES NO CENÁRIO SANITÁRIO BRASILEIRO.

Dedico ao meu pal, Rafael Moreira da Silva, Pelo seU exemplo deiXado em VIDA PARA QUE A NOSSA CAMINHADA NESTE MUNDO PUDESSE SER FEITA COM MUITO AMOR, PAIXÃO E MOTIVAÇÃO CONSTANTE NA BUSCA DIGNA DO CONHECIMENTO

TAMBÉM DEDICO ESTE TRABALHO A DEUS, POR PERMITIR A MANIFESTAÇÃO DA VIDA E DE SEUS ATRIBUTOS. 


\section{AGRADECIMENTOS}

Agradeço imensamente ao Prof. Júlio César Rodrigues Pereira que, DESDE O INÍCIO DO CURSO, SE MOSTROU NÃO APENAS UM EXCELENTE E COMPETENTE ORIENTADOR, MAS PRINCIPALMENTE UM AMIGO. SUA CRENÇA EM MEU PROJETO DE PESQUISA E NAS MINHAS INTENÇÕES ACADÊMICAS FEZ COM QUE ELE APOSTASSE EM MIM MESMO SEM TER ME CONHECIDO PREVIAMENTE. AGRADEÇO POR TER ME DESPERTADO UM SENTIMENTO DE PRAZER PELA BUSCA DO CONHECIMENTO E, CONSEQUENTEMENTE, PELO AUMENTO DA MINHA IGNORÂNCIA. AGRADEÇO POR TER ME TORNADO BEM MAIS MALICIOSO NO QUE SE REFERE ÀS REPRESENTAÇÕES SIMBÓLICAS DO CONHECIMENTO E POR DEIXAR COM QUE A DÚVIDA SOBRE A EXISTÊNCIA DA VERDADE OU DA VALIDADE, OU SE O MUNDO É ALGO DISCRETO OU CONTÍNUO, QUANTIFICÁVEL OU QUALIFICÁVEL, ME TORNASSE

BEM MAIS CURIOSO DO QUE ANTES. AGRADEÇO PELA SUA CONFIANÇA NA CONDUÇÃO DESSA PESQUISA E PELAS DELICIOSAS CONVERSAS SOBRE AS COISAS DO MUNDO. COM CERTEZA, O PESQUISADOR E A PESSOA QUE SOU HOJE TEM UMA FORTE INFLUÊNCIA SUA. MUITO OBRIGADO PELA SUA COMPANHIA NESSA INCANSÁVEL JORNADA!!!

À minha co-Orientadora e amiga Profa. Lígia Vizeu BarRozo, PELA SEMPRe DISPONIBILIDADE E PACIÊNCIA NOS DIÁLOGOS E INTERFACES ESTABELECIDAS NO CAMPO DA GEOGRAFIA DA SAÚDE. DESDE A ÉPOCA DOS MEUS ESTUDOS DURANTE o MESTRAdo EM SAÚde ColetiVA SUA REFleXÃo E doAÇÃo No CAMPO dA ANÁLISE ESPACIAL DA SAÚDE FORAM SEMPRE MARCANTES.

Aos professores Paulo Capel narvai e Paulo frazão, militantes da SAÚdE BUCAL COLETIVA, COM QUEM TIVE A HONRA E O PRIVILÉGIO DE APRENDER, DISCUTIR E REFLETIR SOBRE MEU OBJETO DE ESTUDO E SOBRE IMPORTANTES TEMAS QUE IMPULSIONAM O MOVIMENTO DA SAÚDE BUCAL COLETIVA EM NOSSO PAÍS.

Aos PRofessores José Leopoldo FerReira ANTUNES E RicARdo CoRdeiro, MESTRES SEMPRE PRESENTES NA DISCUSSÃO DA SAÚDE BUCAL E DA ANÁLISE ESPACIAL EM SAÚDE.

Aos demais PRofessores da Faculdade de SaÚde Pública CoM QUem tive 0 PRAZER DE APROFUNDAR EM VÁRIOS TEMAS LIGADOS À SAÚDE COLETIVA, EM SEUS TRÊS PILARES: EPIDEMIOLOGIA, CIÊNCIAS SOCIAIS E POLÍTICA, PLANEJAMENTO E GESTÃO DE SERVIÇOS DE SAÚDE.

À toda EquiPE ADMinistrativa da CPG (Comissão de Pós-Graduação), do Departamento de Epidemiologia e de Prática de Saúde Pública, Serviço DE ALUNOS, LABORATÓRIO DE INFORMÁTICA, ENFIM, TODA ESTA EXCELENTE ESTRUTURA QUE PROPICIOU O SUPORTE CONSTANTE EM MEUS ESTUDOS E EM MINHA TRAJETÓRIA ACADÊMICA E A PARTICIPAÇÃO DE INÚMEROS EVENTOS E CURSOS NA SAÚDE PÚBLICA. 
À Profa. MÁrcia Faria WestPHAL, QUE PROPICIOU A UNIÃo dA EPIDEMIOLOGIA COM A PROMOÇão dA SAÚdE POR MEIO DE UM EXCELENTE PROJETO DE PESQUISA NO QUAL TIVE A HONRA DE PARTICIPAR E A TODA SUA EQUIPE DE ALUNOS E PROFESSORES COLABORAdores do Departamento de PrÁtica de SAÚde PÚBLICA.

À todos os meus colegas do Journal Club: Clóvis, Valéria, Ângela, PAULO, MôNICA E TODOS AQUELES QUE PASSARAM POR ESTE DELICIOSO E RARO MOMENTO DE REFLEXÃO SOBRE A NATUREZA E SEUS ATRIBUTOS.

AO GRUPO DA "SALINHA" EM QUE EU PASSEI A MAIOR PARTE DA MINHA VIDA DE doutorando: Ricardo, Rossana, Dalva, Natália, Anderson, Prof. Victor WÜNSCH FILHO.

Ao meu pal, Rafael Moreira da Silva, pelos ensinamentos que continuam ME GUIANDO. À MINHA MÃE ANAILDA DA SiLVEIRA MOREIRA, PELO INCENTIVO E APOIO CONSTANTE EM MINHA CAMINHADA. AOS MEUS IRMÃOS HELOÍSA E JÚLIO, PELA FRATERNIDADE IMENSA E AOS AMIGOS VALIOSOS E VERDADEIROS.

À TODOS OS COLEGAS COM OS QUAIS TIVE A ALEGRIA DE CURSAR VÁRIAS DISCIPLINAS DURANTE ESSA CAMINHADA DENTRO E FORA DA FACULDADE DE SAÚde PÚBLICA.

À LUCÉLIA, PARCEIRA INCANSÁVEL NA BUSCA POR MELHORES CONDIÇÕES DE SAÚDE DOS IDOSOS EM NOSSO PAÍS, POR TER ME SEDUZIDO A TRILHAR ESTE CAMINHO DENTRO DO CAMPO DA SAÚDE COLETIVA E POR SUA VALIOSA PRESENÇA E COMPANHEIRISMO NESSA CAMINHADA!!!

Agradeço ao Conselho Nacional de Desenvolvimento Científico e TECNOLÓGICO (CNPQ) PELA BOLSA DE DOUTORADO.

Por fim, AGRAdeço também aOS novos amigos e colegas do Centro de Pesquisa Aggeu Magalhães da Fundação Oswaldo Cruz de Recife Pernambuco (CPQAM-FIocruZ-PE), LUGAR QUE ME ACOLHEU COMO Pesquisador em Saúde Pública e que Vem me dando apolo constante na REALIZAÇÃO E CONCRETIZAÇÃO DESTE ESTUDO, ALÉM DE OFERECER VALIOSAS OPORTUNIDADES DE PESQUISA E ENSINO NO CAMPO DA SAÚDE COLETIVA. 
A dúvida é um estado de insatisfação e inquietude do qual lutamos para nos desvencilhar e passar para um estado de crença, ao passo que este é um estado calmo e satisfatório que não desejamos evitar ou transformar numa crença em outra coisa. Ao contrário, nós nos agarramos tenazmente não só ao acreditar, mas acreditar precisamente naquilo em que acreditamos. Tanto a dúvida como a crença têm efeitos positivos sobre nós, ainda que bem distintos. A crença não nos faz agir prontamente, mas nos predispõe a agir de uma certa maneira quando surge a ocasião. A dívida é desprovida desse efeito ativo, mas nos estimula a investigar até que ela própria seja aniquilada. [...] A irritação da dúvida provoca uma luta para alcançar um estado de crença.

Charles Peirce (1877)

Vale à pena lembrar que, embora haja uma vasta diferença entre nós no que diz respeito aos fragmentos que conhecemos, somos todos iguais no infinito da nossa ignorância.

Karl Popper (1961)

Uma crença forte demonstra apenas a sua força, não a verdade daquilo em que se acredita.

Nietzsche (1878) 
RESUMO

Moreira RS. Perda dentária em adultos e idosos no Brasil: a influência de aspectos individuais, contextuais e geográficos. [tese de doutorado]. São Paulo: Faculdade de Saúde Pública da USP; 2009.

Introdução - As transições demográfica e epidemiológica vêm gerando mudanças no perfil sanitário de vários países. Dentre os vários campos da saúde, a saúde bucal expressa pela perda dentária encontra-se em situação preocupante. Objetivo - Identificar os fatores individuais e contextuais associados à perda dentária de adultos e idosos no Brasil e as características da distribuição espacial desses fatores. Métodos - Foram utilizados dados secundários do Projeto SB Brasil 2003, em que foi realizado um levantamento epidemiológico das condições de saúde bucal da população brasileira. Neste inquérito foi utilizada a técnica de amostragem probabilística por conglomerados, realizada em três estágios, totalizando 13.431 adultos entre 35 e 44 anos e 5.349 idosos entre 65 e 74 anos. A metodologia de análise empregou um modelo multinível de abordagem e a associação foi medida pela Razão de Médias e Razão de Prevalências, brutas e ajustadas. Utilizou-se a técnica de Processo Analítico Hierárquico (Analytical Hierarchy Process - AHP) e testes de dependência espacial para conhecer a distribuição espacial dos fatores associados à perda dentária. Resultados - Entre os adultos, as variáveis contextuais associadas com maior perda dentária foram: baixo número de cirurgiões-dentistas por mil habitantes (nível regional), maior número de exodontias por habitante (nível estadual) e municípios com menor porte populacional (nível municipal). As variáveis individuais associadas à perda dentária foram: maior número de pessoas por cômodo, ter consultado o cirurgião-dentista alguma vez na vida, há três anos ou mais e por motivo de dor, não ter recebido informações sobre prevenção de doenças bucais, ser do sexo feminino e a idade maior. Entre os idosos, duas análises foram feitas. Na primeira análise, as variáveis contextuais associadas ao edentulismo funcional foram as mesmas encontradas nos adultos, exceto o porte populacional. Na segunda análise, as variáveis contextuais associadas à menor necessidade de prótese total foram: maior taxa de primeira consulta odontológica programática (nível regional), da média de anos de estudo (nível estadual) e do porte municipal. Morar na área rural, maior número de pessoas por cômodo, ter tido a última consulta odontológica em serviço público, ser do sexo masculino, nãobranco e idade mais avançada foram associados à necessidade de prótese total. A análise espacial revelou áreas de risco estatisticamente significantes para a perda dentária e para a necessidade de prótese total. Conclusões O estudo revelou os principais aspectos contextuais e individuais associados com maior perda dentária. A combinação espacial simultânea desses atributos gerou mapas de predisposição para a perda dentária e necessidade de prótese total que podem nortear as ações de Saúde Bucal Coletiva.

Descritores: Saúde Bucal, Idosos, Adulto, Levantamento Epidemiológico de Saúde Bucal, Análise Espacial, Análise Multinível. 
ABSTRACT

Moreira RS. Tooth-loss in adults and the elderly in Brazil: the influence of individual, contextual and geographical features. [PhD Thesis]. São Paulo: Faculdade de Saúde Pública da USP; 2009.

Introduction - The demographic and epidemiological transitions are causing changes in the health profile worldwide. Among the various areas of health care, oral health expressed by tooth loss is in a precarious situation. Objective - The objective was thus to identify the individual and contextual factors associated with tooth-loss in adults and the elderly in Brazil and the characteristics of the spatial distribution of these factors. Methods Secondary data from the 2003 SB Brasil Project were used. This was an epidemiological survey of the oral health of the Brazilian population. The study used the technique of probability sampling by clusters, in three stages, covering 13,431 adults aged between 35 and 44 years old and 5,349 elderly individuals aged between 65 and 74 years. A multilevel analysis was employed and the degree of association was measured using the crude and adjusted mean and prevalence ratios. The Analytical Hierachy Process (AHP) technique was used to ascertain the spatial distribution of factors associated with tooth- loss, along with tests of spatial dependence. Results Among adults, the contextual variables associated with increased tooth-loss were: a lower number of dentists per thousand inhabitants (at regional level), an increased number of tooth extractions per capita (at state level) and a smaller population size (at municipal level). The individual variables associated with tooth-loss were: a greater number of individuals living in the same room, never having consulted a dentist, having consulted a dentist three years or more ago and because of pain, not having received information on prevention of dental diseases, being female, and increased age. A further two analyses were carried out for the elderly group. In the first analysis, the contextual variables associated with functional edentulism were found to be the same in adults, with the exception of the population size. Living in rural areas and being female were associated with functional edentulism. In the second analysis, the contextual variables associated with reduced need for total prosthesis were: greater coverage of the first dental consult program (at regional level), average number of years of schooling (at state level) and population size. Living in rural areas, a greater number of individuals per room, having had the last dental consultation in the public sector, being male, non-white and of greater age were associated with the need for total prosthesis. Spatial analysis shows critical areas of risk for tooth loss. Conclusions - The study revealed the key contextual and individual aspects associated with greater tooth-loss. The combination of simultaneous spatial attributes generated maps showing the geographical predisposition to tooth loss and the need for total prosthesis that will be able to guide the work of those working in the area of Collective Oral Health.

Key words: Oral Health, Elderly, Adult, Epidemiological Oral Health Survey, Spatial Analysis, Multilevel Analysis. 


\section{ÍNDICE}

LISTA DE FIGURAS ..............................................................................................................

LISTA DE TABELAS ...................................................................................................................12

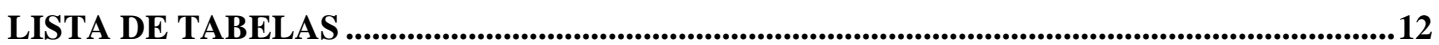

LISTA DE SIGLAS E ABREVIATURAS.......................................................................................13

APRESENTAÇÃO ......................................................................................................14

1 INTRODUÇÃO

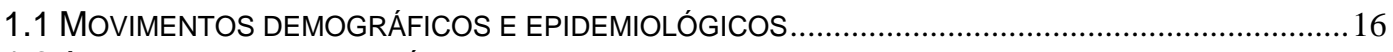

1.2 A EPIDEMIOLOGIA DA SAÚDE BUCAL DOS ADULTOS E IDOSOS ..............................................19

1.3 O ESTUDO DAS CONDIÇÕES DE SAÚDE BUCAL POR MEIO DE UMA EPIDEMIOLOGIA

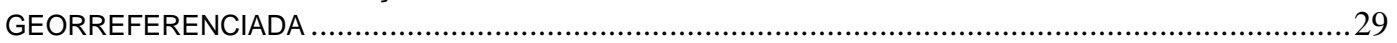

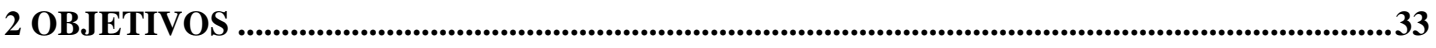

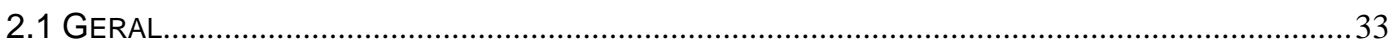

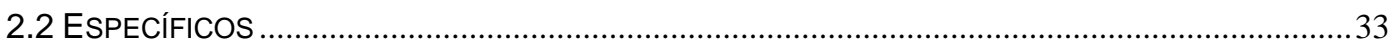

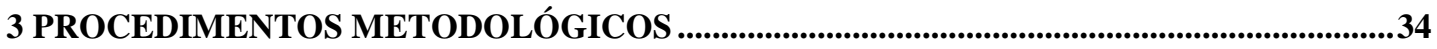

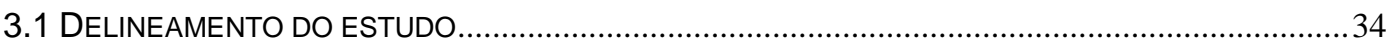

3.2 CARACTERÍSTICAS DO LEVANTAMENTO EPIDEMIOLÓGICO NACIONAL DAS CONDIÇÕES DE

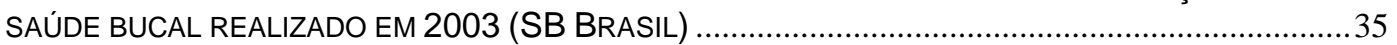

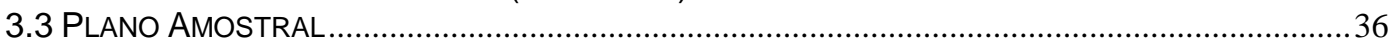

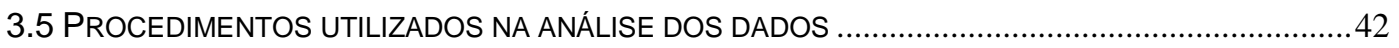

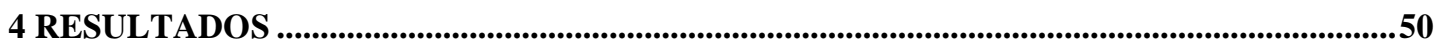

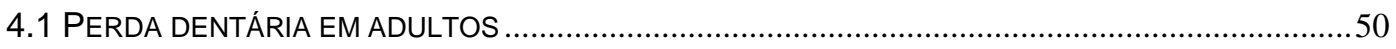

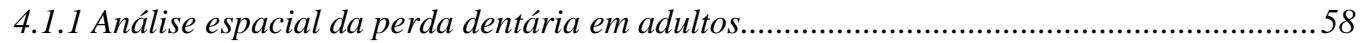

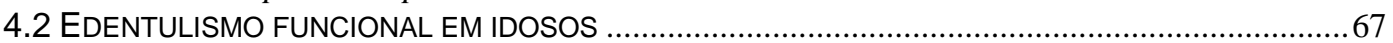

4.2.1 Análise espacial do edentulismo funcional em idosos....................................................... 72

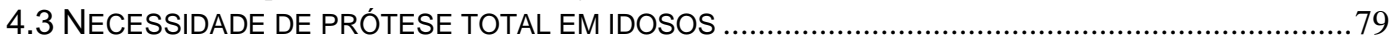

4.3.1 Análise espacial da necessidade de prótese total em idosos .............................................85

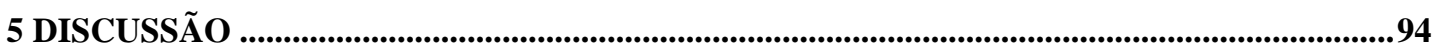

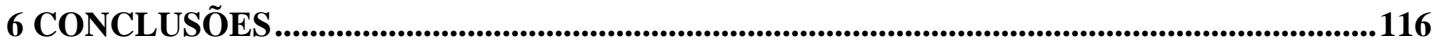

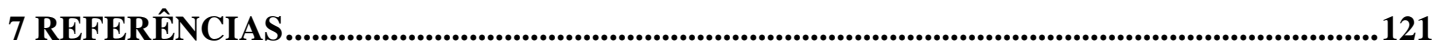

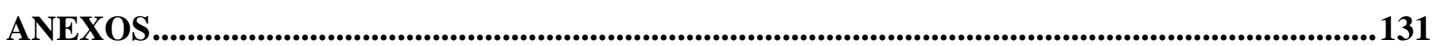

CURRÍCULO LATTES DO AUTOR......................................................................................136

CURRÍCULO LATTES DO ORIENTADOR.........................................................................................137 


\section{Lista de Figuras}

Figura 1 - Distribuição espacial dos 250 municípios que participaram do inquérito epidemiológico de saúde bucal da população brasileira e divisão geográfica dos níveis analisados na amostra. Brasil, 2004.

Figura 2 - Distribuição dos dentes perdidos entre os idosos não edêntulos. Brasil, 2004... 45

Figura 3 - Diagrama de Espalhamento de Moran

Figura 4 - Modelo teórico-hierárquico da perda dentária em adultos $(A)$, do edentulismo funcional em idosos(B), da necessidade de prótese total em idosos (C).

Figura 5 - Razão de Médias (RM) e intervalo de 95\% das variáveis contextuais e individuais que apresentaram interações. Brasil, 2004.

Figura 6 - Densidade de dentistas por 1000 habitantes segundo o estado. Brasil, 2003. ... 59

Figura 7 - Taxa de exodontia segundo a microrregião. Brasil, 2003. 60

Figura 8 - Porte populacional segundo a microrregião. Brasil, 2003. 61

Figura 9 - Mapa de risco para perda dentária gerado pelo Processo Analítico Hierárquico (AHP). Brasil, 2003.

Figura 10 - Mapa de risco para perda dentária gerado pela Krigeagem Ordinária. Brasil, 2003.

Figura 11 - Box Map: Mapa de espalhamento de Moran para o risco de perda dentária gerado pelo Processo Analítico Hierárquico (AHP). Brasil, 2003.

Figura 12 - Lisa Map: Mapa de espalhamento de Moran para o risco de perda dentária gerado pelo Processo Analítico Hierárquico (AHP). Brasil, 2003.

Figura 13 - Moran Map: Mapa de espalhamento de Moran para o risco de perda dentária gerado pelo Processo Analítico Hierárquico (AHP). Brasil, 2003.

Figura 14 - Razão de Prevalência (RP) e intervalo de 95\% para as variáveis contextuais e individuais que apresentaram interações. Brasil, 2004.

Figura 15 - Taxa de urbanização segundo quintis, por microrregião, Brasil, 2003.

Figura 16 - Mapa de risco para perda o edentulismo funcional em idosos gerado pelo Processo Analítico Hierárquico (AHP). Brasil, 2003.

Figura 17 - Mapa de risco para edentulismo funcional após o procedimento de Krigeagem Ordinária, Brasil, 2003...

Figura 18 - Box Map: Mapa de espalhamento de Moran para o risco de edentulismo funcional gerado pelo Processo Analítico Hierárquico (AHP). Brasil, 2003.

Figura 19 - LISA Map para o risco de edentulismo funcional gerado pelo Processo Analítico Hierárquico (AHP). Brasil, 2003.

Figura 20 - Moran Map: Mapa de espalhamento de Moran para o risco de edentulismo funcional gerado pelo Processo Analítico Hierárquico (AHP). Brasil, 2003. 
Figura 21 - Razão de Prevalência (RP) e intervalo de 95\% para as variáveis contextuais e individuais que apresentaram interações, para a necessidade prótese total em idosos.

Brasil, 2004

Figura 22 - Taxa de primeira consulta odontológica programática segundo quintis, por microrregião, Brasil, 2003.

Figura 23 - Média de anos de estudo da população de 25 anos ou mais de idade segundo quintis, por microrregião, Brasil, 2000.

Figura 24 - Mapa de risco para necessidade de prótese total em idosos gerado pelo Processo Analítico Hierárquico (AHP). Brasil, 2003.

Figura 25 - Mapa de risco para necessidade de prótese total em idosos gerado pelo Processo Analítico Hierárquico (AHP). Brasil, 2003.

Figura 26 - Box Map: Mapa de espalhamento de Moran para o risco de necessidade de prótese total em pelo menos um arco dentário. Brasil, 2003.

Figura 27 - LISA Map para o risco de necessidade de prótese total em pelo menos um arco dentário. Brasil, 2003.

Figura 28 - Moran Map: Mapa de espalhamento de Moran para o risco de necessidade de prótese total em pelo menos um arco dentário gerado pelo Processo Analítico Hierárquico (AHP). Brasil, 2003 


\section{Lista de Tabelas}

Tabela 1 - Variáveis dependentes e independentes utilizadas nos modelos de regressão empregados em adultos e idosos segundo a fonte e o ano.

Tabela 2- Descrição da média de perda dentária em adultos brasileiros. Brasil, 2004

Tabela 3 - Razão de média da perda dentária em adultos segundo estimativas do modelo univariado de regressão binomial negativa para as variáveis do nível contextual. Brasil, 2004.

Tabela 4 - Razão de média da perda dentária em adultos segundo estimativas do modelo multinível hierárquico múltiplo de regressão binomial negativa. Brasil, 2004.

Tabela 5 - Razão de prevalência de edentulismo funcional em idosos segundo estimativas do modelo univariado de regressão de Poisson. Brasil, 2004.

Tabela 6 - Razão de prevalência de edentulismo funcional ${ }^{\star}$ em idosos segundo estimativas do modelo múltiplo de regressão de Poisson. Brasil, 2004.

Tabela 7 - Razão de prevalência da necessidade de prótese total em pelo menos um arco em idosos segundo estimativas do modelo univariado de regressão de Poisson. Brasil, 2004.

Tabela 8 - Razão de prevalência da necessidade de prótese total em pelo menos um arco em idosos segundo estimativas do modelo hierárquico múltiplo de regressão de Poisson multinível. Brasil, 2004. 


\section{Lista de Siglas e Abreviaturas}

$\mathrm{ABO}=$ Associação Brasileira de Odontologia

$\mathrm{AHP}=$ Analytical Hierarchy Process

$\mathrm{PAH}=$ Processo Analítico Hierárquico

$\mathrm{CFO}=$ Conselho Federal de Odontologia

CPO-D = índice de dentes cariados, perdidos ou obturados

CSE $=$ Condição Socioeconômica

DATASUS = Departamento de Informática do Sistema Único de Saúde

FFLCH = Faculdade de Filosofia, Letras e Ciências Humanas

FSP = Faculdade de Saúde Pública

OMS = Organização Mundial de Saúde

PNAD = Pesquisa Nacional por Amostras de Domicílios

$\mathrm{RM}=$ Razão de Médias

$\mathrm{RP}=$ Razão de Prevalência

SIG = Sistemas de Informação Geográfica

$\mathrm{TD}=$ Transição demográfica

TE = Transição epidemiológica

USP = Universidade de São Paulo 


\section{APRESENTAÇÃO}

Este trabalho consiste na tese de doutorado do cirurgião-dentista Rafael da Silveira Moreira, aluno regular do Programa de Pós-Graduação em Saúde Pública da Faculdade de Saúde Pública da Universidade de São Paulo (FSP-USP), sob a orientação do Professor Associado Júlio César Rodrigues Pereira, docente do Departamento de Epidemiologia da FSPUSP, e co-orientação da Profạ. Drạ. Ligia Vizeu Barrozo, docente do Departamento de Geografia da Faculdade de Filosofia, Letras e Ciências Humanas da Universidade de São Paulo (FFLCH-USP).

A pesquisa consistiu em uma análise aprofundada do estudo epidemiológico transversal da saúde bucal da população brasileira - SB BRASIL 2003 - com ênfase na identificação dos aspectos individuais e contextuais associados à perda dentária de adultos e idosos, além da distribuição espacial desses fatores, visando uma compreensão das interrelações no processo saúde-doença-território.

No Capítulo 1 encontra-se uma introdução ao tema deste estudo, com ênfase no atual processo de envelhecimento populacional, a saúde bucal dos adultos e idosos diante deste contexto e a importância da realização de levantamentos epidemiológicos em saúde bucal. É apresentada também a relevância da utilização de análises espaciais em saúde com auxílio de tecnologias de geoprocessamento. 
No Capítulo 2 encontram-se sistematizados os objetivos geral e específicos.

O Capítulo 3 descreve o método empregado neste estudo, com descrição do delineamento do estudo, plano amostral, caracterização dos instrumentos e descrição das variáveis, procedimentos e formas utilizadas para a análise dos resultados.

No Capítulo 4 são apresentados os resultados, subdivididos em três partes: 1) Perda Dentária em Adultos; 2) Edentulismo Funcional em idosos e; 3) Necessidade de Prótese Total em Idosos.

O Capítulo 5 destaca-se pelo aprofundamento na discussão e cotejamento desses achados com a literatura.

No Capítulo 6 são tecidas as conclusões, com a reflexão sobre os resultados encontrados.

Os anexos consistem nas fichas utilizadas no Projeto SB Brasil 2003 e na aprovação do projeto de pesquisa desta tese pelo Comitê de Ética em Pesquisas da Faculdade de Saúde Pública da USP. 


\section{INTRODUÇÃO}

\subsection{Movimentos demográficos e epidemiológicos}

O momento demográfico mundial é representado pelo evidente processo de envelhecimento populacional. Embora seja um fenômeno global, o estágio em que se encontra cada país neste processo apresenta algumas diferenças. A heterogeneidade é a marca principal deste cenário demográfico e pode ser observada tanto entre diferentes nações (abordagens internacionais) quanto entre diferentes municípios ou, até mesmo, entre bairros de uma mesma cidade (abordagens locais).

Como todo processo histórico, a configuração de uma população é o resultado de sua própria trajetória política, econômica e social, ao longo do tempo e do espaço. Nos países desenvolvidos, o processo de envelhecimento ocorreu como conseqüência de padrões elevados de vida, minimizando as desigualdades sociais e econômicas e planejando estratégias institucionais para compensar os efeitos das desigualdades residuais, inclusive com relação ao acesso aos serviços de saúde. Em contraposição, nos países em desenvolvimento, especialmente na América Latina e Caribe, um acelerado processo de envelhecimento vem ocorrendo em um contexto altamente desfavorável, caracterizado por economias frágeis, crescentes níveis de pobreza, contribuindo para o aumento das 
desigualdades sociais e econômicas, ao mesmo tempo em que limita o acesso aos serviços de saúde e os recursos coletivamente financiados ${ }^{58}$.

Estas mudanças na composição etária de uma população são conhecidas pelo nome de Transição Demográfica (TD). A TD é claramente visualizada na configuração da pirâmide etária, caracterizada pelo estreitamento de sua base (resultado da queda da fecundidade) e um alargamento de seu ápice (conseqüência da diminuição da mortalidade e aumento da expectativa de vida).

São vários os determinantes da TD gerando o envelhecimento populacional. Tais determinantes estão relacionados a outro processo de mudança, também mundialmente experimentado: a Transição Epidemiológica (TE). Do mesmo modo que a primeira, esta também não se apresenta de forma homogênea, possui diferentes estágios e varia de região para região.

Segundo CHAIMOWICZ ${ }^{14}$, o termo "Transição Epidemiológica" refere-se às modificações, em longo prazo, dos perfis de morbi-mortalidade e invalidez que definem uma determinada população e que, geralmente, ocorrem simultaneamente a outras transformações demográficas, sociais e econômicas. A principal característica deste processo é a diminuição da mortalidade por doenças infecto-contagiosas, substituída pelo aumento da mortalidade por doenças crônico-degenerativas não transmissíveis. Com isto, os grupos mais velhos da população passam a concentrar as maiores cargas de morbi-mortalidade. As conseqüências deste fenômeno geram mudanças nos padrões de uso dos serviços de saúde, com aumento da 
demanda de indivíduos com doenças crônicas. Estas, ao contrário dos processos agudos que evoluem rápido, seja para a cura, seja para a morte, demandam maior tempo e uso dos serviços de saúde.

Embora se tenham relatado os avanços na área da saúde, tais como a evolução do saneamento básico, o combate às doenças infecciosas e à desnutrição, progressos técnico-científicos no tratamento de várias doenças, redução da exposição aos agravos e a ampliação no acesso aos serviços de saúde como os principais determinantes dos perfis demográficos e epidemiológicos brasileiros, a expressão que melhor estampa este cenário é a desigualdade.

A maioria dos determinantes e condicionantes do processo saúdedoença apresenta grandes desigualdades entre as diferentes regiões do Brasil e também entre os diferentes estratos dentro de uma mesma locorregião. Doenças infecciosas ainda se apresentam com elevadas prevalências em algumas regiões como Norte e Nordeste ${ }^{76}$. Tais diferenças também são observadas no interior de várias cidades que convivem com variados coeficientes de mortalidade infantil, refletindo as grandes diferenças sociais representadas pelos "bolsões de pobreza" nas grandes metrópoles, indicando que o país ainda se encontra em processo de transições.

Estas desigualdades, muitas vezes ocultadas por números expressos em médias nacionais, revelam a existência de "Muitos Brasis", ou seja, um complexo processo demográfico, social e sanitário, impossível de ser reduzido a um modelo de polarização entre desenvolvimento e subdesenvolvimento, burguesia e proletariado, riqueza e pobreza, campo e 
cidade, agricultura e indústria, exploradores e explorados, passado e presente, arcaico e moderno $0^{50}$.

\subsection{A epidemiologia da saúde bucal dos adultos e idosos}

Tendo-se esboçado um cenário das condições demográficas e epidemiológicas da população brasileira, emergem no mínimo dois objetos de estudos a serem considerados em pesquisas em Saúde Coletiva: o envelhecimento humano (com suas características e conseqüências) e as condições de vida e saúde dos idosos. Como o primeiro objeto por si só já é alvo de ricas investigações na área da Demografia, o estudo das condições de saúde dos idosos tem sido objeto freqüente de pesquisas em Saúde Coletiva nos últimos 20 anos. Dentre os vários campos da saúde, as evidências científicas mostram que a saúde bucal do idoso brasileiro se apresenta em precárias condições, com alta prevalência de edentulismo (perda de todos os dentes), doenças periodontais, dentes cariados e necessidades de uso de próteses ${ }^{53,16}$.

Considerando o caráter cumulativo das principais doenças bucais (cárie e doença periodontal), o conhecimento das condições bucais da população adulta adquire especial importância na medida em que estes indivíduos representam a coorte mais próxima da população idosa e que serão objetos de futuras investigações sobre a saúde bucal dos idosos. Suas condições de vida e saúde poderão indicar um prognóstico epidemiológico 
bucal, possibilitando a chance de se intervir em grupos de risco de reprodução dos agravos bucais encontrados atualmente na população idosa.

A perda dentária precoce em adultos é considerada um fator de risco para o edentulismo. Em um estudo realizado no Estado de São Paulo, FRAZÃO et al. ${ }^{29}$ consideraram como indicador da perda dentária precoce a proporção de indivíduos com mais de 12 dentes perdidos. Este critério de classificação tem como base as metas da Organização Mundial de Saúde (OMS) recomendadas para o ano 2000 e que recomenda para o grupo etário de 35 a 44 anos a presença de 20 ou mais dentes na boca em $75 \%$ da população ${ }^{25}$.

Segundo dados do Instituto Brasileiro de Geografia e Estatística ${ }^{37}$, em sua pesquisa nacional por amostra de domicílios no ano de 1998 (PNAD/98), quase 30 milhões de brasileiros $(29,6$ milhões $-18,7 \%$ da população brasileira) nunca tiveram acesso a um cirurgião-dentista. De cada quatro brasileiros com mais de 60 anos de idade, três são desdentados em pelo menos uma arcada ${ }^{9}$.

No Brasil, são escassos os estudos que descrevem o quadro epidemiológico da saúde bucal, em âmbito nacional. Os levantamentos epidemiológicos realizados pelo Ministério da Saúde nos anos de 1986 e 1996 tiveram como prioridade o grupo dos escolares, não contemplando os indivíduos maiores de 60 anos. No estudo epidemiológico realizado em 1986, foram observados indivíduos adultos de 35 a 44 anos. Apesar de a OMS recomendar o exame das condições bucais da população idosa utilizando como grupo-índice os indivíduos de 64 a 75 anos, esta faixa etária 
foi alterada para 50 a 59 anos devido à configuração etária da população brasileira, caracterizada na época por uma expectativa de vida de 65,5 anos para as mulheres e 61,3 anos para os homens (dados do período de 19751980) ${ }^{19}$. Já o levantamento realizado em 1996 se restringiu aos aspectos bucais de escolares entre seis e 12 anos de idade.

Mais recentemente, foi realizado o Levantamento das Condições de Saúde Bucal da População Brasileira - Projeto SB Brasil 2003. Operacionalizado pelo Ministério da Saúde em parceria com a Associação Brasileira de Odontologia - ABO nacional, o Conselho Federal de Odontologia - CFO e várias Faculdades de Odontologia (públicas e privadas), o Projeto SB BRASIL 2003 visou uma amostra representativa em âmbito macrorregional. A média nacional encontrada nesse estudo para o grupo etário de 65 a 74 anos, referente ao número de dentes cariados, perdidos ou obturados (CPO-D), por indivíduos, foi de 27,93. Isto significa que cada pessoa desse grupo possui, em média, apenas quatro dentes livres da cárie e de suas conseqüências (obturação/extração). No caso dos idosos, ressalta-se maior participação do componente "perdido" (92,16\%) na composição percentual do índice CPO- $D^{9}$.

Quanto à necessidade do uso de prótese, $56 \%$ e $32,4 \%$ necessitavam de próteses inferior e superior, respectivamente, sendo a prótese total o tipo de prótese com maior necessidade, indicando a alta prevalência de edentulismo ${ }^{9}$.

Nos adultos (35 a 44 anos), a participação do componente perdido no índice CPO-D foi de $65,7 \%$, sendo que a média do índice foi de 20,1 . 
Entretanto, no que diz respeito às metas da OMS para o ano 2000, os adultos se aproximaram muito mais da meta de $75 \%$ de indivíduos com 20 ou mais dentes na boca $(53,96 \%)$ do que o resultado observado nos idosos, cuja meta era de $50 \%$ de indivíduos nessas condições. No entanto, apenas $10,23 \%$ dos idosos apresentaram 20 ou mais dentes ${ }^{9}$.

Deve-se destacar a magnitude deste último levantamento epidemiológico. Diferente do levantamento de 1986, que se restringiu aos aspectos relacionados à cárie, doença periodontal e uso e necessidade de prótese, limitado à área urbana de 16 capitais brasileiras, o SB Brasil incorporou outros índices bucais como a maloclusão e a fluorose dentaria, tornando-se pioneiro no estudo dessas condições em âmbito nacional. Também gerou informações relativas às condições socioeconômicas, ao acesso aos serviços e à autopercepção em saúde bucal, incluindo grupos etários não abordados pelos levantamentos anteriores como os idosos (64 a 75 anos) e bebês (18 a 36 meses). Aproximadamente dois mil trabalhadores (cirurgiões-dentistas, auxiliares e agentes de saúde, dentre outros) de 250 municípios estiveram envolvidos na realização do estudo.

Uma vez revelado o contexto e identificadas as variáveis que nele atuam, o conhecimento das condições de saúde bucal das populações adulta e idosa é um trabalho importante que encontra na epidemiologia um referencial epistemológico e metodológico para auxiliar o pesquisador ou o profissional da área de saúde na mensuração da distribuição de doenças na população (analisada pelo tempo, espaço e classes sociais de pessoas afetadas); na descoberta dos determinantes, sejam eles fatores físicos, 
biológicos, sociais, culturais ou comportamentais; na definição de métodos de prevenção; no controle de doenças em grupos populacionais e no planejamento e avaliação de serviços de saúde ${ }^{43}$.

A perda dentária é um reconhecido problema de saúde pública. Considerada como uma importante medida da condição de saúde bucal de uma população, a perda dentária possui forte efeito sobre a qualidade de vida das pessoas. Seus impactos podem ser expressos pela diminuição das capacidades funcionais de mastigação e fonação, bem como por prejuízos de ordem nutricional, estética e psicológica, com reduções de auto-estima e de integração social. ${ }^{61,56,69,71}$. Adicionalmente, a perda dentária produz aumento na demanda por reabilitações protéticas. Em um estudo realizado em adultos na Suécia, os custos do tratamento protético, incluindo material e hora de trabalho, representaram $67 \%$ do total dos custos com assistência odontológica $^{38}$. Se por um lado esta situação afeta os indivíduos sem recursos próprios para o pagamento de próteses dentária e que, geralmente são os que mais apresentam perdas dentárias, por outro lado, os serviços públicos odontológicos necessitam aumentar seus gastos com procedimentos reabilitadores, notadamente mais caros do que os preventivos.

Mesmo em países desenvolvidos, a perda de dentes permanentes é elevada. Em países da Europa, o edentulismo, condição caracterizada pela perda de todos os dentes permanentes e expressão do grau máximo deste agravo à saúde, atinge mais da metade das populações idosa ${ }^{6}$. Enquanto em países como Madagascar (África) a prevalência de 
edentulismo em idosos chega a $25 \%$, em países da Europa, como o Reino Unido, esta prevalência chega a $46 \%{ }^{61}$. Nesse sentido, a Organização Mundial de Saúde (OMS) junto com a FÉDÈRATION DENTAIRE INTERNATIONALE ${ }^{25}$ estabeleceram para o ano 2000 a meta de $75 \%$ de indivíduos adultos (35-44 anos) e 50\% dos indivíduos idosos (65-74 anos) com pelo menos 20 dentes em condições funcionais. Contudo, sem a compreensão dos aspectos relacionados à perda dentária, será difícil o alcance de qualquer meta na área da saúde.

A maioria dos estudos sobre a perda dentária tem dado muita atenção em descrever a prevalência do edentulismo ou o número de dentes perdidos $^{17}$. A taxa de edentulismo é obviamente um importante indicador de saúde bucal. No entanto, dicotomiza a população em duas grandes categorias: pessoas com no mínimo um dente e pessoas sem nenhum dente. Dessa forma, é revelada a tênue fronteira entre essas duas categorias, situação típica da imposição de pontos de cortes em fenômenos contínuos. Em oposição, a contagem de dentes perdidos é uma variável quantitativa discreta, com distribuição conhecida e pode ser considerada como um desfecho bem definido e de fácil obtenção para ser utilizado em estudos epidemiológicos.

A rede de causalidade da perda dentária envolve fatores em níveis contextuais e individuais, com diferentes gradientes e interações entre estes níveis. Esta rede acomoda-se perfeitamente na teoria ecossocial, proposta por KRIEGER ${ }^{42}$, como uma possibilidade de integrar os conhecimentos biológico e social, correspondendo a uma estrutura de um objeto de 
natureza fractal, com a inter-relação das diversas variáveis em todos os níveis, do molecular ao social. Nesse mesmo sentido, a análise conjunta de variáveis individuais e variáveis ecológicas corrobora a idéia de investigação em múltiplos níveis, levando-se em conta a hierarquia de complexidade e as múltiplas interações entre e através os diferentes níveis, vislumbrando o que é denominado por SUSSER e SUSSER ${ }^{74}$ como uma eco-epidemiologia. MOYSÉS e SHEIHAM ${ }^{55}$ sugerem a adoção destas correntes interativas e em múltiplos níveis como um novo paradigma para a Epidemiologia predominando uma sócio-eco-epidemiologia.

A influência de fatores do nível individual e do nível dentário sobre a perda dentária já foi objeto de vários estudos em diferentes países, inclusive com abordagens multiníveis ${ }^{17,31,73,23,36}$. Embora a análise dos fatores contextuais seja objeto dos estudos ecológicos, a análise da influência do nível individual controlado pelo nível contextual sobre o fenômeno da perda dentária permanece como uma oportunidade para o melhor conhecimento da complexidade desse fenômeno e de seus fatores determinantes.

Neste sentido, resgata-se a importância do retorno às discussões sobre os Determinantes Sociais da Saúde, tema já discutido no século XIX por Virchow e pelo movimento da Medicina Social que sucedeu este período, com importantes contribuições de pesquisadores latino-americanos tais como Jaime Breilh e Asa Cristina Laurell na emergência da Epidemiologia Social $^{2}$. Este referencial de determinação do processo saúde-doença é hoje revisitado pela discussão dos determinantes sociais em saúde com a criação 
da Comissão Nacional sobre Determinantes Sociais da Saúde*, seguindo uma recomendação da OMS neste sentido. A comissão propõe vários modelos que buscam dar sustentabilidade a esta determinação. Dentre eles, destaca-se o modelo proposto por DAHLGREN e WHITEHEAD ${ }^{22}$. Este modelo assume um sentido estrutural no processo de determinação, com uma sequência linear e ao mesmo tempo concêntrica de determinantes macro-estruturais no nível mais distal e abrangendo todos os outros níveis, passando por determinantes intermediários representados principalmente pelas condições de vida e de trabalho, redes sociais e comunitárias e estilo de vida dos indivíduos, até o nível mais proximal representado pelos atributos individuais ligados à idade, gênero e fatores hereditários.

A partir de um quadro teórico amplo, que aponta diferentes níveis de condições causais, que vai do indivíduo para as comunidades, até o nível das políticas nacionais de saúde, os autores indicam quatro níveis conexos de ação, a partir dos quais a política pela equidade deve ser orientada: fortalecimento dos indivíduos, fortalecimento das comunidades; melhoria do acesso a instalações e serviços essenciais e o encorajamento a mudança macroeconômica e cultural.

Embora tal modelo seja passível de críticas pelos seus aspectos estruturalista e linear, e principalmente por colocar os indivíduos na posição de atores "determinados", sem nenhum poder de determinação e influência sobre o processo saúde-doença, o modelo se torna útil para a análise em curso haja vista não apenas sua praticidade operacional, mas seu poder de

\footnotetext{
* Comissão Nacional sobre Determinantes Sociais da Saúde. Disponível em: http://www.determinantes.fiocruz.br. Acesso em 08.11.2009
} 
revelar o papel dos determinantes sociais na iniqüidade em saúde bucal no Brasil. Contudo, vale destacar a consciência de que o modelo proposto não dá conta da complexidade envolvida neste processo, embora seja útil para responder algumas formulações teóricas sobre o problema aqui exposto.

Nesta direção, a pergunta condutora que motivou a realização desta pesquisa foi: Quais são os fatores individuais e contextuais associados à perda dentária e à necessidade de próteses dentárias em adultos e idosos no Brasil, e qual a localização espacial desses fatores no espaço geográfico socialmente construído como dimensão constitutiva do processo saúde-doença bucal?

A resposta a esta pergunta se apóia no referencial teórico da Epidemiologia enquanto Ciência da Saúde $^{1}$ e enquanto um arsenal de ferramentas que conferem a possibilidade de se testar empiricamente uma constatação antiga e constantemente revisitada no discurso da medicina social. A presente tese se sustenta simultaneamente nas vantagens e desvantagens de um estudo de natureza ecológica hibridizado com um estudo de natureza transversal/seccional ou de prevalência. Dito isso, é necessário esclarecer e ressaltar que os efeitos das variáveis contextuais não devem ser interpretados como atributos individuais (devido à existência da falácia ecológica ou simplesmente efeito de conglomerado), mas sim como predicados do ambiente sociogeográfico em que vivem os indivíduos pesquisados. Dessa forma, é possível e plausível que as variáveis contextuais aqui investigadas não se apliquem à realidade de todos os 
indivíduos de modo isolado, mas representam a força do contexto sobre o conjunto dos resultados individuais.

O referencial metodológico que mais se aproxima da teoria ecossocial de explicação do processo saúde-doença é a análise multinível, sendo possível pela existência da informação do desfecho em nível individual e pela viabilidade de incorporação de variáveis ecológicas, respeitando a natureza hierárquica dos dados disponíveis. A análise em mais de um nível objetiva incluir elementos contextuais/ecológicos, muitas vezes expressos por informações agregadas em unidades geográficas mais amplas, permitindo uma análise não só dos indivíduos, mas também dos fenômenos coletivos que contextualizam determinada população.

No Brasil, a saúde bucal poucas vezes foi alvo de estudos epidemiológicos de abrangência nacional e que abordassem a população adulta e idosa. Tradicionalmente, tanto a pesquisa quanto a resposta oferecida pelos serviços odontológicos priorizaram a saúde bucal de escolares. Apesar de existir no país um sistema de saúde universal, a herança do modelo de atenção odontológica revela a perda dentária em adultos como um problema cumulativo de saúde bucal, relacionado tanto com as condições objetivas de vida e saúde desta população, seus valores culturais e suas crenças, quanto com as características do serviço odontológico existente no país. A configuração desta rede de relações expressa nitidamente a influência de aspectos individuais e contextuais sobre a perda dentária que devem ser levados em consideração no estudo epidemiológico deste agravo. 


\subsection{O estudo das condições de saúde bucal por meio de uma epidemiologia georreferenciada}

A influência do meio ambiente sobre as condições de saúde das pessoas é uma preocupação antiga do ser humano. Ainda no século $V$ a.C., Hipócrates já defendia a importância do espaço como o lócus de ocorrência das doenças em sua obra, pioneira neste aspecto, Dos ares, dos mares e dos lugares ${ }^{49}$

A evolução da própria Epidemiologia, revelando um potencial epistemológico e metodológico para se postular como Ciência da Saúde ${ }^{1}$, e o reconhecimento de uma necessidade de se buscar transformações estruturais que desequilibrem o sistema desencadeante das iniqüidades, ao invés de apenas propor medidas corretivas biológico-ecológicas ${ }^{10}$, reforçam a validade de uma estratégia conceitual e metodológica que tenha como perspectiva a abordagem do espaço geográfico-social entendido como expressão das condições de vida da população ${ }^{20}$.

O uso de técnicas de geoprocessamento para a manipulação e análise de dados georreferenciados, ou seja, reunião de informações socioeconômicas, ambientais e de saúde em bases espaciais, possibilita o entendimento do contexto em que se verificam fatores determinantes de agravos à saúde à medida que se compreende que a diferenciação espacial sugere diversos outros diferenciais, tais como educação, cultura, renda, características genéticas e ambientais ${ }^{3}$. 
Contudo, como sugerem BARCELLOS e BASTOS ${ }^{3}$, devido ao conjunto de elementos inter-relacionados presente no espaço, torna-se difícil o estabelecimento de relações de causalidade entre condições ambientais e saúde. A análise das informações de saúde por meio de geoprocessamento permite a identificação de variáveis que revelem a estrutura social, econômica e ambiental, onde riscos à saúde estão presentes.

Com relação à análise espacial dos dados, torna-se necessário destacar que o território se configura em uma dimensão constitutiva da situação social em que se encontram os diferentes grupos sociais no espaço, especialmente entre os mais pobres. MARQUES e TORRES ${ }^{47}$, partindo desta premissa, afirmam que

indivíduos e famílias igualmente pobres e escolarizados têm condições
e características diferentes dependendo de onde morem". Neste
sentido, "o próprio espaço, ao contrário de ser apenas um produto
desses elementos, representa também um conjunto de
constrangimentos e possibilidades, diferenciando as oportunidades que
moradores de lugares mais ou menos segregados experimentam
(MARQUES e TORRES, 2005, p.11) ${ }^{47}$.

As pessoas se movimentam em espaços físicos cujas características interagem com suas potencialidades, tendo em vista as limitações apontadas pelas fronteiras físicas, sociais e simbólicas do território ${ }^{51}$.

Retomando o objeto de estudo da Epidemiologia, anteriormente citado na definição de $\mathrm{LAST}^{43}$ e resumidamente definido pelo estudo da distribuição de doenças e agravos em coletividades humanas, o fato de que todos os eventos de saúde (nascimento, a infecção, o adoecimento e a morte) se manifestam em pessoas ${ }^{4}$, se obtivermos uma referência geográfica destes indivíduos, seja como um dado individual seja como um 
dado coletivo, será possível localizar os casos de uma doença ou mesmo seus fatores relacionados, vislumbrando o que poderia ser chamado de uma Epidemiologia Georreferenciada ${ }^{54}$.

O georreferenciamento de um atributo nada mais é do que a sua informação geográfica em termos de posicionamento na superfície terrestre. Dessa forma, ao fazermos essa referência geográfica sobre os elementos do processo saúde-doença (pessoas, serviços de saúde, agentes condicionantes), ultrapassamos a fronteira do corpo biológico e alcançamos uma dimensão mais próxima do que seria um corpo sócio-espacial, já que a doença passaria a habitar não só as pessoas, mas todo o território que, como já discutido anteriormente, é um aspecto constitutivo desse processo.

Nesse sentido, sabemos que a saúde bucal não é um atributo espacial ou uma característica do território. Porém, temos consciência de que sua realização final se manifesta em pessoas que apresentam diferentes condições de saúde bucal. Sendo assim, ao localizarmos espacialmente a população e seus atributos, dentre eles as condições de saúde bucal, poderemos conhecer a distribuição espacial dessas condições em um determinado território. Dessa forma, elementos abstratos como as condições de vida e saúde da população passam a ter uma posição geográfica sobre a superfície terrestre, propriedade exclusiva de elementos concretos.

Tanto a saúde bucal quanto as condições socioeconômicas, ambientais e de saúde em geral podem ser caracterizadas por indicadores bem estabelecidos na Saúde Pública e acessíveis por consulta a bancos de 
dados oficiais. São emblemáticos, e inequívocos pontos de referência, os levantamentos epidemiológicos nacionais de 1986, 1996 e 2003, conduzidos pelo Ministério da Saúde (Área Técnica de Saúde Bucal) em parceria com diferentes instituições como a Associação Brasileira de Odontologia, Conselho Federal de Odontologia (CFO) e Secretarias Estaduais de Saúde.

Tomando-se como base de referência o levantamento epidemiológico realizado em 2003 (SB Brasil), desenvolveu-se um estudo no sentido de oferecer uma informação concisa de diagnóstico de situação e fatores condicionantes da saúde bucal no país para a população adulta e idosa. As características amostrais do SB Brasil permitiram uma análise espacial do processo saúde-doença bucal nesses indivíduos, possibilitando incluir nas análises dos fatores determinantes a influência do espaço como aspecto constitutivo desse processo.

Superando a concepção natural do espaço apenas como um ambiente inerte e passivo, a visão de um espaço geográfico socialmente construído, tanto como um receptor dos processos sociais quanto como o próprio ativador destes processos, torna-se cada vez mais relevante na compreensão dos fenômenos envolvidos no processo saúde-doença. Neste sentido, a epidemiologia se apresenta como um referencial privilegiado na articulação entre os elementos lugar-tempo-pessoas. 


\section{OBJETIVOS}

\subsection{Geral}

Identificar os fatores individuais e contextuais associados à perda dentária em adultos e idosos no Brasil, além da interação entre estes e sua distribuição espacial.

\subsection{Específicos}

a) Caracterizar a amostra adulta quanto à perda dentária;

b) Caracterizar a amostra idosa quanto à prevalência de edentulismo funcional e de necessidade de prótese total;

c) Identificar os fatores contextuais e individuais associados à perda dentária em adultos e ao edentulismo funcional e necessidade de prótese total nos idosos;

d) Identificar as interações entre as variáveis dos níveis individuais e contextuais;

e) Explorar a dependência e a distribuição espacial dos fatores contextuais associados à perda dentária nos adultos e ao edentulismo funcional e necessidade de prótese total nos idosos. 


\section{PROCEDIMENTOS METODOLÓGICOS}

\subsection{Delineamento do estudo}

Este estudo corresponde a um aprofundamento dos resultados encontrados no levantamento epidemiológico nacional de saúde bucal de 2003 (SB Brasil), por meio de análises estatísticas de associação e de efeito entre os índices epidemiológicos bucais e as diferentes variáveis coletadas neste levantamento, incluindo co-variáveis contextuais, provenientes de outras fontes de dados, igualmente públicas. Este tipo de abordagem é um privilégio do levantamento epidemiológico de 2003, pelo que teve seu escopo restrito a este inquérito, haja vista a diversidade de co-variáveis coletadas no referido levantamento e a disponibilidade de um banco de dados que contempla estas informações para cada indivíduo participante do estudo.

Aproxima-se dos referenciais teóricos da Eco-Epidemiologia e da Epidemiologia Ecossocial, conforme sugeridos anteriormente por SUSSER e SUSSER ${ }^{74}$ e KRIEGER ${ }^{42}$, respectivamente. Trata-se de uma aproximação do modelo sistêmico de explicação para a ocorrência de doenças em populações humanas. Tal modelo baseia-se na premissa de que as causas das doenças estão dispostas em diferentes sistemas de organização, desde o celular até o social, proporcionando uma visão mais holística do processo saúde-doença, ao revelar uma estrutura hierárquica entre os níveis de atuação das causas ${ }^{57}$. 
Em conformidade com a direção teórica proposta, o referencial metodológico que mais se aproxima do modelo sistêmico de explicação do processo saúde-doença é a análise multinível, sendo possível pela existência dos dados em nível individual, pela viabilidade de incorporação de dados ecológicos e pela natureza hierárquica dos dados disponíveis, conforme será apresentado posteriormente. A análise em mais de um nível objetiva incluir elementos contextuais/ecológicos, muitas vezes expressos por informações agregadas em unidades geográficas mais amplas, permitindo uma espacialização não só dos indivíduos, mas também dos fenômenos coletivos que contextualizam determinada população.

\subsection{Características do levantamento epidemiológico nacional das condições de saúde bucal realizado em 2003 (SB Brasil)}

O SB Brasil consistiu em um estudo epidemiológico transversal das condições de saúde bucal da população brasileira. O estudo teve início em 1999, com a criação do Subcomitê responsável pela elaboração e execução do levantamento. Em 2001 foi realizado um estudo piloto, em duas cidades de portes populacionais diferentes (Canela-RS e Diadema-SP), visando à validação da metodologia e dos instrumentos desenhados para o estudo. As oficinas de treinamento e calibração das equipes foram realizadas nos anos de 2002 e 2003, sendo que posteriormente foi iniciado o trabalho de campo, com realização dos exames e entrevistas ${ }^{9}$. 
Houve a participação de várias instituições e entidades odontológicas (Conselhos Federal e Regionais de Odontologia, Associação Brasileira de Odontologia e suas seções regionais, Faculdades de Odontologia, além do decisivo suporte das Secretarias Estaduais e Municipais de Saúde). A amostra pesquisada torna os achados representativos para cada idade ou grupo etário, por macrorregião, por porte populacional das cidades envolvidas e do próprio município para alguns agravos e grupos etários ${ }^{9}$.

\subsection{Plano Amostral}

No inquérito objeto deste estudo, foi utilizada a técnica de amostragem probabilística por conglomerados, realizada em três estágios. Inicialmente, os municípios foram estratificados pelo porte populacional em cinco categorias (até 5.000 habitantes; de 5.001 a 10.000 habitantes; de 10.001 a 50.000 habitantes; de 50.001 a 100.000 habitantes; mais de 100.000 habitantes). Posteriormente, foram sorteados 50 municípios em cada uma das cinco regiões brasileiras (Norte, Nordeste, Centro-Oeste, Sudeste e Sul) de forma proporcional ao porte populacional. Finalmente, as residências foram sorteadas com o auxílio de mapas dos setores censitários e examinados os indivíduos na faixa etária elegível (sendo objeto deste estudo as faixas de 35 a 44 anos e 65 a 74 anos de idade). Ao todo foram selecionados, por meio de sorteio, 250 municípios. 
Esse processo amostral faz com que os indivíduos selecionados não possuam a propriedade de independência porque estão vinculados a blocos definidos pelas unidades superiores de amostragem ou por unidades de divisão geográfica. Considerar que os indivíduos foram selecionados independentemente, como em amostragem aleatória simples, tende a subestimar os erros-padrão em testes estatísticos, resultando em estimativas espúrias para a precisão das estimativas pontuais e a rejeição de hipóteses nulas que de fato não deveriam ser rejeitadas. Visando evitar esse tipo de problema, o cluster ou aninhamento dos dados deve ser levado em consideração na análise dos dados, e esta é a propriedade característica da análise multinível ${ }^{32}$.

Nesse sentido, a forma com que os dados foram coletados permite a identificação de quatro níveis de hierarquia baseada na organização geográfica dos estágios da amostra: a) o quarto nível que são as cinco regiões brasileiras; b) o terceiro nível que, embora não tenha sido um estrato amostral, participa da organização político-geográfica do país, e se refere aos 27 estados brasileiros; c) o segundo nível que são os 250 municípios sorteados segundo o porte populacional e; d) o primeiro nível que é a unidade primária deste estudo, ou seja, os indivíduos. Desse modo, existe uma provável dependência entre os indivíduos segundo o município ao qual pertencem assim como com relação ao seu estado e à sua região de origem. A Figura 1 ilustra a estrutura multinível da amostra.

Com relação aos indivíduos adultos (35 a 44 anos) e idosos (65 a 74 anos) que participaram deste levantamento, grupos-índices da OMS que 
serão analisados no presente estudo, o tamanho total da amostra foi de 13.431 e 5.349 indivíduos, respectivamente. Apesar de o plano inicial ter previsto a pesquisa em 250 municípios, os dados disponíveis para a população adulta contaram com a participação de 249 municípios e de 247 para a população idosa.

Figura 1 - Distribuição espacial dos 250 municípios que participaram do inquérito epidemiológico de saúde bucal da população brasileira e divisão geográfica dos níveis analisados na amostra. Brasil, 2004.

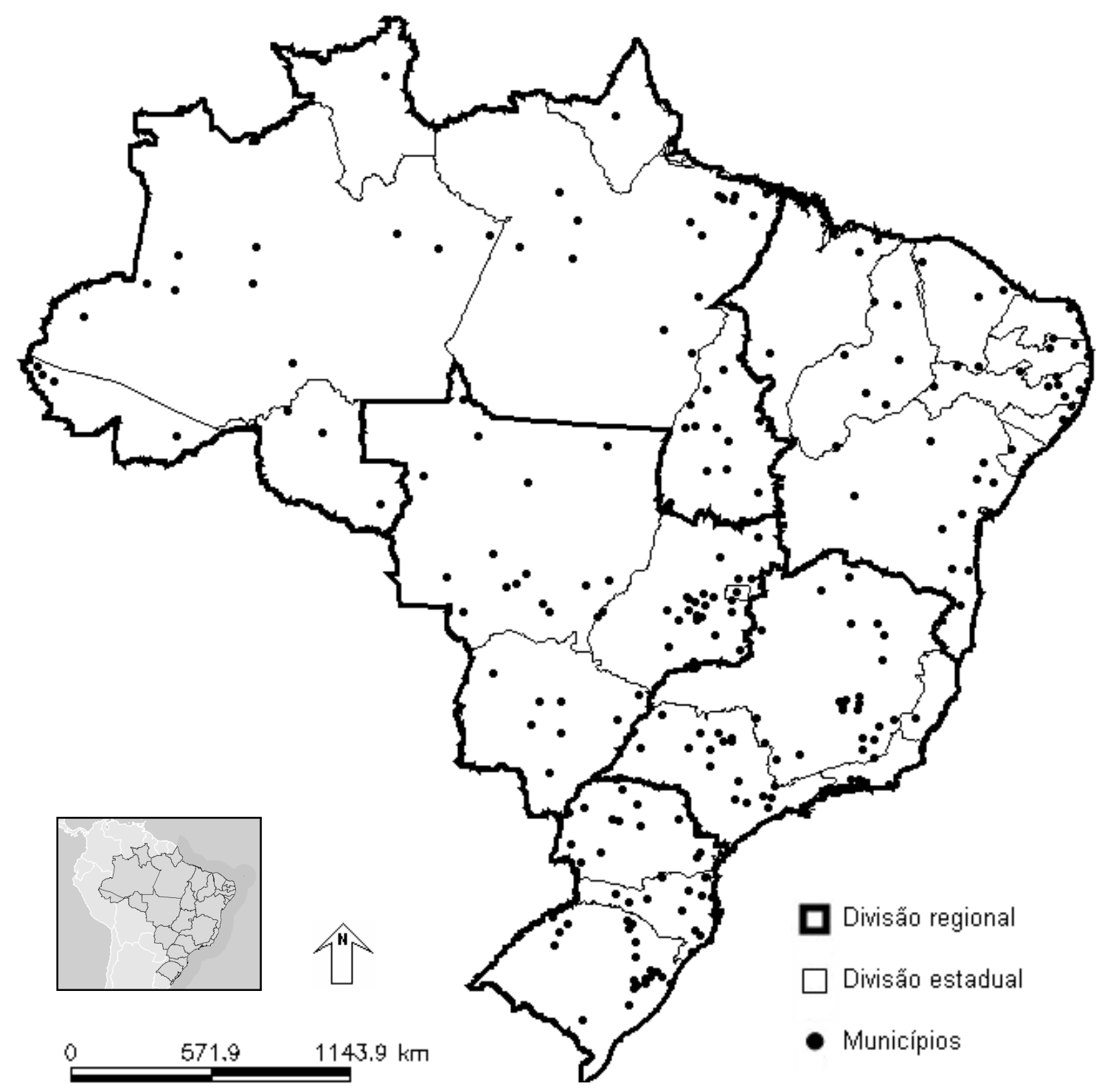




\subsection{Caracterização dos instrumentos e descrição das variáveis}

Os instrumentos de coleta de dados foram baseados nas fichas propostas para a realização do último levantamento epidemiológico nacional das condições de saúde bucal (SB Brasil) ${ }^{9}$. Os códigos e critérios adotados foram aqueles propostos pela OMS na publicação Oral health surveys: basic methods, quarta edição ${ }^{78}$. Tais fichas (de exame e de avaliação socioeconômica e acesso), bem como o resumo dos códigos e critérios adotados para cada uma das condições pesquisadas se encontram resumidos e ilustrados conforme Anexo $\mathrm{A}$.

Nos adultos, a variável dependente foi a perda dentária, mensurada em cada indivíduo, e representada pela contagem de dentes perdidos (variando de 0 a 32 dentes), seja por motivo de cárie ou outros motivos. Para evitar a imposição de pontos de cortes, manteve-se a variável dependente em sua condição original.

No nível individual, as variáveis independentes utilizadas foram: local geográfico, escolaridade, moradia, posse de automóvel, número de pessoas por cômodo, visita ao dentista, tempo da última consulta odontológica, local da última consulta, motivo da última consulta, informações sobre prevenção de doenças bucais, sexo, grupo étnico e idade. Estas variáveis constam no banco de dados do inquérito epidemiológico. Optou-se pela renúncia na utililização da variável renda, embora esteja disponível no banco de dados, considerando as possibilidades de inconsistências na mensuração da mesma e pelo fato de 
que a escolaridade pode ser uma boa aproximação da renda funcionado como proxy da mesma.

No nível contextual, as variáveis independentes foram: 1) número de dentistas/1000 habitantes (nível regional); 2) a taxa de exodontia, representada pela razão entre o número de extrações realizadas pelos serviços públicos de saúde e a população de determinada área (nível estadual); 3) porte populacional (nível municipal). As variáveis dos níveis regionais e estaduais foram coletadas do Departamento de Informática do Sistema Único de Saúde (DATASUS) ${ }^{8}$ referentes ao ano de 2003. A informação sobre o porte municipal está disponível no banco de dados do inquérito epidemiológico. Essas variáveis contextuais independentes foram selecionadas dentre um conjunto de outras variáveis que, após uma análise de correlação de Pearson e pela pertinência das mesmas para o tema estudado, foram incluídas no estudo. O processo de seleção se deu inicialmente pela análise de colinearidade entre as variáveis. Devido à natureza quantitativa das mesmas e pela aderência à distribuição normal, foi implementada a análise de correlação de Pearson e aquelas variáveis que apresentavam correlação/colineariedade maior do que 0,90, com nível de significância de 5\%, passaram por um julgamento da pertinência sobre qual delas deveriam permanecer no plano de análise e serem analisadas à luz de suas implicações com a saúde bucal ou mesmo pelo interesse de se testar a relação das mesmas com os desfechos investigados. O conjunto dessas variáveis assim como suas fontes pode ser observado na Tabela 1. 
Tabela 1 - Variáveis dependentes e independentes utilizadas nos modelos de regressão empregados em adultos e idosos segundo a fonte e o ano.

\begin{tabular}{ll}
\hline Variáveis dependentes & Fonte (Ano) \\
Contagem de dentes perdidos em adultos & \\
Prevalência de edentulismo funcional em idosos & MS (2003) \\
Prevalência de necessidade de prótese total em idosos &
\end{tabular}

\section{Variáveis independentes}

Fonte (Ano)

Esperança de vida ao nascer

IBGE (2003)

Proporção de pobres

IBGE (2003)

Grau de urbanização

IBGE (2003)

Taxa de mortalidade infantil

IBGE (2003)

Número de médicos por mil habitantes

IBGE (2003)

Número de cirurgiões-dentistas por mil habitantes

Indivíduos em moradias com três cômodos ou mais (\%)

IBGE (2000)

Indivíduos com cobertura de rede de esgoto (\%)

IBGE (2004)

Indivíduos com cobertura de coleta de lixo (\%)

IBGE (2003)

Indivíduos com cobertura de rede de água encanada (\%)

IBGE (2003)

Indivíduos com menos de um ano de estudo (\%)

IBGE (2003)

Indivíduos com oito ou mais anos de estudo (\%)

IBGE (2003)

Média de anos de estudo em indivíduos maiores de 25 anos

PNUD (2000)

Índice de Desenvolvimento Humano (IDH)

PNUD (2000)

Índice de Gini

PNUD (2000)

Razão de dependência

IBGE (2003)

PIB per capita

IBGE (2003)

Cobertura PSF

DATASUS (2003)

Cobertura ESB/PSF

DATASUS (2003)

Taxa de exodontia de dente permanente

DATASUS (2003)

Taxa de primeira consulta odontológica programática

DATASUS (2003)

MS: Ministério da Saúde

IBGE: Instituto Brasileiro de Geografia e Estatística

PNUD: Programa das Nações Unidas para o Desenvolvimento

DATASUS: Departamento de Informática do Sistema Único de Saúde 
Os idosos foram divididos em dois grupos: edêntulos e nãoedêntulos. Nos idosos não-edêntulos a variável dependente foi a presença de edentulismo funcional (indivíduos sem a presença de no mínimo 20 dentes naturais). O termo "edentulismo funcional" foi definido dessa forma levando em consideração os conceitos de arco reduzido e de dentição funcional propostos por KAISER ${ }^{39}$. Entretanto, não foi aferida a condição funcional destes dentes, apenas sua presença ou ausência. As variáveis independentes individuais e contextuais foram as mesmas utilizadas nos adultos.

No grupo dos idosos edêntulos a variável dependente foi a presença de necessidade de prótese total em pelo menos um arco. As variáveis independentes contextuais foram: taxa de primeira consulta odontológica programática (nível regional); média de anos de estudo (nível estadual), ambas coletadas do Departamento de Informática do Sistema Único de Saúde $^{8}$ referentes ao ano de 2003; e porte municipal (nível municipal). As variáveis independentes individuais foram as mesmas para os demais grupos.

\subsection{Procedimentos utilizados na análise dos dados}

Inicialmente foram descritos os parâmetros das variáveis dependentes segundo as categorias de variáveis independentes.

Para o cálculo das medidas de efeito, devido às características de distribuição binomial negativa da variável dependente na população adulta, e 
para evitar o fenômeno da superdispersão (quando a variância da variável resposta é maior do que a sua média) ${ }^{33}$, foi utilizado um modelo de regressão log-linear binomial negativa. O cálculo exponencial aplicado ao coeficiente de regressão gerou uma medida de efeito que pode ser interpretada como uma razão de médias (RM). A interpretação epidemiológica desta medida é similar ao risco relativo, indicando risco ou proteção os valores de RM maiores ou menores que um, respectivamente. Trata-se de uma medida que compara a média de um atributo de um grupo em relação a outro grupo. Neste estudo comparou-se a média de perda dentária entre as diferentes categorias das variáveis independentes. Contudo, devido à característica transversal do estudo, é limitante considerar as associações encontradas como relações de causalidade. Os fatores de risco ou de proteção encontrados representam medidas de efeito e devem ser interpretadas em seu sentido e em sua força de associação com a variável dependente.

Foi utilizado um modelo multinível de regressão com intercepto aleatório $^{32}$ conforme a equação abaixo:

$E\left(Y_{\mathrm{ijkl}}\right)=\mu_{\mathrm{ijkl}}$

$\log \left(\mu_{\mathrm{ijkl}}\right)=\beta_{0 \mathrm{jkl}}+\sum \beta_{\mathrm{n}} \mathrm{x}_{\mathrm{ijkl}}+U_{0 \mathrm{jkl}}+\varepsilon_{\mathrm{ijjk} l}$

em que $Y_{i j k l}$ representa a variável dependente perda dentária, com expectativa para o i-ésimo indivíduo, do j-ésimo município, do k-ésimo estado e da l-ésima região. $\beta_{0 j k l}$ é o intercepto da função associado ao efeito 
aleatório $U_{0 \mathrm{jk} l}$. $\beta_{\mathrm{n}}$ é o parâmetro fixo estimado para cada variável independente $\mathrm{X}_{\mathrm{ijkl}}$ de acordo com o nível ao qual pertence e $\varepsilon_{\mathrm{ijjkl}}$ é o erro aleatório associado ao indivíduo $\mathrm{ijjk}_{\mathrm{j} k}$.

As estimativas de RM foram geradas com o auxílio do programa estatístico MLwiN 2.02 ${ }^{\circledR 63}$. O processo de estimação foi o IGLS (Iterative Generalised Least Squares), utilizando-se o procedimento de quaseverossimilhança penalizada (Penalised Quasi-Likelihood - PQL) de segunda ordem. O valor-p e os intervalos de confiança foram estimados pelo Teste de Wald. Análise de resíduos foi realizada para se verificar o ajuste do modelo final.

No grupo dos idosos não-edêntulos, devido às características da distribuição da perda dentária nesse grupo, como pode ser observado na Figura 2, pode-se claramente observar a composição de dois grupos: os edêntulos funcionais (perda de 13 dentes ou mais) e os não-edêntulos funcionais (presença de 20 dentes ou mais). Dessa forma, a perda dentária passou por uma transformação dicotômica, herdando as características de uma distribuição binária. 
Figura 2 - Distribuição dos dentes perdidos entre os idosos não edêntulos. Brasil, 2004.

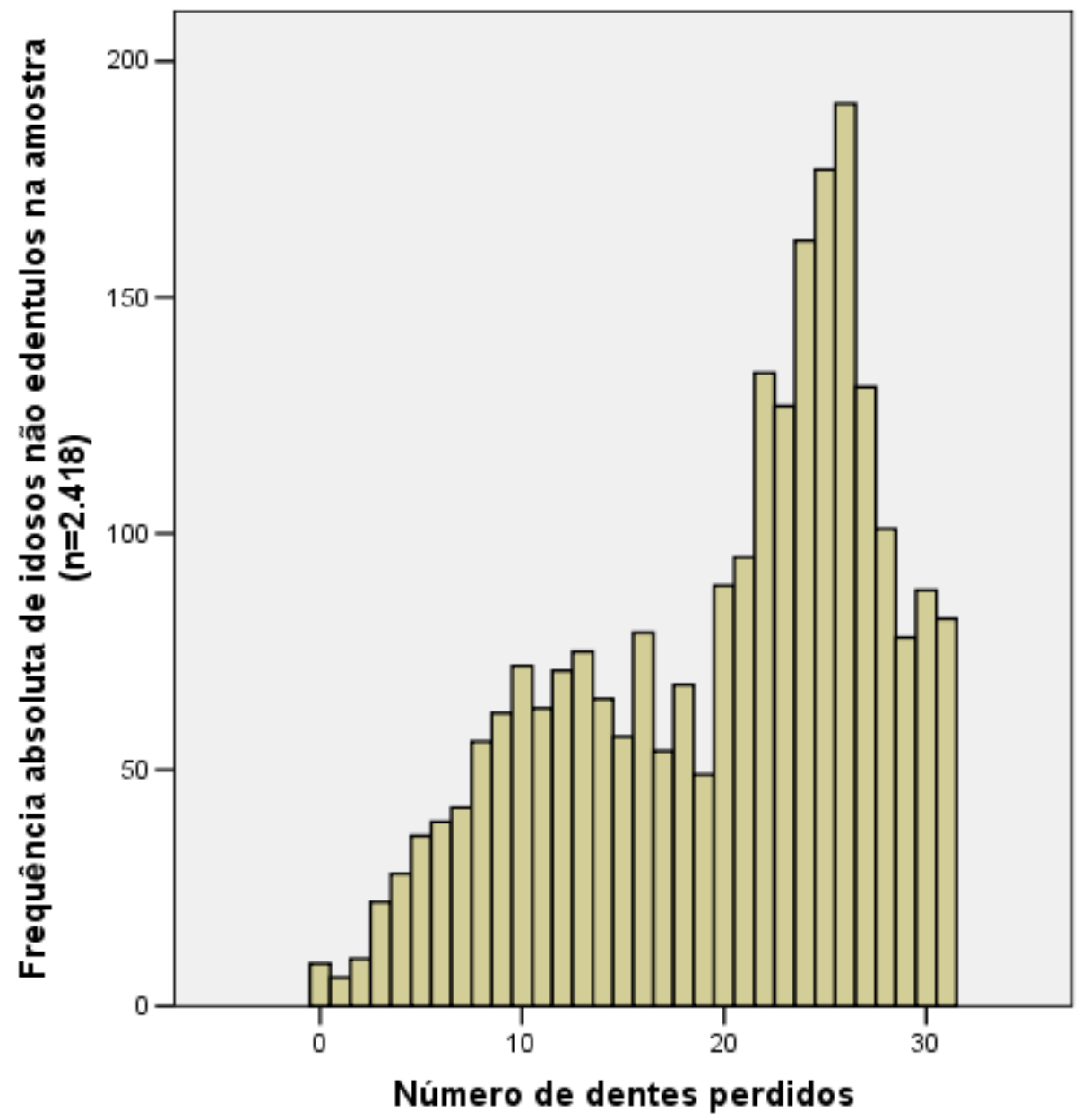

A mesma situação de distribuição binária ocorreu com a presença de necessidade de prótese total em pelo menos um arco nos idosos edêntulos, caracterizando igualmente uma variável dependente dicotômica.

Para a identificação dos fatores associados ao edentulismo funcional e à necessidade de prótese total foram calculadas medidas de efeito expressas pelas Razões de Prevalências (RP) brutas e ajustadas, com respectivos intervalos de confiança de $95 \%$, estimadas por modelos de regressão log-linear de Poisson simples e múltiplo, com estimadores robustos da variância ${ }^{5}$. 
As estimativas de RP foram geradas com o auxílio do programa estatístico MLwiN 2.02 ${ }^{\circledR 63}$. O processo de estimação foi o IGLS (Iterative Generalised Least Squares), utilizando-se o procedimento de quaseverossimilhança marginal (Marginal Quasi-Likelihood - MQL) de primeira ordem. A significância estatística de cada variável no modelo (valor-p) foi estimada pelo Teste de Wald.

A influência dos fatores em estudo sobre as variáveis dependentes seguiu o modelo hierarquizado proposto por VICTORA et al. ${ }^{77}$. Assumindo como referência um modelo conceitual a priori, com inclinação teórica para o modelo estruturalista proposto por DAHLGREN e WHITEHEAD ${ }^{22}$, iniciou-se a análise univariada no nível contextual e em cada bloco do nível individual. Dentro de cada nível hierárquico, as variáveis com $p<0,20$ foram testadas em modelos múltiplos. Ao final, as variáveis com $p<0,05$ permaneceram no modelo final de cada nível e foram consideradas fatores de ajuste para os blocos subseqüentes. Os modelos que guiaram as análises, para cada desfecho abordado, estão apresentados na Figura 4.

Para a análise espacial foi inicialmente realizada a distribuição espacial dos fatores contextuais associados aos desfechos analisados, por microrregião, visando uma melhor visualização dos mesmos em uma escala geográfica nacional. Em seguida, testes de dependência espacial foram aplicados sobre estes fatores, visando identificar a estrutura de correlação espacial que melhor descreva os dados. Foi utilizado o Índice Global de Moran e em seguida o Índice Local de Moran. Estes índices servem para estimar quanto o valor observado de um atributo numa região é dependente 
dos valores desta mesma variável nas localizações vizinhas, a partir de uma hipótese nula de independência espacial ${ }^{13}$. Foi adotado um nível de significância espacial de 5\%.

O Índice Global de Moran fornece uma idéia geral da autocorrelação espacial dos dados, mas não indica quais são as áreas responsáveis por esta dependência global. Esta informação será provida pelo Índice Local de Moran, que por meio do Diagrama de Espalhamento de Moran, irá apontar quatro tipos de configuração espacial (Figura 3):

- Q1 (valores positivos, médias positivas) e Q2 (valores negativos, médias negativas): indicam pontos de associação espacial positiva, no sentido que uma localização possui vizinhos com valores semelhantes;

- Q3 (valores positivos, médias negativas) e Q4 (valores negativos, médias positivas): indicam pontos de associação espacial negativa, no sentido que uma localização possui vizinhos com valores distintos.

Figura 3 - Diagrama de Espalhamento de Moran

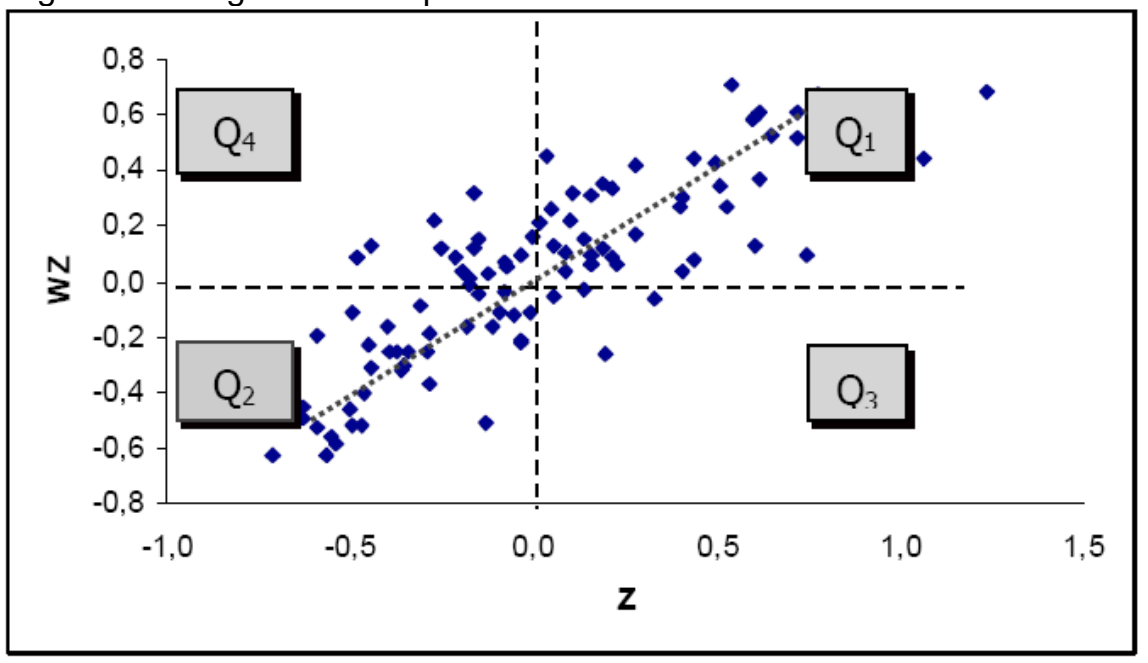

Fonte: CARVALHO et al. ${ }^{13}$ 
Nesse sentido, três mapas de dependência espacial foram construídos: a) Box Map: em que são apresentadas as áreas geográficas de acordo com os quadrantes; b) Lisa Map: em que são apresentadas apenas as áreas com significância estatística; c) Moran Map: em que são apresentadas as áreas com significância estatística segundo o diagrama de espalhamento de Moran.

Utilizou-se a técnica de Processo Analítico Hierárquico (AHP) ${ }^{52}$, com auxílio do programa Spring ${ }^{\odot} 4.3 .3$, para conhecer a distribuição espacial dos fatores de risco para a perda dentária em adultos e para o edentulismo funcional e a necessidade de prótese total em idosos. Neste procedimento os diferentes fatores que influenciam a variável dependente são comparados dois-a-dois, e um critério de importância relativa é atribuído ao relacionamento entre estes fatores. A importância de cada atributo foi definida pela força da associação (intensidade da medida de efeito) com o desfecho estudado.

Além destes mapas de dependência espacial, foi realizado um procedimento de Krigeagem Ordinária para visualizar o mapa de risco gerado pelo AHP, transformando o mapa discreto de risco em um mapa contínuo e suavizado ${ }^{12}$.

Esta pesquisa foi aprovada pelo Comitê de Ética em Pesquisa da Faculdade de Saúde Pública da Universidade de São Paulo (Anexo B). 


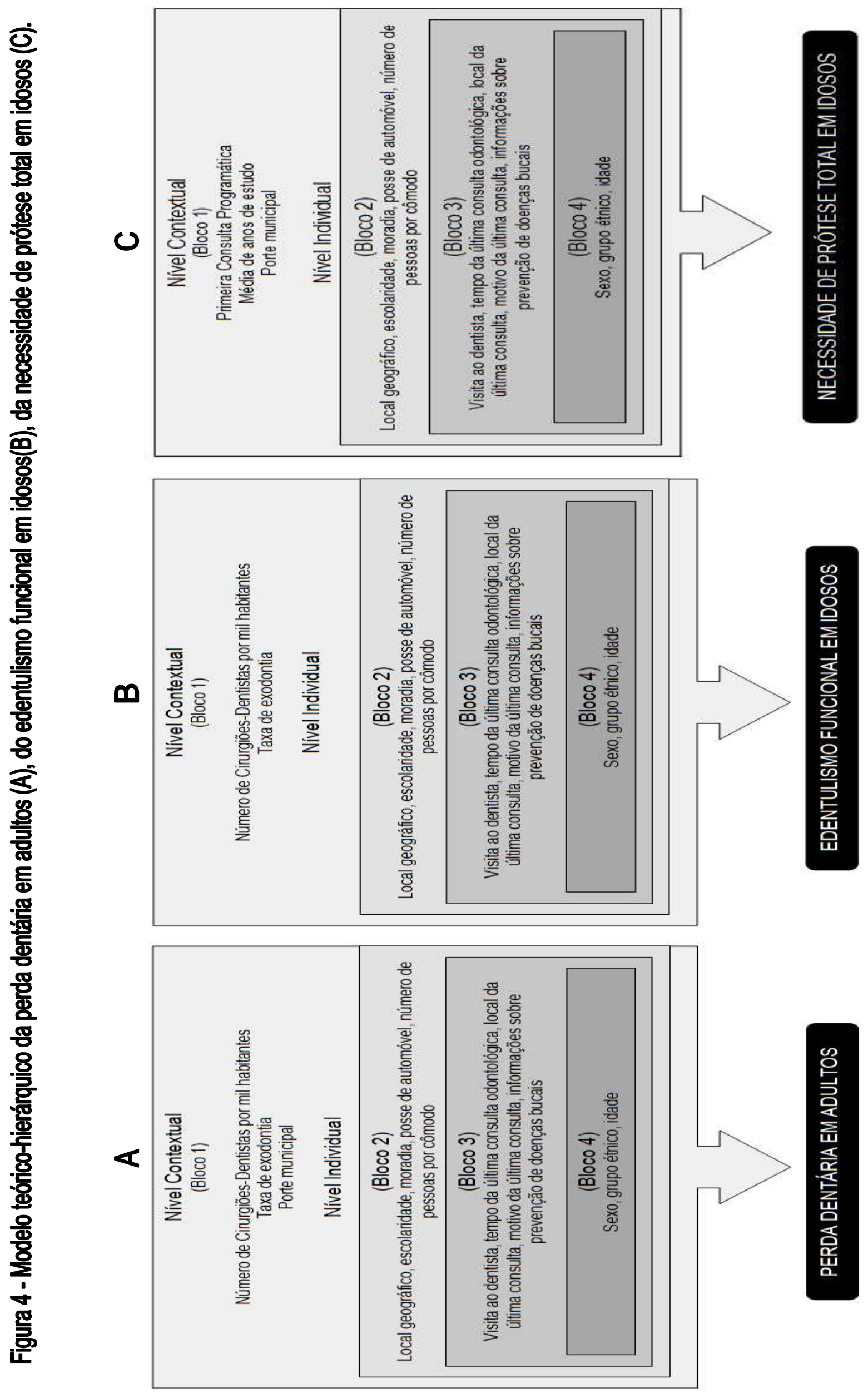




\section{RESULTADOS}

\subsection{Perda dentária em adultos}

A média de perda dentária foi de 14 dentes $( \pm 9,5)$. Metade dos indivíduos analisados já havia perdido 12 dentes. A Tabela 2 apresenta a composição da amostra e a perda dentária segundo as variáveis independentes. Observou-se que 33\% dos indivíduos residiam em regiões com maior número de dentistas $/ 1000$ habitantes. Cerca de $30 \%$ eram provenientes de estados com maior taxa de exodontia e $23 \%$ moravam em municípios de maior porte.

A estrutura sociodemográfica da população estudada foi de $33 \%$ do sexo masculino, $44 \%$ brancos e idade mediana de 39 anos. Cerca de $26 \%$ possuíam nove anos ou mais de estudo e $7 \%$ eram sem escolaridade. Com relação à moradia, $81 \%$ possuíam casa própria e $27 \%$ possuíam pelo menos um automóvel. Com relação ao acesso aos serviços odontológicos, 378 indivíduos (3\%) nunca foram ao dentista na vida, 37\% tiveram a última consulta odontológica em menos de um ano e $48 \%$ a realizaram em um serviço público. O principal motivo da última consulta para $45 \%$ dos indivíduos foi ter sentido dor. Já outros $45 \%$ não receberam informações sobre prevenção de doenças bucais. 
Tabela 2- Descrição da média de perda dentária em adultos brasileiros. Brasil, 2004.

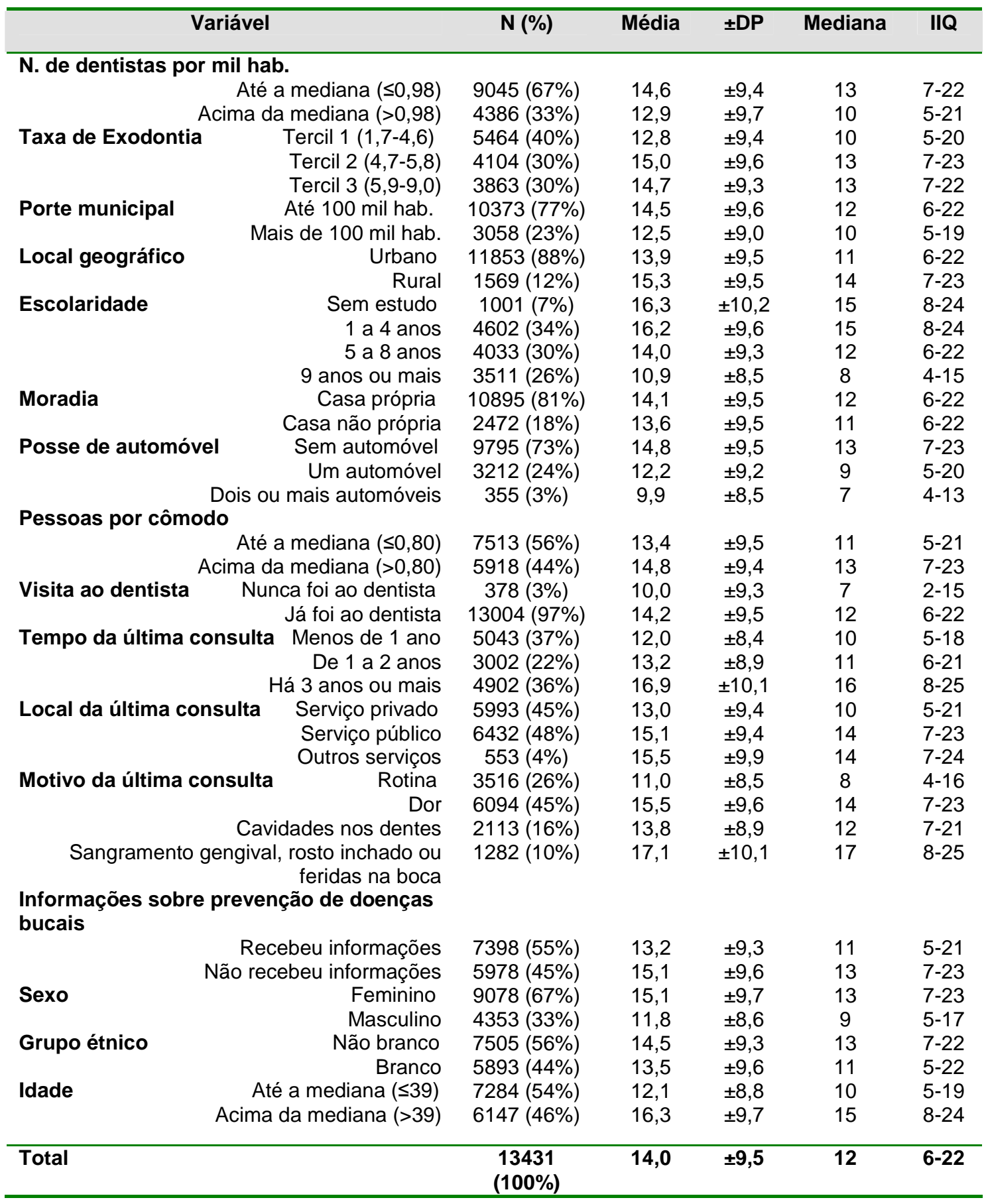

DP: desvio-padrão

IIQ: Intervalo interquartil 
A Tabela 3 apresenta os resultados do modelo de regressão univariado corrigido para cada nível amostral do indivíduo. A razão de média (RM) apresentada considera a variância presente em cada nível e se mostra como uma medida de efeito corrigida dos fatores associados à perda dentária.

Indivíduos provenientes de regiões com maior número de dentistas/1000 habitantes apresentaram menor perda dentária e uma RM de 0,874. Porém, residir em estados com maior taxa de exodontia (tercil 3) aumenta o risco em $16,8 \%$ em comparação aos estados com menor taxa (tercil 1). Já o maior porte municipal representou proteção contra a perda dentária com uma RM de 0,867.

Com relação às variáveis do bloco 2 , residir em área rural aumentou o risco de perda dentária $(R M=1,025)$, porém sem significância estatística. Possuir nove anos ou mais de estudo representou um aumento de $30 \%$ na proteção $(\mathrm{RM}=0,699)$ em comparação aos indivíduos sem escolaridade. Nesse mesmo sentido, a posse de pelo menos um automóvel também representou proteção $(\mathrm{RM}=0,848)$. O tipo de moradia não foi significante e o maior número de pessoas por cômodo aumentou o risco de perda dentária $(\mathrm{RM}=1,083)$.

Todas as variáveis do bloco 3 apresentaram associação significativa com a perda dentária na análise univariada. Chama a atenção o fato de que as pessoas que já foram ao dentista aumentaram $53,7 \%$ o risco de perda dentária em comparação aos que nunca foram. A perda dentária foi maior em quem realizou a última consulta odontológica há três anos ou mais 
$(\mathrm{RM}=1,349)$ e ter consultado um serviço público aumentou o risco em $11,5 \%$. Ter como motivo da última consulta o sangramento gengival, rosto inchado ou feridas na boca aumentou cerca de $54 \%$ o risco de perda dentária, seguido pela dor $(R M=1,343)$ e cavidades nos dentes $(R M=1,206)$ quando comparados aos indivíduos que realizaram consulta de rotina. Não ter recebido informações sobre prevenção de doenças bucais aumentou o risco em $13,1 \%$.

Com relação às variáveis do bloco 4 , apresentaram maior risco de perda dentária o sexo feminino $(\mathrm{RM}=1,278)$, ser do grupo étnico não-branco $(R M=1,029)$ e a idade acima da mediana $(R M=1,370)$.

A Tabela 4 apresenta os resultados do modelo hierárquico múltiplo, segundo o modelo teórico apresentado na Figura 4(A). Observouse que as variáveis contextuais mantiveram significância estatística e apresentaram efeitos independentes sobre a perda dentária. No Bloco 2 apenas as variáveis escolaridade e posse de automóvel permaneceram no modelo final e seus efeitos foram controlados pelas variáveis do nível contextual. Observou-se que as variáveis escolaridade acima de cinco anos de estudo e ter um automóvel apresentaram proteção contra a perda dentária. A RM para quem possui nove anos ou mais de estudo e dois ou mais automóveis foi de 0,723 e 0,763, respectivamente.

No bloco 3 apenas o local da última consulta não permaneceu no modelo final. Mesmo controlando seus efeitos pelos blocos superiores, ter ido ao dentista e ter realizado a consulta há três anos ou mais representaram, respectivamente, um aumento de $37,5 \%$ e de $21,3 \%$ no risco 
de perda dentária. O maior risco observado foi relacionado ao sangramento gengival, rosto inchado ou feridas na boca como motivo da última consulta $(\mathrm{RM}=1,387)$.

Tanto a idade acima da mediana quanto o sexo feminino representaram aumento no risco de perda dentária de 32,2\% e 27,5\%, respectivamente, independente da presença das variáveis dos blocos anteriores. Entretanto, o grupo étnico não foi fator significativo e não permaneceu no modelo final.

Interações contextuais, individuais e interníveis foram testadas e revelaram importantes aspectos da avaliação de efeito. A Figura 5 mostra que a maior taxa de exodontia apresentou interação com indivíduos que receberam informações sobre prevenção de doenças bucais e com nove anos ou mais de estudo, alterando o efeito protetor dessas duas variáveis. A interação entre indivíduos que já foram ao dentista e que possuem dois ou mais automóvel alterou significativamente o risco isolado da primeira. 
Tabela 3 - Razão de média da perda dentária em adultos segundo estimativas do modelo univariado de regressão binomial negativa para as variáveis do nível contextual. Brasil, 2004.

\begin{tabular}{|c|c|c|c|c|c|c|}
\hline \multicolumn{2}{|c|}{$\begin{array}{l}\text { Variáveis do nível contextual } \\
\text { Bloco } 1\end{array}$} & $\begin{array}{l}\text { Coeficiente } \\
\text { regressão }\end{array}$ & EP & $\mathbf{R M}^{*}$ & IC 95\% & Valor-p \\
\hline \multicolumn{7}{|c|}{ Nível Regional } \\
\hline \multirow{2}{*}{$\begin{array}{l}\text { N. de Dentistas } \\
\text { por mil habitantes }\end{array}$} & Até a mediana $(\leq 0,98)$ & & & 1,000 & & \\
\hline & Acima da mediana $(>0,98)$ & $-0,135$ & 0,039 & 0,874 & 0,$809 ; 0,943$ & 0,0005 \\
\hline \multicolumn{7}{|l|}{ Nível Estadual } \\
\hline \multirow[t]{3}{*}{ Taxa de exodontia } & Tercil 1 & & & 1,000 & & \\
\hline & Tercil 2 & 0,083 & 0,037 & 1,087 & 1,$011 ; 1,168$ & 0,0255 \\
\hline & Tercil 3 & 0,155 & 0,040 & 1,168 & 1,$080 ; 1,263$ & 0,0008 \\
\hline \multicolumn{7}{|l|}{ Nível Municipal } \\
\hline \multirow[t]{2}{*}{ Porte municipal } & Até 100 mil habitantes & & & 1,000 & & \\
\hline & Mais de 100 mil habitantes & $-0,143$ & 0,032 & 0,867 & 0,$814 ; 0,923$ & $<0,0001$ \\
\hline \multicolumn{2}{|c|}{$\begin{array}{l}\text { Variáveis do nível individual } \\
\text { Bloco } 2\end{array}$} & $\begin{array}{l}\text { Coeficiente } \\
\text { regressão }\end{array}$ & EP & RM & IC 95\% & Valor-p \\
\hline \multirow[t]{2}{*}{ Local geográfico } & Urbano & & & 1,000 & & \\
\hline & Rural & 0,025 & 0,023 & 1,025 & 0,$980 ; 1,073$ & 0,2668 \\
\hline \multirow[t]{4}{*}{ Escolaridade } & Sem estudo & & & 1,000 & & \\
\hline & Até quatro anos & 0,010 & 0,024 & 1,010 & 0,$964 ; 1,059$ & 0,6629 \\
\hline & Até oito anos & $-0,095$ & 0,024 & 0,909 & 0,$868 ; 0,953$ & $<0,0001$ \\
\hline & Nove anos ou mais & $-0,358$ & 0,025 & 0,699 & $0.666 ; 0,734$ & $<0,0001$ \\
\hline \multirow[t]{2}{*}{ Moradia } & Casa própria & & & 1,000 & & \\
\hline & Casa não própria & -0.004 & 0.015 & 0,996 & 0,$967 ; 1,026$ & 0,7972 \\
\hline \multirow{3}{*}{$\begin{array}{l}\text { Posse de } \\
\text { automóvel }\end{array}$} & Sem automóvel & & & 1,000 & & \\
\hline & Um automóvel & $-0,165$ & 0,015 & 0.848 & 0,$823 ; 0,873$ & $<0,0001$ \\
\hline & Dois ou mais automóveis & $-0,392$ & 0,039 & 0,676 & 0,$626 ; 0,729$ & $<0,0001$ \\
\hline \multirow{2}{*}{$\begin{array}{l}\text { Pessoas por } \\
\text { cômodo }\end{array}$} & Até a mediana $(\leq 0.80)$ & & & 1,000 & & \\
\hline & Acima da mediana $(>0.80)$ & 0,080 & 0,012 & 1,083 & 1,$058 ; 1,109$ & $<0,0001$ \\
\hline \multicolumn{2}{|c|}{$\begin{array}{c}\text { Variáveis do nível individual } \\
\text { Bloco } 3\end{array}$} & $\begin{array}{l}\text { Coeficiente } \\
\text { regressão }\end{array}$ & EP & RM & IC 95\% & Valor-p \\
\hline \multirow[t]{2}{*}{ Visita ao dentista } & Nunca foi ao dentista & & & 1,000 & & \\
\hline & Já foi ao dentista & 0,430 & 0,038 & 1,537 & 1,$427 ; 1,656$ & $<0,0001$ \\
\hline \multirow{3}{*}{$\begin{array}{l}\text { Tempo da última } \\
\text { consulta }\end{array}$} & Menos de um ano & & & 1,000 & & \\
\hline & De um a dois anos & 0,066 & 0,016 & 1,068 & 1,$035 ; 1,102$ & $<0,0001$ \\
\hline & Há três anos ou mais & 0,299 & 0,014 & 1,349 & 1,$312 ; 1,386$ & $<0,0001$ \\
\hline \multirow{3}{*}{$\begin{array}{l}\text { Local da última } \\
\text { consulta }\end{array}$} & Serviço privado & & & 1,000 & & \\
\hline & Serviço público & 0,109 & 0,013 & 1,115 & 1,$087 ; 1,144$ & $<0,0001$ \\
\hline & Outros serviços & 0,108 & 0,031 & 1,114 & 1,$048 ; 1,184$ & $<0,0001$ \\
\hline \multirow{2}{*}{$\begin{array}{l}\text { Motivo da última } \\
\text { consulta }\end{array}$} & Rotina & & & 1,000 & & \\
\hline & Dor & 0,295 & 0,015 & 1,343 & 1,$304 ; 1,383$ & $<0,0001$ \\
\hline
\end{tabular}


Tabela 3 - Razão de média da perda dentária em adultos segundo estimativas do modelo univariado de regressão binomial negativa para as variáveis do nível contextual. Brasil, 2004.

\begin{tabular}{|c|c|c|c|c|c|c|}
\hline \multicolumn{2}{|c|}{$\begin{array}{c}\text { Variáveis do nível individual } \\
\text { Bloco } 3\end{array}$} & $\begin{array}{l}\text { Coeficiente } \\
\text { regressão }\end{array}$ & EP & RM & IC 95\% & Valor-p \\
\hline \multirow{4}{*}{$\begin{array}{l}\text { Informações } \\
\text { prevenção }\end{array}$} & Cavidades nos dentes & 0,187 & 0,019 & 1,206 & 1,$162 ; 1,251$ & $<0,0001$ \\
\hline & $\begin{array}{l}\text { Sangramento gengival, } \\
\text { rosto inchado ou feridas na } \\
\text { boca }\end{array}$ & 0,431 & 0,022 & 1,539 & 1,$474 ; 1,607$ & $<0,0001$ \\
\hline & Recebeu informações & & & 1,000 & & \\
\hline & Não recebeu informações & 0,123 & 0,012 & 1,131 & 1,$105 ; 1,158$ & $<0,0001$ \\
\hline \multicolumn{2}{|c|}{$\begin{array}{c}\text { Variáveis do nível individual } \\
\text { Bloco } 4\end{array}$} & $\begin{array}{l}\text { Coeficiente } \\
\text { regressão }\end{array}$ & EP & RM & IC $95 \%$ & Valor-p \\
\hline \multirow[t]{2}{*}{ Sexo } & Masculino & & & 1,000 & & \\
\hline & Feminino & 0,245 & 0,013 & 1,278 & 1,$245 ; 1,311$ & $<0,0001$ \\
\hline \multirow[t]{2}{*}{ Grupo étnico } & Branco & & & 1,000 & & \\
\hline & Não branco & 0,029 & 0,014 & 1,029 & 1,$002 ; 1,058$ & 0,0385 \\
\hline \multirow[t]{2}{*}{ Idade } & Até a mediana $(\leq 39)$ & & & 1,000 & & \\
\hline & Acima da mediana $(>39)$ & 0,315 & 0,012 & 1,370 & 1,$338 ; 1,403$ & $<0,0001$ \\
\hline
\end{tabular}

EP: erro-padrão

RM: razão de média

IC 95\%: intervalo de confiança de $95 \%$ 
Tabela 4 - Razão de média da perda dentária em adultos segundo estimativas do modelo multinível hierárquico múltiplo de regressão binomial negativa. Brasil, 2004.

\begin{tabular}{|c|c|c|c|c|c|c|}
\hline \multicolumn{2}{|c|}{$\begin{array}{l}\text { Variáveis do nível contextual } \\
\text { Bloco } 1\end{array}$} & $\begin{array}{l}\text { Coeficiente } \\
\text { regressão }\end{array}$ & EP & $\mathbf{R M}^{*}$ & IC 95\% & Valor-p \\
\hline \multicolumn{7}{|l|}{ Nível Regional } \\
\hline \multirow{2}{*}{$\begin{array}{l}\text { N. de Dentistas } \\
\text { por mil habitantes }\end{array}$} & Até a mediana $(\leq 0,98)$ & & & 1,000 & & \\
\hline & Acima da mediana $(>0,98)$ & $-0,093$ & 0,032 & 0,911 & 0,$856 ; 0,970$ & 0,0039 \\
\hline \multicolumn{7}{|l|}{ Nível Estadual } \\
\hline \multirow[t]{3}{*}{ Taxa de exodontia } & Tercil 1 & & & 1,000 & & \\
\hline & Tercil 2 & 0,068 & 0,037 & 1,070 & 0,$995 ; 1,151$ & 0,0672 \\
\hline & Tercil 3 & 0,126 & 0,038 & 1,134 & 1,$053 ; 1,222$ & 0,0008 \\
\hline \multicolumn{7}{|l|}{ Nível Municipal } \\
\hline \multirow[t]{2}{*}{ Porte municipal } & Até 100 mil habitantes & & & 1,000 & & \\
\hline & Mais de 100 mil habitantes & $-0,136$ & 0,032 & 0,873 & 0,$820 ; 0,929$ & $<0,0001$ \\
\hline \multicolumn{2}{|c|}{$\begin{array}{c}\text { Variáveis no modelo hierárquico } \\
\text { Bloco } 2\end{array}$} & $\begin{array}{l}\text { Coeficiente } \\
\text { regressão }\end{array}$ & EP & $\mathbf{R M \dagger}$ & IC 95\% & Valor-p \\
\hline \multirow[t]{4}{*}{ Escolaridade } & Sem estudo & & & 1,000 & & \\
\hline & Até quatro anos & 0,018 & 0,023 & 1,018 & 0,$973 ; 1,065$ & 0,4443 \\
\hline & Até oito anos & $-0,075$ & 0,024 & 0,928 & 0,$885 ; 0,972$ & 0,0019 \\
\hline & Nove anos ou mais & $-0,324$ & 0,025 & 0,723 & 0,$689 ; 0,760$ & $<0,0001$ \\
\hline \multirow{3}{*}{$\begin{array}{l}\text { Posse de } \\
\text { automóvel }\end{array}$} & Sem automóvel & & & 1,000 & & \\
\hline & Um automóvel & $-0,098$ & 0,015 & 0,907 & 0,$880 ; 0,934$ & $<0,0001$ \\
\hline & Dois ou mais automóveis & $-0,271$ & 0,040 & 0,763 & 0,$705 ; 0,825$ & $<0,0001$ \\
\hline \multicolumn{2}{|c|}{$\begin{array}{c}\text { Variáveis no modelo hierárquico } \\
\text { Bloco } 3\end{array}$} & $\begin{array}{l}\text { Coeficiente } \\
\text { regressão }\end{array}$ & EP & RM‡ & IC 95\% & Valor-p \\
\hline \multirow[t]{2}{*}{ Visita ao dentista } & Nunca foi ao dentista & & & 1,000 & & \\
\hline & Já foi ao dentista & 0,289 & 0,040 & 1,335 & 1,$234 ; 1,444$ & $<0,0001$ \\
\hline \multirow{3}{*}{$\begin{array}{l}\text { Tempo da última } \\
\text { consulta }\end{array}$} & Menos de um ano & & & 1,000 & & \\
\hline & De um a dois anos & 0,034 & 0,015 & 1,035 & 1,$005 ; 1,065$ & 0,0269 \\
\hline & Há três anos ou mais & 0,193 & 0,014 & 1,213 & 1,$180 ; 1,247$ & $<0,0001$ \\
\hline \multirow{4}{*}{$\begin{array}{l}\text { Motivo da última } \\
\text { consulta }\end{array}$} & Rotina & & & 1,000 & & \\
\hline & Dor & 0,149 & 0,016 & 1,161 & 1,$125 ; 1,198$ & $<0,0001$ \\
\hline & Cavidades nos dentes & 0,098 & 0,019 & 1,103 & 1,$063 ; 1,145$ & $<0,0001$ \\
\hline & $\begin{array}{l}\text { Sangramento gengival, } \\
\text { rosto inchado ou feridas na } \\
\text { boca }\end{array}$ & 0,327 & 0,022 & 1,387 & 1,$328 ; 1,448$ & $<0,0001$ \\
\hline \multirow{2}{*}{$\begin{array}{l}\text { Informações } \\
\text { prevenção }\end{array}$} & Recebeu informações & & & 1,000 & & \\
\hline & Não recebeu informações & 0,057 & 0,012 & 1,059 & 1,$034 ; 1,084$ & $<0,0001$ \\
\hline \multicolumn{2}{|c|}{$\begin{array}{c}\text { Variáveis no modelo hierárquico } \\
\text { Bloco } 4\end{array}$} & $\begin{array}{l}\text { Coeficiente } \\
\text { regressão }\end{array}$ & EP & RM§ & IC $95 \%$ & Valor-p \\
\hline \multirow[t]{2}{*}{ Sexo } & Masculino & & & 1,000 & & \\
\hline & Feminino & 0,243 & 0,012 & 1,275 & 1,$245 ; 1,305$ & $<0,0001$ \\
\hline \multirow[t]{2}{*}{ Idade } & Até a mediana $(\leq 39)$ & & & 1,000 & & \\
\hline & Acima da mediana $(>39)$ & 0,279 & 0,011 & 1,322 & 1,$294 ; 1,351$ & $<0,0001$ \\
\hline
\end{tabular}


Figura 5 - Razão de Médias (RM) e intervalo de 95\% das variáveis contextuais e individuais que apresentaram interações. Brasil, 2004.

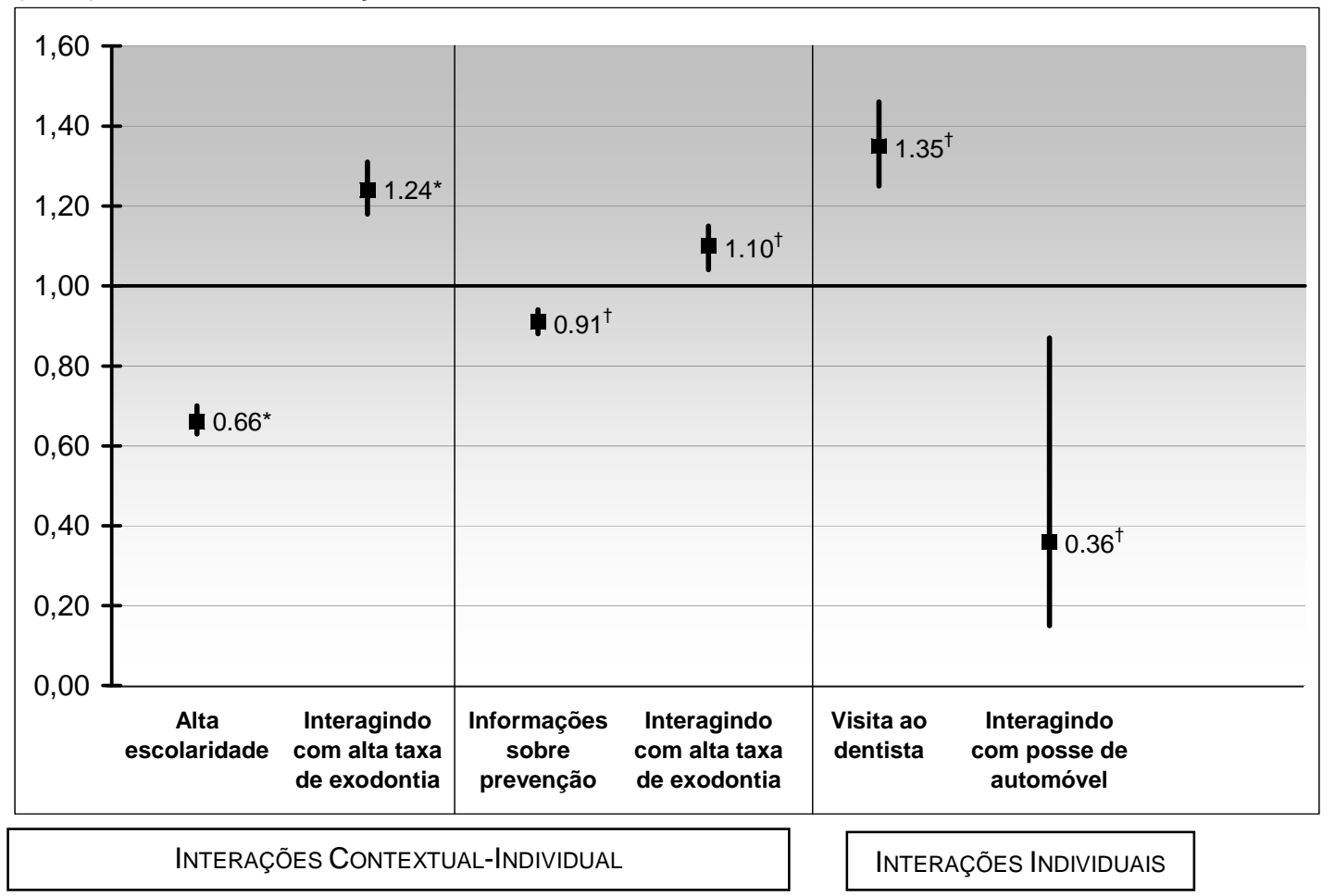

* RM para as variáveis contextuais e do bloco 2

† RM para as variáveis contextuais e dos blocos 2 e 3

\subsubsection{Análise espacial da perda dentária em adultos}

A Figura 6 indica o número de dentistas por mil habitantes segundo quintis e por Unidade da Federação, devido à inexistência deste dado em um nível maior de desagregação.

Observou-se que a dependência espacial não foi significativa, segundo o Índice Global de Moran. A maioria dos estados da região Norte e o estado da Bahia possuem as menores quantidades de dentistas por habitantes. 
Figura 6 - Densidade de dentistas por 1000 habitantes segundo o estado. Brasil, 2003.

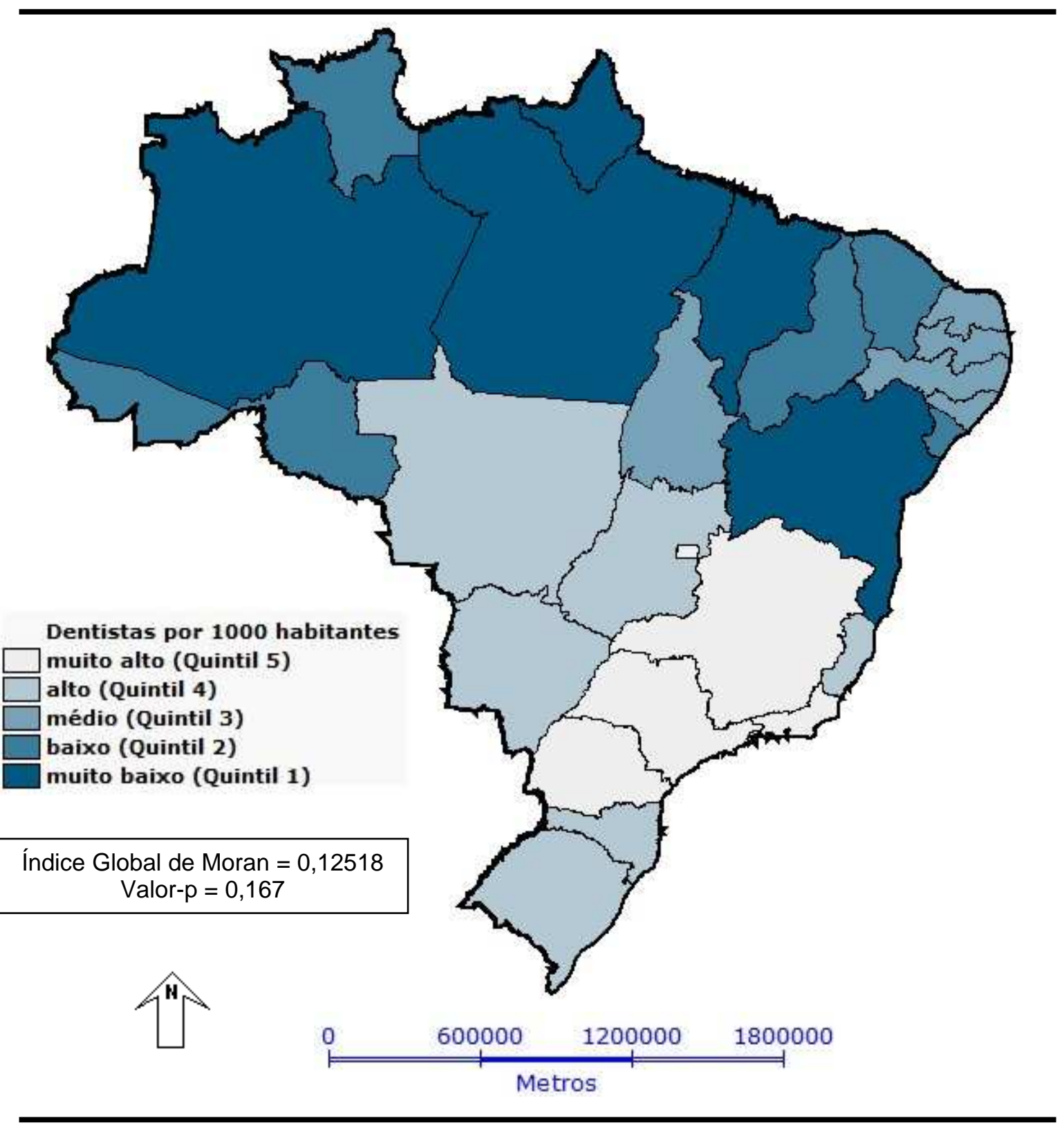


A Figura 7 mostra os quintis das taxas de exodontia.

Figura 7 - Taxa de exodontia segundo a microrregião. Brasil, 2003.

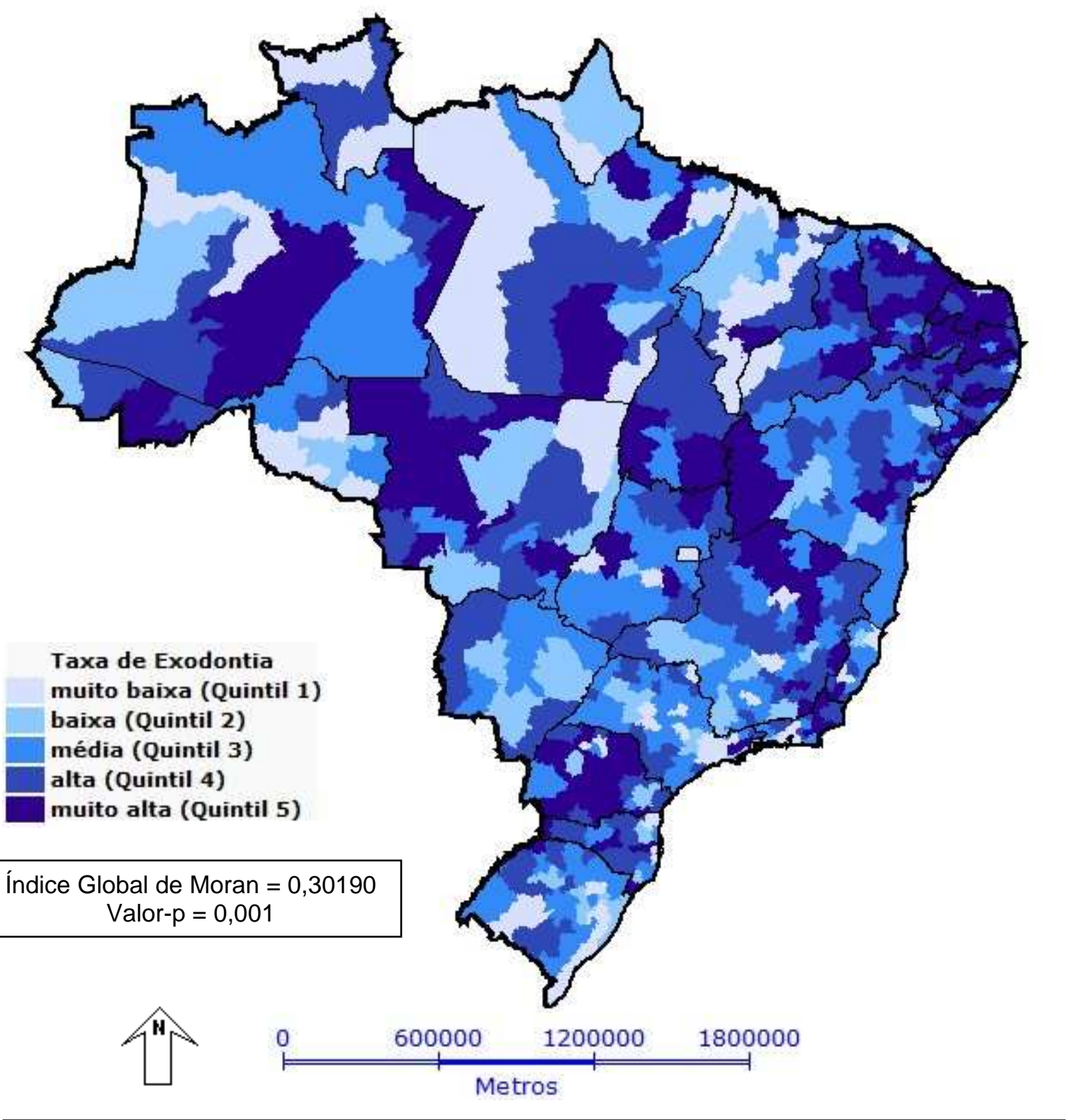


Observa-se que a taxa de exodontia apresentou uma dependência espacial significativa.

O próximo mapa (Figura 8) mostra a distribuição das microrregiões segundo o porte populacional por quintis, com uma dependência espacial significante.

Figura 8 - Porte populacional segundo a microrregião. Brasil, 2003.

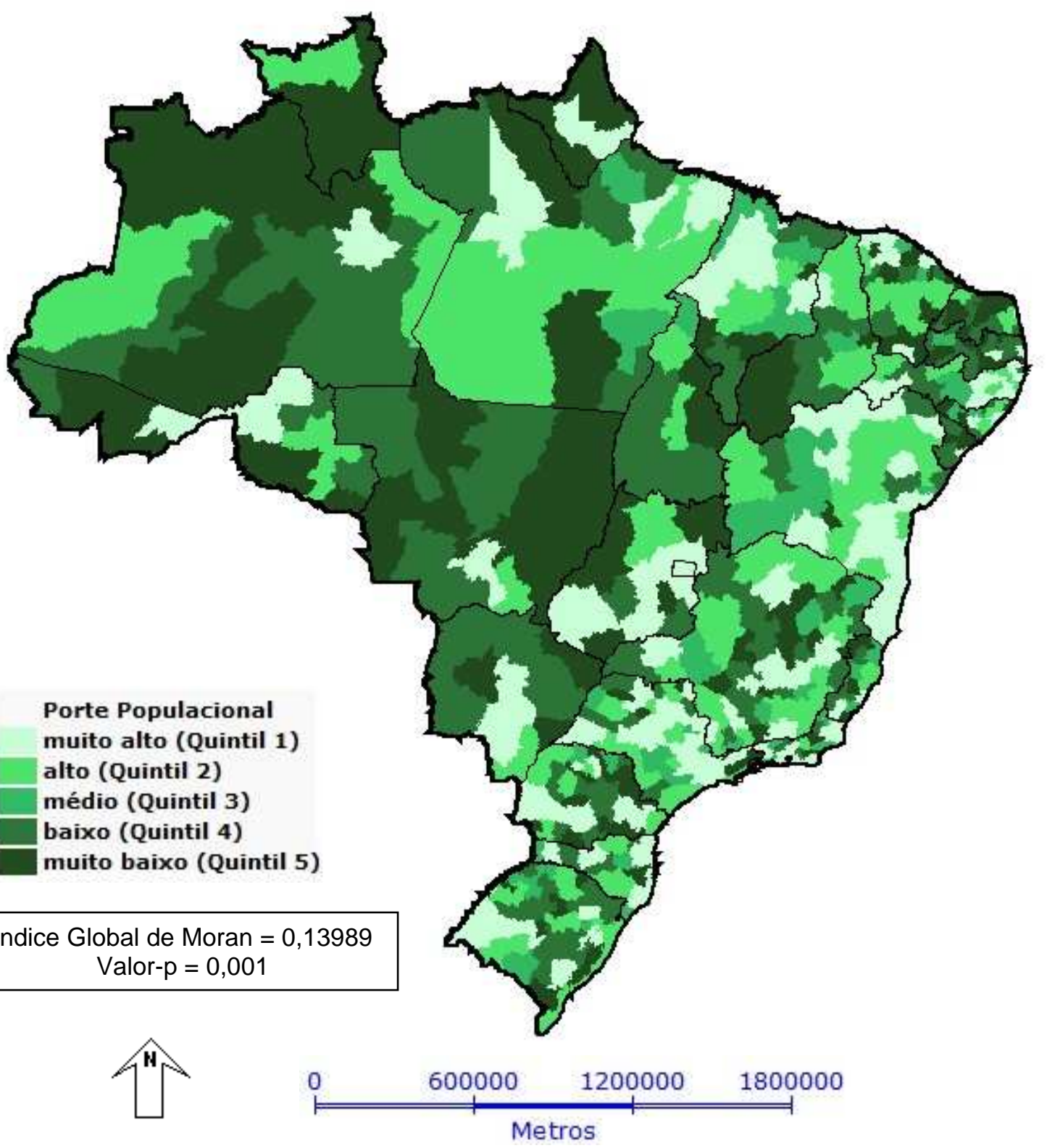


O próximo passo foi o uso do Processo Analítico Hierárquico (AHP) para construir um mapa de risco baseado no efeito conjunto dessas três variáveis. O mapa gerado está apresentado a seguir (Figura 9).

Figura 9 - Mapa de risco para perda dentária gerado pelo Processo Analítico Hierárquico (AHP). Brasil, 2003.

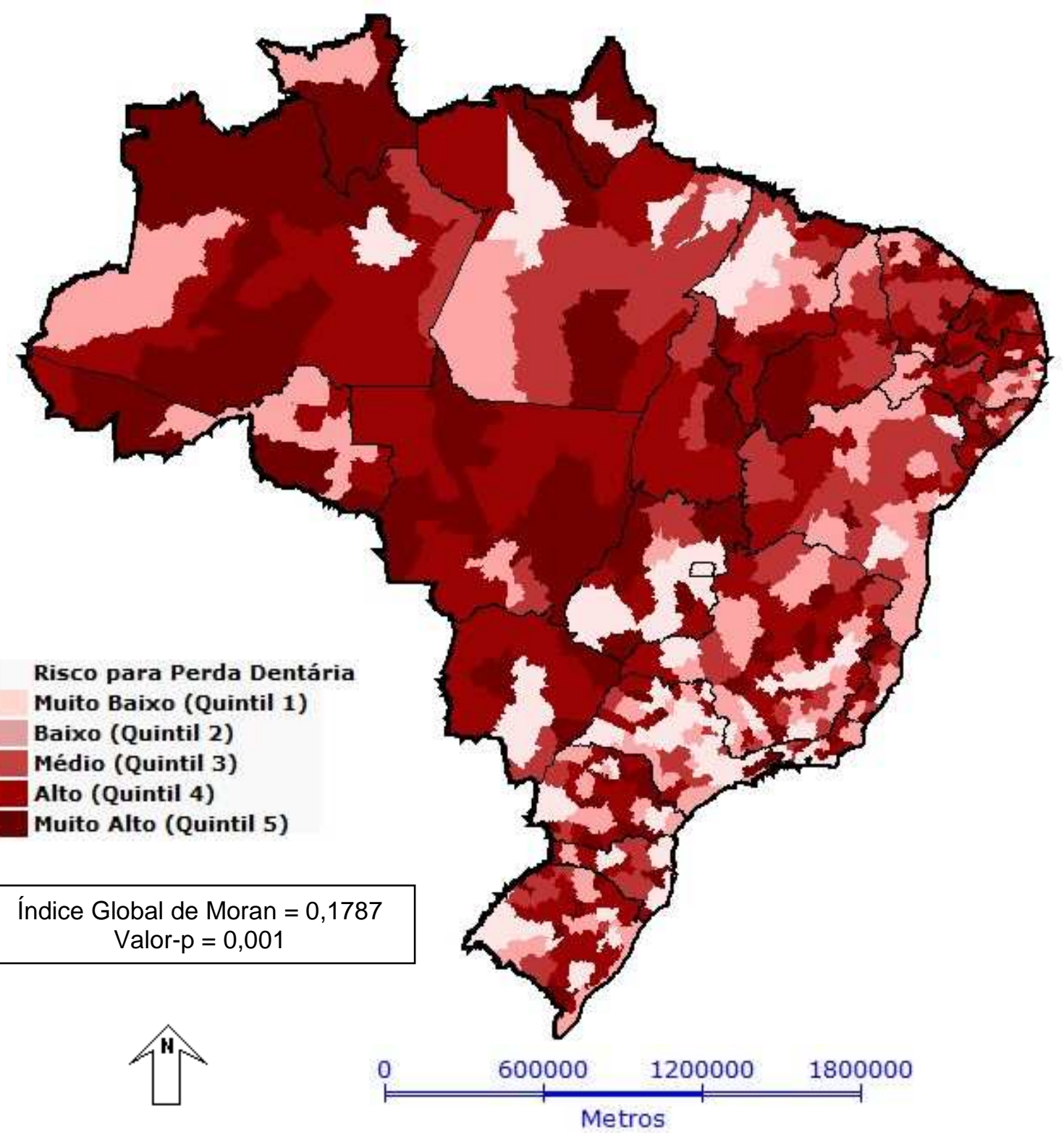


O mapa de risco gerado apresentou dependência espacial global significante. Visando construir um mapa de superfície contínua, este mapa foi suavizado pelo procedimento de Krigeagem Ordinária, conforme ilustrado na Figura 10.

Figura 10 - Mapa de risco para perda dentária gerado pela Krigeagem Ordinária. Brasil, 2003.

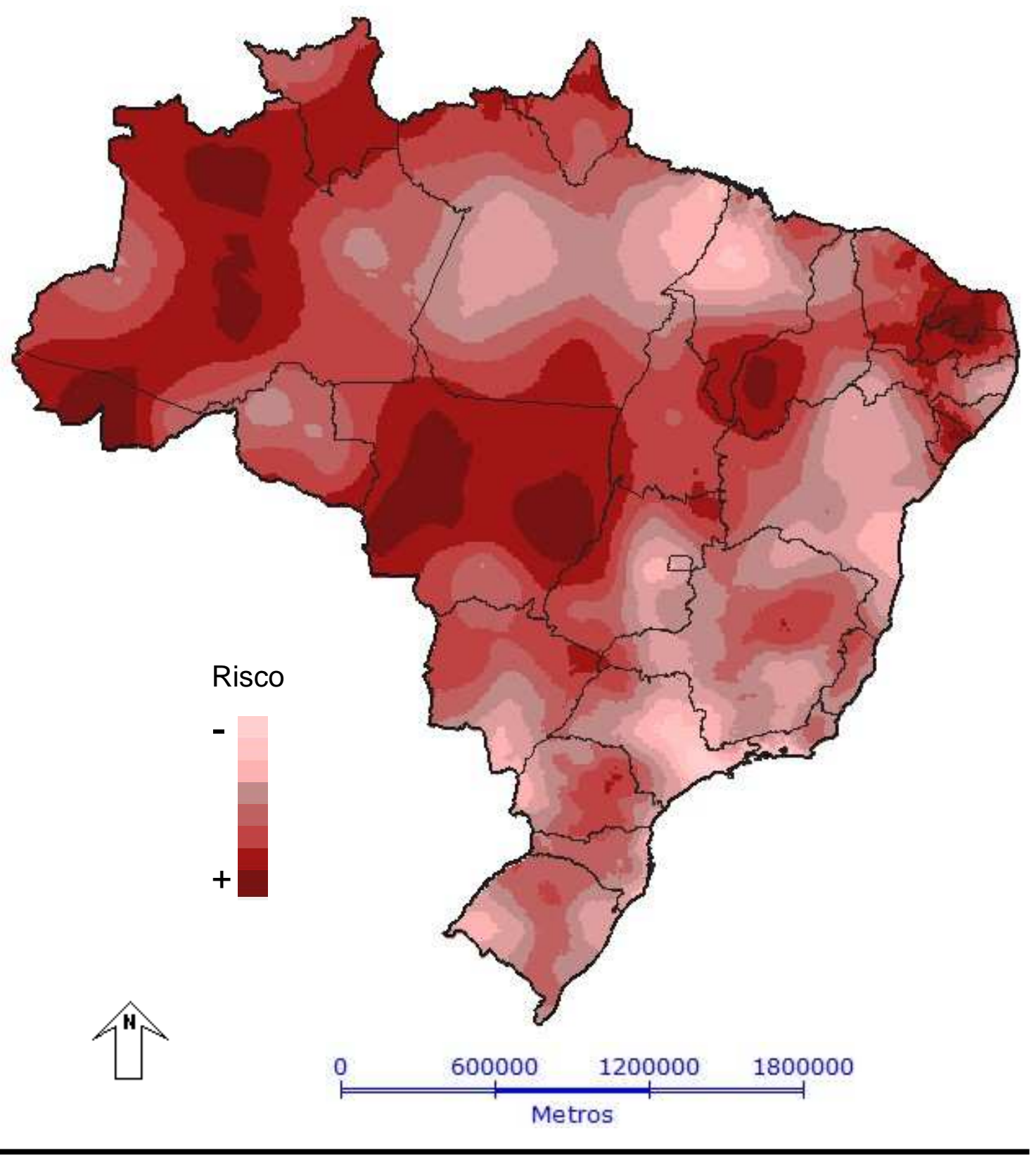


No sentido de conhecer a distribuição espacial do Diagrama de

Espalhamento de Moran foi construído o Box Map, como ilustrado na Figura 11.

Figura 11 - Box Map: Mapa de espalhamento de Moran para o risco de perda dentária gerado pelo Processo Analítico Hierárquico (AHP). Brasil, 2003.

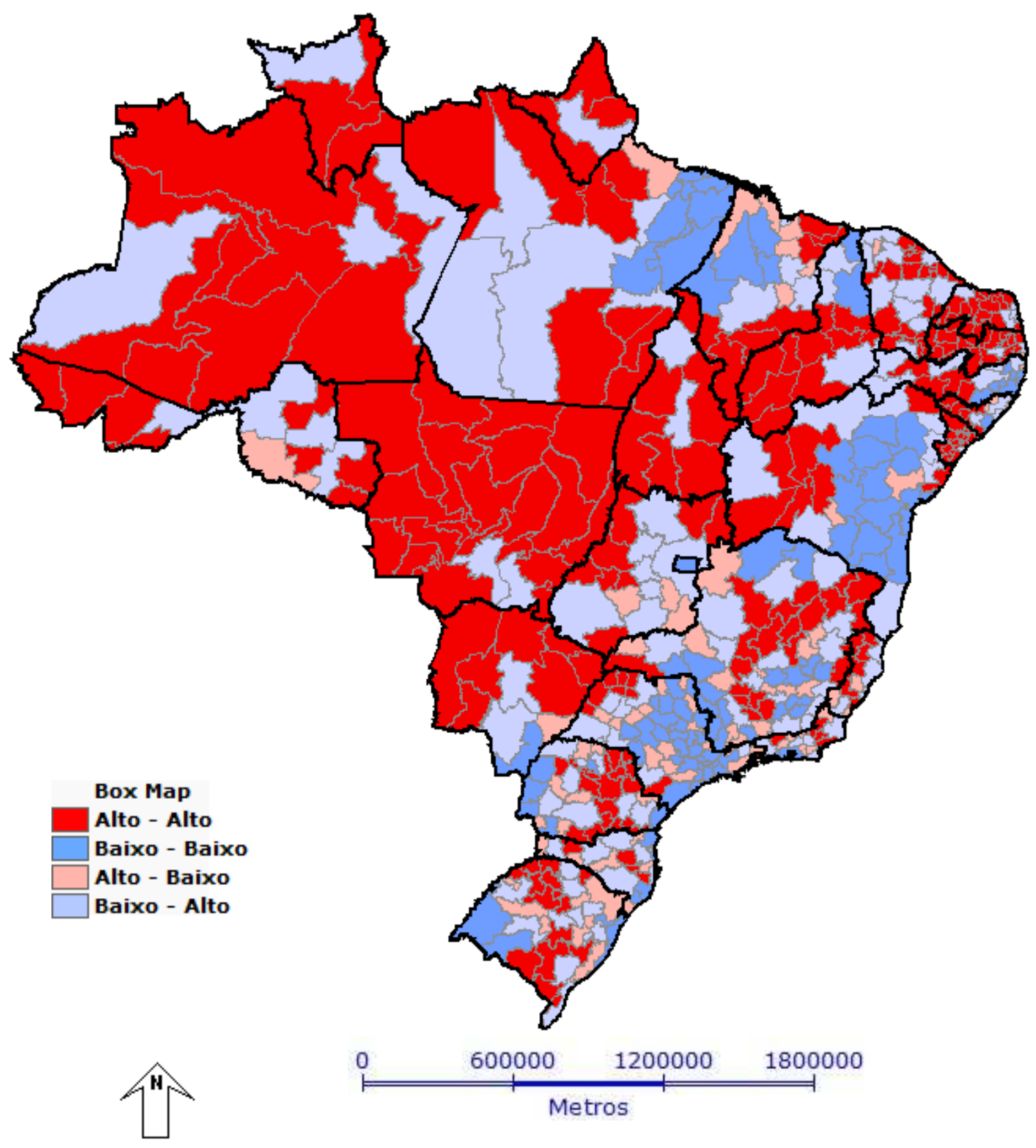


O Box Map ilustra em vermelho as áreas com alto risco e que são vizinhas às áreas de alto risco também. Em azul escuro estão as áreas de baixo risco vizinhas às áreas de baixo risco. As demais áreas são consideradas de transição ou de fronteira, pois representam áreas de alto risco vizinhas às de baixo risco (vermelho claro) ou de baixo risco vizinhas às de alto risco (azul claro). O Lisa Map ilustra apenas as áreas com dependência espacial significante, conforme Figura 12.

Figura 12 - Lisa Map: Mapa de espalhamento de Moran para o risco de perda dentária gerado pelo Processo Analítico Hierárquico (AHP). Brasil, 2003.

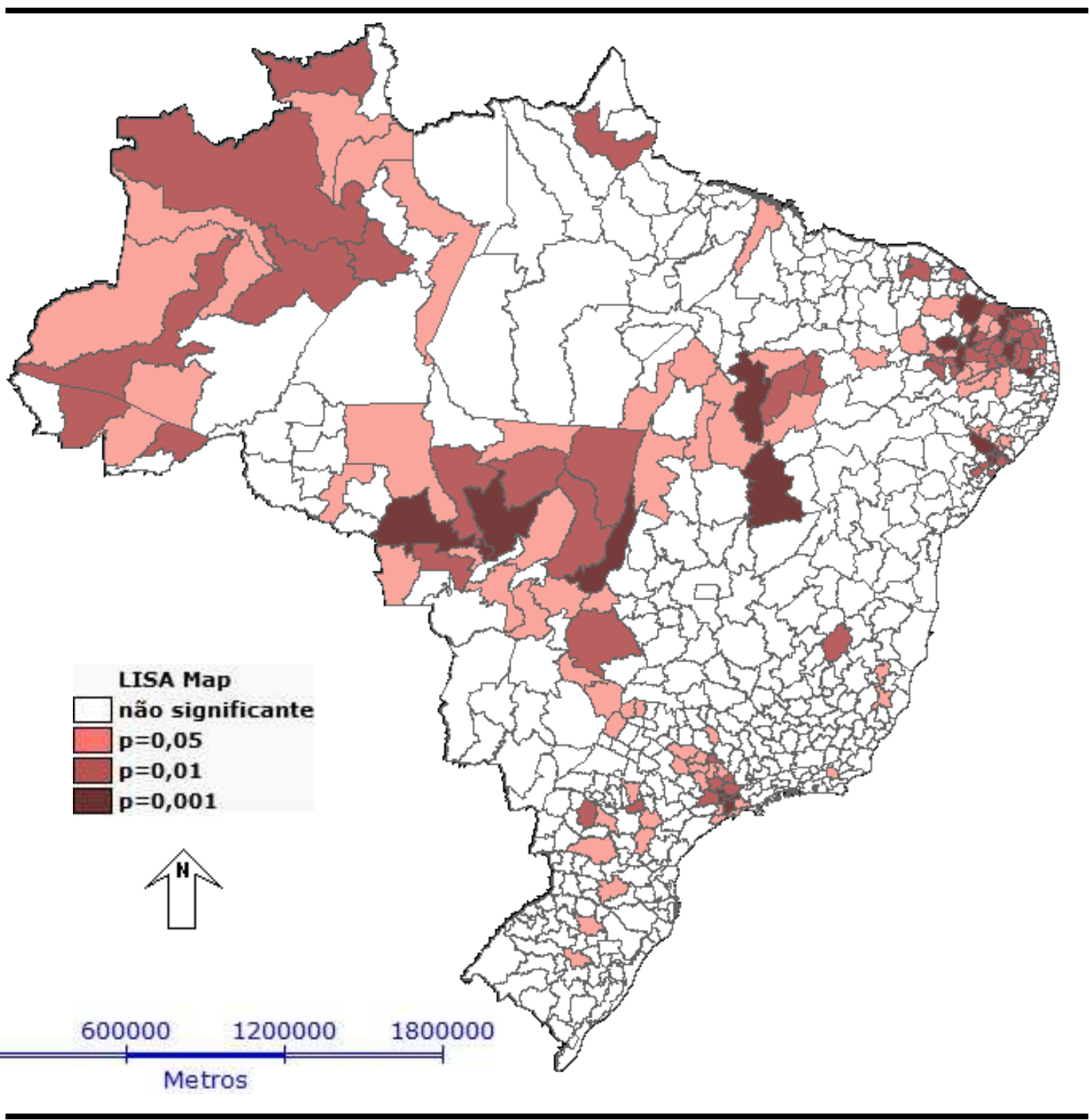


Finalmente, o Moran Map discrimina as áreas de dependência espacial significante segundo o Diagrama de Espalhamento de Moran, como ilustrado na Figura 13.

Figura 13 - Moran Map: Mapa de espalhamento de Moran para o risco de perda dentária gerado pelo Processo Analítico Hierárquico (AHP). Brasil, 2003.

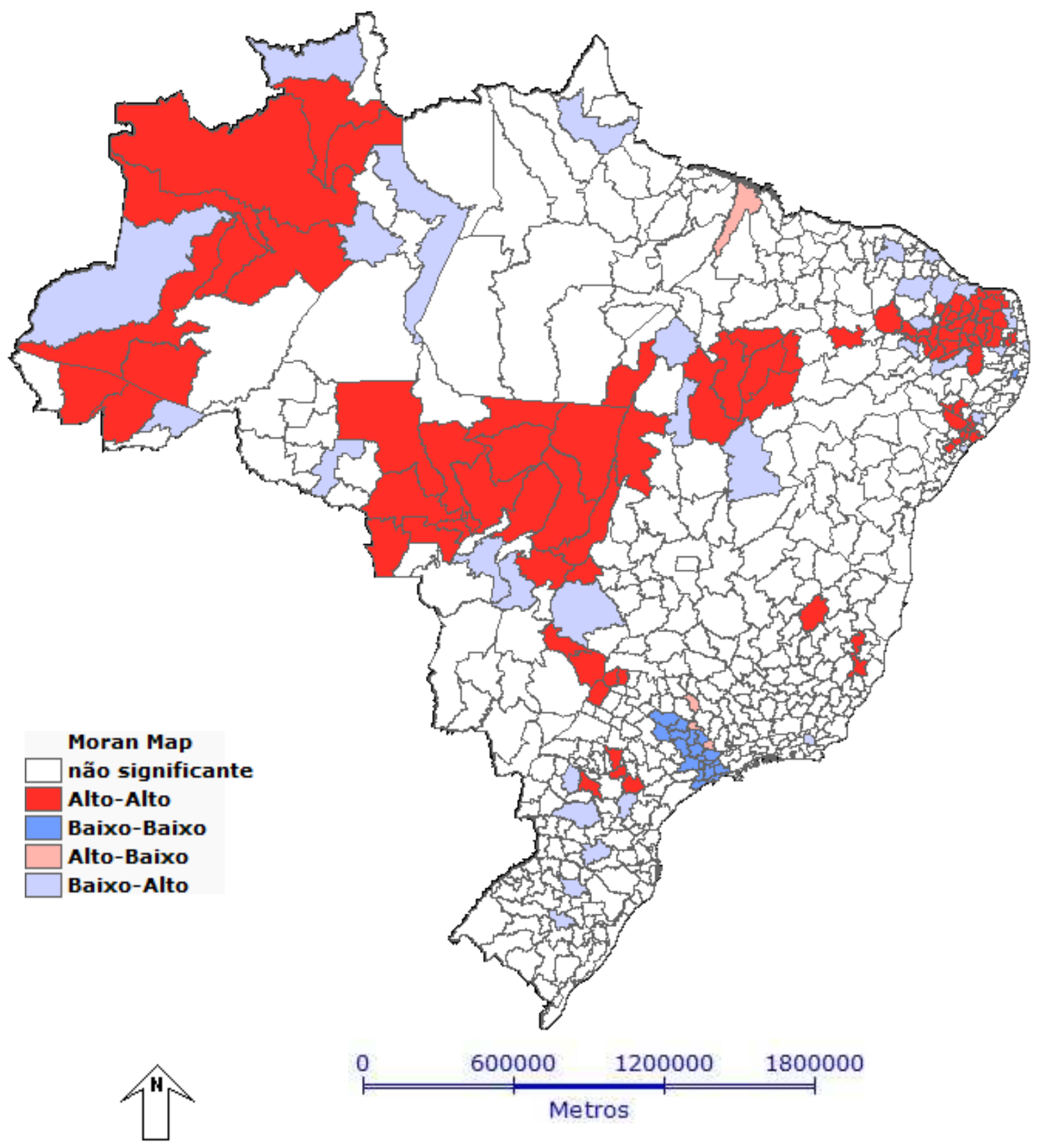


O Moran Map permite apontar as áreas de risco e de proteção para a perda dentária. Observou-se que as áreas vermelhas (risco) se concentram ao extremo oeste da região Norte, grande parte do estado do Mato Grosso e sul do Pará, Maranhão e Piauí, e grande parte do interior do Rio Grande do Norte, Paraíba, Sergipe e sul do estado do Ceará. Áreas isoladas de risco foram encontradas em Minas Gerais, Mato Grosso do Sul e Paraná.

Áreas de proteção (azul) cobriram boa parte do estado de São Paulo.

\subsection{Edentulismo funcional em idosos}

O edentulismo funcional é caracterizado pela ausência de no mínimo 20 dentes permanentes em condições funcionais. Foram considerados edêntulos funcionais os idosos que apresentavam perda dentária de no mínimo 13 dentes permanentes, restando apenas 19 dentes ou menos. Foram analisados 2418 idosos. A prevalência encontrada de edentulismo funcional entre estes foi de 78,7\% (IC 95\% = 77\% 80\%).

A Tabela 5 mostra a análise univariada e a descrição do desfecho segundo as variáveis independentes. Morar na área rural foi associado ao edentulismo funcional, assim como quem já foi ao dentista há três anos ou mais, em serviço público, por motivo de dor, cavidade nos dentes, sangramento gengival ou feridas na boca e que não recebeu informações sobre prevenção das doenças bucais. Entre as variáveis do bloco 4, apenas o sexo feminino esteve associado ao edentulismo funcional. 
Tabela 5 - Razão de prevalência de edentulismo funcional em idosos segundo estimativas do modelo univariado de regressão de Poisson. Brasil, 2004.

\begin{tabular}{|c|c|c|c|c|c|c|}
\hline \multicolumn{2}{|c|}{$\begin{array}{l}\text { Variáveis do nível contextual } \\
\text { Bloco } 1\end{array}$} & $\mathbf{N}(\%)$ & $\begin{array}{l}\text { Prevalência } \\
\text { Edent. F.* }\end{array}$ & $\mathbf{R P}$ & IC 95\% & Valor-p \\
\hline \multirow{3}{*}{$\begin{array}{l}\text { N. de Dentistas } \\
\text { por mil habitantes } \\
\text { Nível Regional }\end{array}$} & Até a mediana $(\leq 0,98)$ & 1104 (46\%) & $80,7 \%$ & 1,000 & & \\
\hline & $\begin{array}{l}\text { Acima da mediana } \\
(>0,98)\end{array}$ & $1314(54 \%)$ & $73,2 \%$ & 0,908 & 0,$818 ; 1,007$ & 0,0674 \\
\hline & Quintil 1 & $629(26 \%)$ & $76,0 \%$ & 1,000 & & \\
\hline \multirow{4}{*}{$\begin{array}{l}\text { Taxa de } \\
\text { exodontia } \\
\text { Nível Estadual }\end{array}$} & Quintil 2 & 396 (16\%) & $75,3 \%$ & 0,990 & 0,$856 ; 1,145$ & 0,8932 \\
\hline & Quintil 3 & $538(22 \%)$ & $79,4 \%$ & 1,044 & 0,$915 ; 1,190$ & 0,5139 \\
\hline & Quintil 4 & $461(20 \%)$ & $83,1 \%$ & 1,093 & 0,$955 ; 1,251$ & 0,1936 \\
\hline & Quintil 5 & $394(16 \%)$ & $80,2 \%$ & 1,055 & 0,$915 ; 1,218$ & 0,4570 \\
\hline \multicolumn{2}{|c|}{$\begin{array}{l}\text { Variáveis do nível individual } \\
\text { Bloco } 2\end{array}$} & N (\%) & $\begin{array}{l}\text { Prevalência } \\
\text { Edent. F.* }\end{array}$ & $\mathbf{R P}$ & IC 95\% & Valor-p \\
\hline \multirow{2}{*}{$\begin{array}{l}\text { Local } \\
\text { geográfico }\end{array}$} & Urbano & 2128 (88\%) & $78,1 \%$ & 1,000 & & \\
\hline & Rural & 290 (12\%) & $82,4 \%$ & 1,054 & 1,$022 ; 1,088$ & 0,0006 \\
\hline \multirow[t]{4}{*}{ Escolaridade } & Sem estudo & 798 (33\%) & $79,3 \%$ & 1,000 & & \\
\hline & Até quatro anos & $1025(42 \%)$ & 79,0 & 0,996 & 0,$941 ; 1,054$ & 0,8962 \\
\hline & Até oito anos & $378(16 \%)$ & $80,4 \%$ & 1,014 & 0,$954 ; 1,078$ & 0.6553 \\
\hline & Nove anos ou mais & 217 (9\%) & $71,4 \%$ & 0,900 & 0,$811 ; 0,999$ & 0,0481 \\
\hline \multirow[t]{2}{*}{ Moradia } & Casa própria & $2140(88 \%)$ & $78,8 \%$ & 1,000 & & \\
\hline & Casa não própria & $278(12 \%)$ & $77,3 \%$ & 0,981 & 0,$947 ; 1,016$ & 0,2987 \\
\hline \multirow{3}{*}{$\begin{array}{l}\text { Posse de } \\
\text { automóvel }\end{array}$} & Sem automóvel & $1948(81 \%)$ & $80,3 \%$ & 1,000 & & \\
\hline & Um automóvel & $419(17 \%)$ & $72,8 \%$ & 0,906 & 0,$886 ; 0,925$ & $<0,0001$ \\
\hline & $\begin{array}{l}\text { Dois ou mais } \\
\text { automóveis }\end{array}$ & $51(2 \%)$ & $62,7 \%$ & 0,781 & 0,$708 ; 0,862$ & $<0,0001$ \\
\hline \multirow{2}{*}{$\begin{array}{l}\text { Pessoas por } \\
\text { cômodo }\end{array}$} & Até a mediana & $1252(52 \%)$ & $78,4 \%$ & 1,000 & & \\
\hline & Acima da mediana & $1166(48 \%)$ & $78,9 \%$ & 1,006 & 0,$967 ; 1,046$ & 0,7667 \\
\hline \multicolumn{2}{|c|}{$\begin{array}{l}\text { Variáveis do nível individual } \\
\text { Bloco } 3\end{array}$} & $\mathbf{N}(\%)$ & $\begin{array}{l}\text { Prevalência } \\
\text { Edent. F.* }\end{array}$ & $\mathbf{R P}$ & IC 95\% & Valor-p \\
\hline \multirow{2}{*}{$\begin{array}{l}\text { Visita ao } \\
\text { dentista }\end{array}$} & Nunca foi ao dentista & $194(8 \%)$ & $74,2 \%$ & 1,000 & & \\
\hline & Já foi ao dentista & 2224 (92\%) & $79,0 \%$ & 1,065 & 0,$985 ; 1,152$ & 0,1170 \\
\hline \multirow{3}{*}{$\begin{array}{l}\text { Tempo da última } \\
\text { consulta }\end{array}$} & Menos de um ano & $608(25 \%)$ & $73,0 \%$ & 1,000 & & \\
\hline & De um a dois anos & $372(15 \%)$ & $77,4 \%$ & 1,060 & 0,$980 ; 1,146$ & 0,1398 \\
\hline & Há três anos ou mais & $1231(51 \%)$ & $82,6 \%$ & 1,131 & 1,$068 ; 1,197$ & $<0,0001$ \\
\hline \multirow{3}{*}{$\begin{array}{l}\text { Local da última } \\
\text { consulta }\end{array}$} & Serviço privado & $1112(46 \%)$ & $76,3 \%$ & 1,000 & & \\
\hline & Serviço público & $988(41 \%)$ & $81,9 \%$ & 1,073 & 1,$052 ; 1,094$ & $<0,0001$ \\
\hline & Outros serviços & 117 (5\%) & $82,1 \%$ & 1,075 & 0,$946 ; 1,221$ & 0,2713 \\
\hline \multirow{5}{*}{$\begin{array}{l}\text { Motivo da última } \\
\text { consulta }\end{array}$} & Rotina & $445(18 \%)$ & $73,9 \%$ & 1,000 & & \\
\hline & Dor & 1166 (48\%) & $80,2 \%$ & 1,084 & 1,$016 ; 1,157$ & 0,0125 \\
\hline & Cavidades nos dentes & $296(12 \%)$ & $81,1 \%$ & 1,096 & 1,$040 ; 1,156$ & 0,0005 \\
\hline & $\begin{array}{l}\text { Sangramento gengival, } \\
\text { rosto inchado ou feridas } \\
\text { na boca }\end{array}$ & $310(13 \%)$ & $80,6 \%$ & 1,091 & 1,$049 ; 1,135$ & $<0,0001$ \\
\hline & & & & & & continua \\
\hline
\end{tabular}


Tabela 5 - Razão de prevalência de edentulismo funcional em idosos segundo estimativas do modelo univariado de regressão de Poisson. Brasil, 2004.

continuação

\begin{tabular}{|c|c|c|c|c|c|c|}
\hline \multicolumn{2}{|c|}{$\begin{array}{c}\text { Variáveis do nível individual } \\
\text { Bloco } 3\end{array}$} & $\mathbf{N}(\%)$ & $\begin{array}{l}\text { Prevalência } \\
\text { Edent. F.* }\end{array}$ & $\mathbf{R P}$ & IC 95\% & Valor-p \\
\hline \multirow{3}{*}{$\begin{array}{l}\text { Informações } \\
\text { prevenção }\end{array}$} & & $1025(42 \%)$ & $76,7 \%$ & & & \\
\hline & Recebeu informações & & & 1,000 & & \\
\hline & $\begin{array}{l}\text { Não recebeu } \\
\text { informações }\end{array}$ & $1393(58 \%)$ & $80,1 \%$ & 1,045 & 1,$007 ; 1,085$ & 0,0223 \\
\hline \multicolumn{2}{|c|}{$\begin{array}{l}\text { Variáveis do nível individual } \\
\text { Bloco } 4\end{array}$} & $\mathbf{N}(\%)$ & $\begin{array}{l}\text { Prevalência } \\
\text { Edent. F.* }\end{array}$ & $\mathbf{R P}$ & IC 95\% & Valor-p \\
\hline \multirow[t]{2}{*}{ Sexo } & Masculino & $1209(50 \%)$ & $74,5 \%$ & 1,000 & & \\
\hline & Feminino & $1209(50 \%)$ & $82,8 \%$ & 1,111 & 1,$051 ; 1,173$ & 0,0001 \\
\hline \multirow[t]{2}{*}{ Grupo étnico } & Branco & $1131(47 \%)$ & $78,5 \%$ & 1,000 & & \\
\hline & Não branco & $1280(53 \%)$ & $78,8 \%$ & 1,004 & 0,$939 ; 1,073$ & 0,9058 \\
\hline \multirow[t]{2}{*}{ Idade } & Até a mediana $(\leq 68)$ & $1391(57 \%)$ & $77,9 \%$ & 1,000 & & \\
\hline & $\begin{array}{l}\text { Acima da mediana } \\
(>68)\end{array}$ & $1027(43 \%)$ & $79,6 \%$ & 1,022 & 0,$975 ; 1,071$ & 0,3705 \\
\hline
\end{tabular}

${ }^{*}$ Prevalência de edentulismo funcional (ausência de no mínimo 20 dentes permanentes)

EP: erro-padrão

RP: razão de prevalência

IC 95\%: intervalo de confiança de $95 \%$

A Tabela 6 mostra os resultados do modelo múltiplo, segundo o modelo teórico apresentado na Figura 4(B). Pode-se observar que, dentre as variáveis contextuais, o maior número de dentistas por mil habitantes foi associado à menor prevalência de edentulismo funcional, enquanto que a maior taxa de exodontia foi associada à maior prevalência.

Outros fatores associados ao edentulismo funcional foram: morar na área rural, ter tido a última consulta odontológica realizada há três anos ou mais, em serviço público e por motivos de sangramento gengival, rosto inchado ou feridas na boca, ser do sexo feminino. Possuir um ou mais automóveis esteve associado à menor prevalência de edentulismo funcional.

A Figura 14 ilustra as interações observadas entre as variáveis independentes associadas ao edentulismo funcional. 
Tabela 6 - Razão de prevalência de edentulismo funcional ${ }^{\star}$ em idosos segundo estimativas do modelo múltiplo de regressão de Poisson. Brasil, 2004.

\begin{tabular}{|c|c|c|c|c|c|c|}
\hline \multicolumn{2}{|c|}{$\begin{array}{l}\text { Variáveis do nível contextual } \\
\text { Bloco } 1\end{array}$} & $\begin{array}{l}\text { Coeficiente } \\
\text { regressão }\end{array}$ & EP & $\mathbf{R P}^{\star \star}$ & IC 95\% & Valor-p \\
\hline \multicolumn{7}{|l|}{ Nível Regional } \\
\hline \multirow{2}{*}{$\begin{array}{l}\text { N. de Dentistas } \\
\text { por mil habitantes }\end{array}$} & Até a mediana $(\leq 0,98)$ & & & 1,000 & & \\
\hline & Acima da mediana $(>0,98)$ & $-0,083$ & 0,030 & 0,920 & 0,$868 ; 0,976$ & 0,0060 \\
\hline Nível Estadual & Quintil 1 & & & 1,000 & & \\
\hline \multirow[t]{4}{*}{ Taxa de exodontia } & Quintil 2 & 0,024 & 0,070 & 1,024 & 0,$893 ; 1,175$ & 0,7268 \\
\hline & Quintil 3 & 0,025 & 0,022 & 1,025 & 0,$982 ; 1,070$ & 0,2571 \\
\hline & Quintil 4 & 0,062 & 0,023 & 1,064 & 1,$017 ; 1,113$ & 0,0074 \\
\hline & Quintil 5 & 0,043 & 0,029 & 1,044 & 0,$986 ; 1,105$ & 0,1300 \\
\hline \multicolumn{2}{|c|}{$\begin{array}{l}\text { Variáveis do nível individual } \\
\text { Bloco } 2\end{array}$} & $\begin{array}{l}\text { Coeficiente } \\
\text { regressão }\end{array}$ & EP & RPt & IC 95\% & Valor-p \\
\hline \multirow[t]{2}{*}{ Local geográfico } & Urbano & & & 1,000 & & \\
\hline & Rural & 0,049 & 0,017 & 1,050 & 1,$016 ; 1,086$ & 0,0040 \\
\hline \multirow{3}{*}{$\begin{array}{l}\text { Posse de } \\
\text { automóvel }\end{array}$} & Sem automóvel & & & 1,000 & & \\
\hline & Um automóvel & $-0,078$ & 0,022 & 0,925 & 0,$886 ; 0,966$ & 0,0003 \\
\hline & Dois ou mais automóveis & $-0,230$ & 0,051 & 0,795 & 0,$719 ; 0,878$ & $<0,0001$ \\
\hline \multicolumn{2}{|c|}{$\begin{array}{c}\text { Variáveis do nível individual } \\
\text { Bloco } 3\end{array}$} & $\begin{array}{l}\text { Coeficiente } \\
\text { regressão }\end{array}$ & EP & RP¥ & IC 95\% & Valor-p \\
\hline \multirow{3}{*}{$\begin{array}{l}\text { Tempo da última } \\
\text { consulta }\end{array}$} & Menos de um ano & & & 1,000 & & \\
\hline & De um a dois anos & 0,047 & 0,038 & 1,048 & 0,$973 ; 1,129$ & 0,2121 \\
\hline & Há três anos ou mais & 0,097 & 0,023 & 1,102 & 1,$053 ; 1,153$ & $<0,0001$ \\
\hline \multirow{3}{*}{$\begin{array}{l}\text { Local da última } \\
\text { consulta }\end{array}$} & Serviço privado & & & 1,000 & & \\
\hline & Serviço público & 0,039 & 0,009 & 1,040 & 1,$022 ; 1,058$ & $<0,0001$ \\
\hline & Outros serviços & 0,018 & 0,061 & 1,018 & 0,$903 ; 1,147$ & 0,7629 \\
\hline \multirow{4}{*}{$\begin{array}{l}\text { Motivo da última } \\
\text { consulta }\end{array}$} & Rotina & & & 1,000 & & \\
\hline & Dor & 0,003 & 0,029 & 1,003 & 0,$948 ; 1,062$ & 0,9244 \\
\hline & Cavidades nos dentes & 0,028 & 0,020 & 1,028 & 0,$989 ; 1,070$ & 0,1763 \\
\hline & $\begin{array}{l}\text { Sangramento gengival, } \\
\text { rosto inchado ou feridas na } \\
\text { boca }\end{array}$ & 0,049 & 0,022 & 1,050 & 1,$006 ; 1,096$ & 0,0249 \\
\hline \multicolumn{2}{|c|}{$\begin{array}{l}\text { Variáveis do nível individual } \\
\text { Bloco } 4\end{array}$} & $\begin{array}{l}\text { Coeficiente } \\
\text { regressão }\end{array}$ & EP & RP§ & IC 95\% & Valor-p \\
\hline \multirow[t]{2}{*}{ Sexo } & Masculino & & & 1,000 & & \\
\hline & Feminino & 0,104 & 0,025 & 1,110 & 1,$057 ; 1,165$ & $<0,0001$ \\
\hline
\end{tabular}

* Prevalência de edentulismo funcional (ausência de no mínimo 20 dentes permanentes) EP: erro-padrão

RP: razão de prevalência

IC 95\%: intervalo de confiança de $95 \%$ **ajustado pelas variáveis contextuais

†ajustado pelas variáveis contextuais e do bloco 2 .

Ғajustado pelas variáveis contextuais e dos blocos 2 e 3

§ajustado pelas variáveis contextuais e dos blocos 2, 3 e 4 
Figura 14 - Razão de Prevalência (RP) e intervalo de 95\% para as variáveis contextuais e individuais que apresentaram interações. Brasil, 2004.

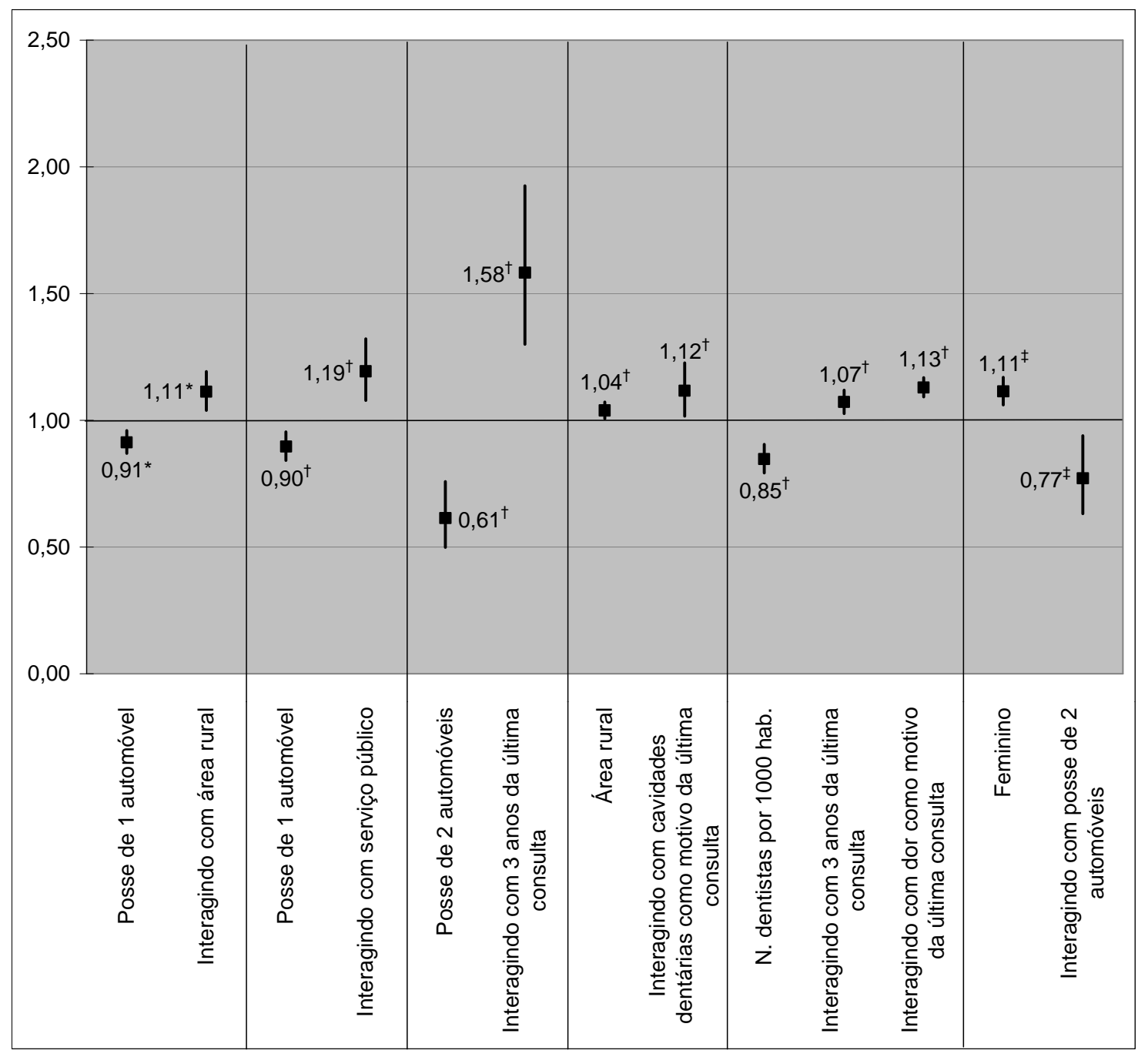

* RP para as variáveis contextuais e do bloco 2

† RP para as variáveis contextuais e dos blocos 2 e 3

‡ RP para as variáveis contextuais e dos blocos 2 , 3 e 4

O teste de interações (Figura 14) permite observar que possuir um automóvel é fator de proteção para o edentulismo funcional, porém, interagindo com morar na área rural e com o uso de serviço público, essa interação se tornou fator de risco. Da mesma forma, possuir dois ou mais 
automóveis foi fator de proteção, mas quando interagindo com a última consulta odontológica realizada há três anos ou mais virou fator de risco.

Morar na área rural teve o risco aumentado quando interagindo com cavidades dentárias como motivo da última consulta odontológica. $\bigcirc$ maior número de dentistas por habitantes é fator de proteção, entretanto, quando interage com a última consulta realizada há três anos ou mais e com dor como motivo da última consulta odontológica, passa a ser um fator de risco. Da mesma forma, ser do sexo feminino é fator de risco, mas quando interage com a posse de dois ou mais automóveis passa a ser fator de proteção.

\subsubsection{Análise espacial do edentulismo funcional em idosos}

As duas variáveis contextuais encontradas para o edentulismo funcional em idosos foram as mesmas que foram encontradas para a perda dentária em adultos. Os mapas da distribuição espacial dessas duas variáveis (dentistas por habitantes e taxa de exodontia) já foram ilustrados nas figuras 6 e 7. Entretanto, a variável "local geográfico", apesar de não pertencer ao bloco contextual, teve a sua distribuição espacial analisada. Observou-se que morar na área rural esteve associado ao edentulismo funcional. Dessa forma, a Figura 15 ilustra a distribuição espacial da taxa de urbanização em quintis segundo microrregião. 
Figura 15 - Taxa de urbanização segundo quintis, por microrregião, Brasil, 2003.

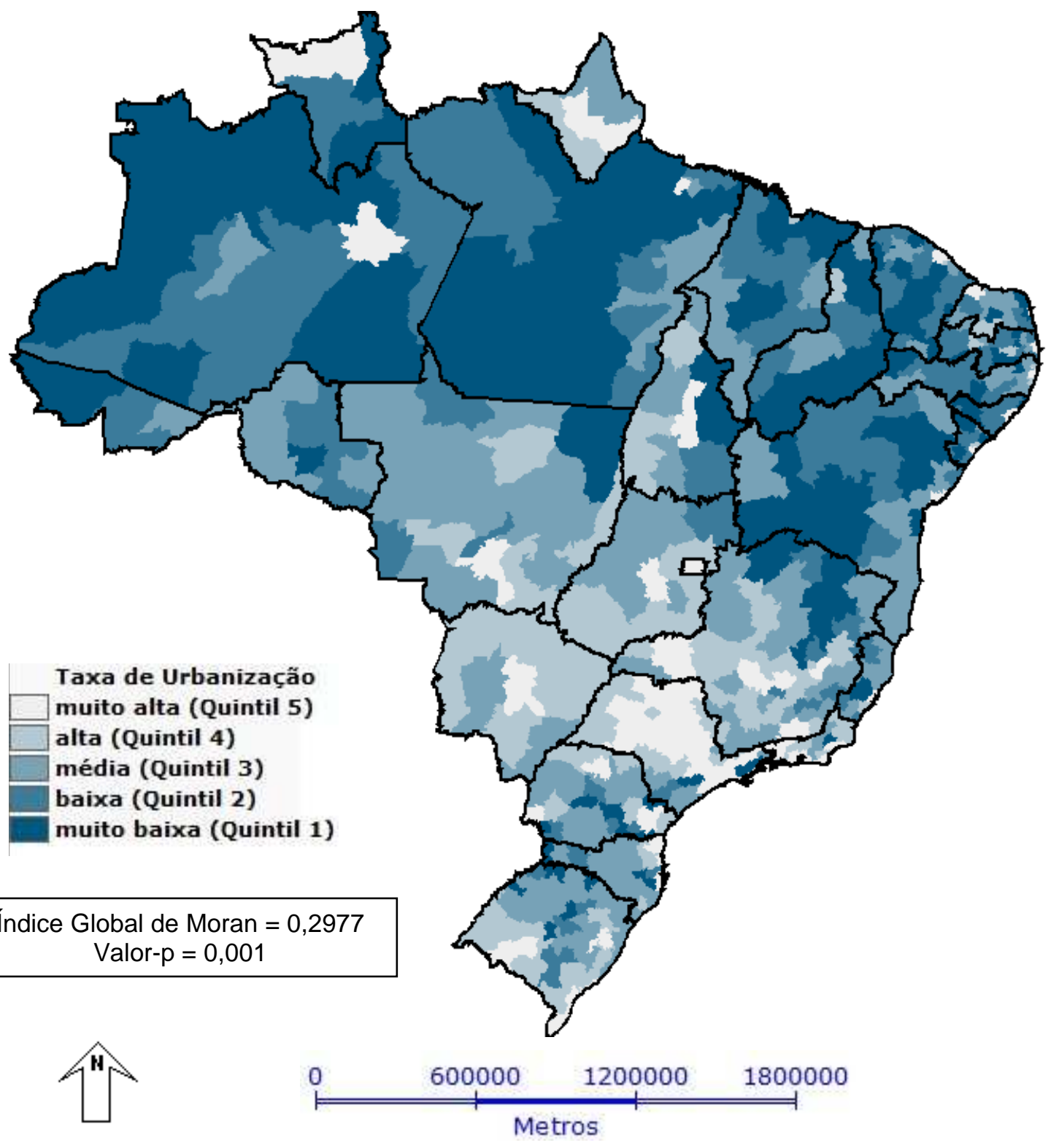

Observa-se que o maior risco para o edentulismo funcional segundo a variável "local geográfico (urbano/rural)" se encontra nos estados das regiões Norte e Nordeste pois são as áreas com menor taxa de 
urbanização e, conseqüentemente, com maior quantidade de pessoas vivendo em áreas rurais.

O mapa de risco para o edentulismo funcional em idosos segundo os resultados do AHP, mediante a interação das duas variáveis contextuais e da variável "local geográfico” está apresentado na Figura 16.

Figura 16 - Mapa de risco para perda o edentulismo funcional em idosos gerado pelo Processo Analítico Hierárquico (AHP). Brasil, 2003.

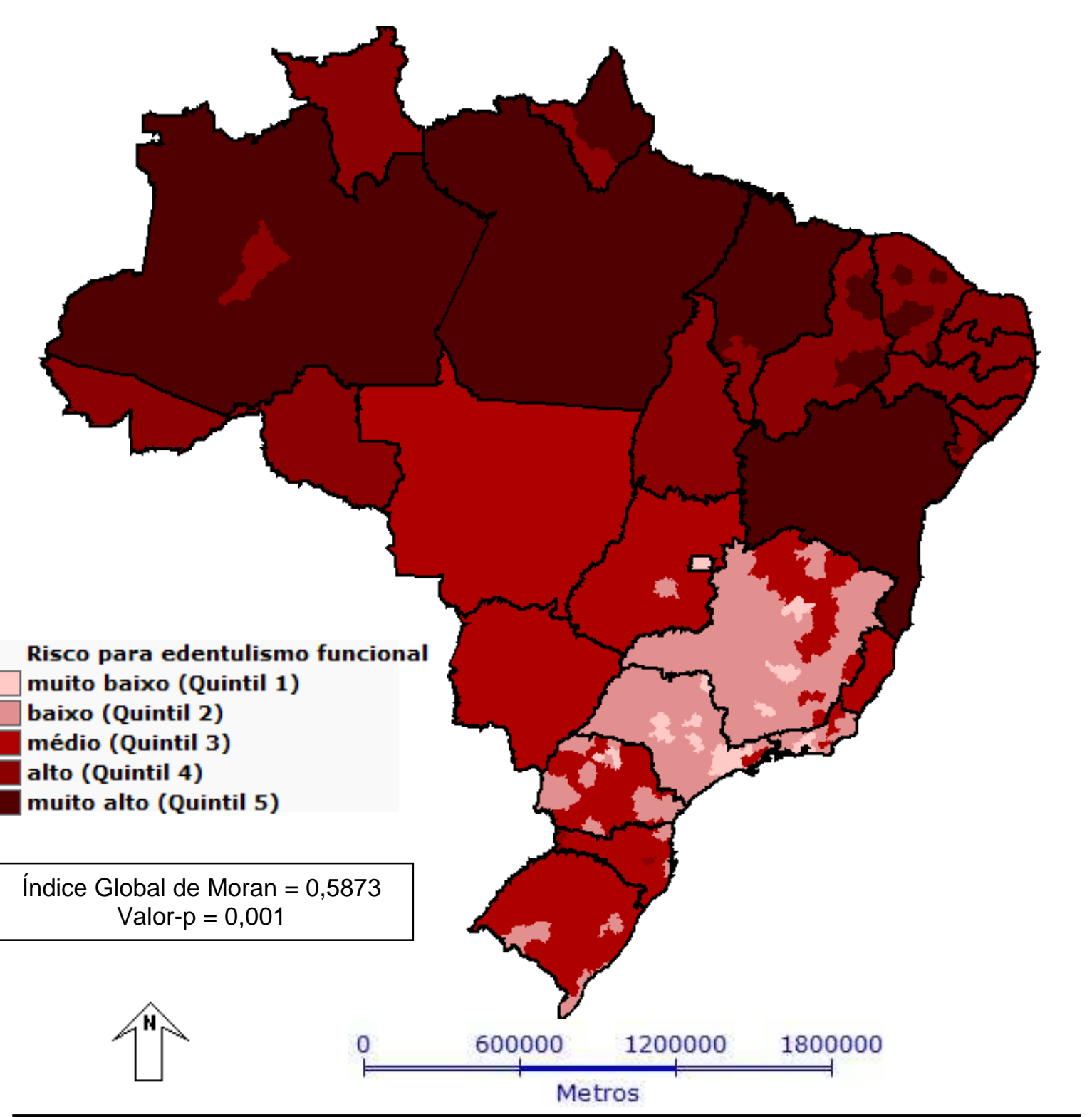


Observa-se uma maior área de risco para o edentulismo funcional nas regiões Norte e Nordeste e menor na região Sudeste. Existe uma delimitação do risco muito precisa segundo as macrorregiões e unidades da federação devido à forte influência da variável contextual "dentistas por habitantes" que possui uma representação por estados. A A Figura 17 ilustra o mapa de risco após o procedimento de suavização.

Figura 17 - Mapa de risco para edentulismo funcional após o procedimento de Krigeagem Ordinária, Brasil, 2003.

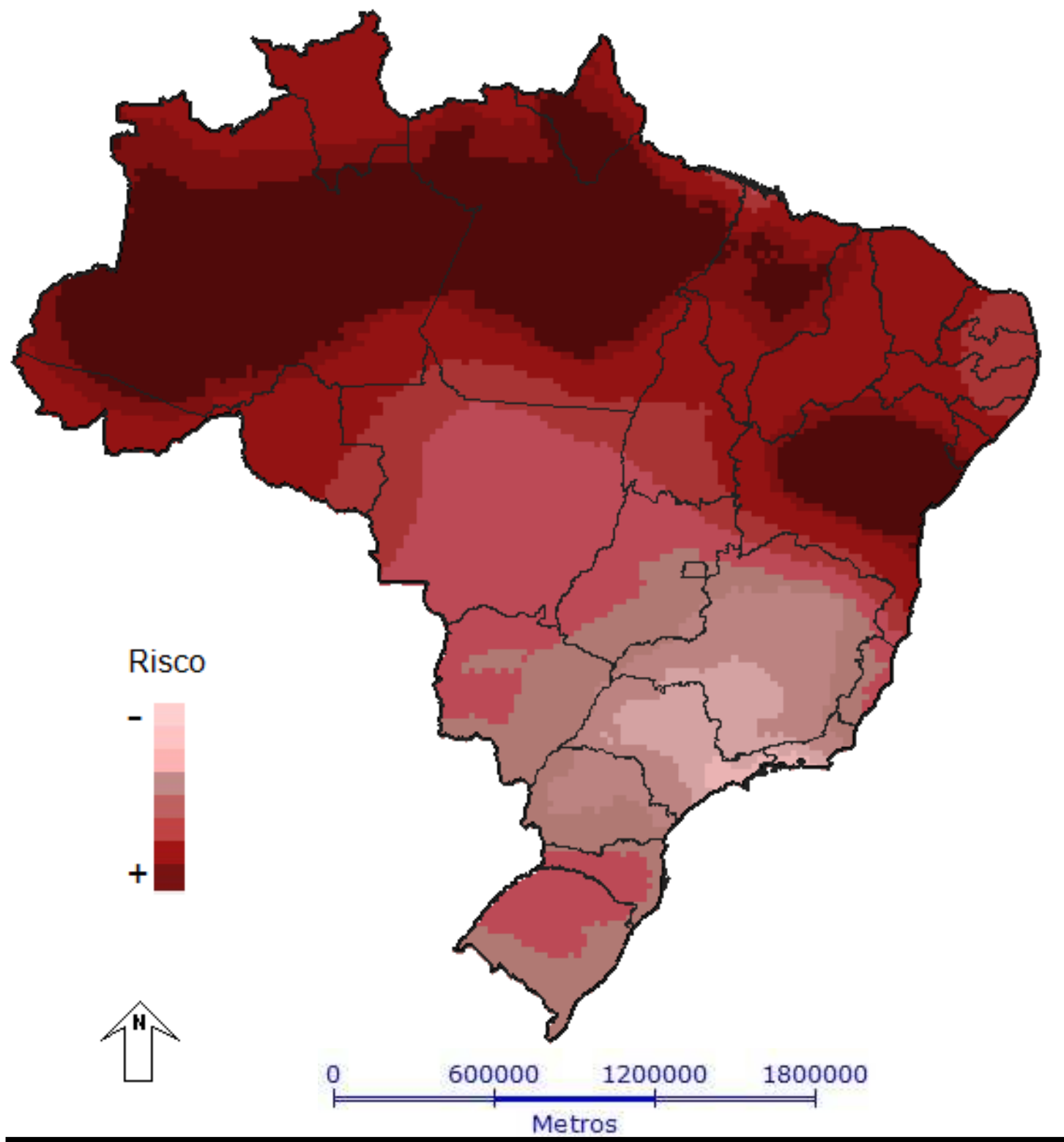


O mapa da Figura 18 ilustra a distribuição espacial do Diagrama de Moran (Box Map). Observa-se uma verdadeira divisão entre o Norte e o Sul do país com relação às áreas de alto risco próximas aos vizinhos de alto risco e áreas de baixo risco próximas umas as outras.

Figura 18 - Box Map: Mapa de espalhamento de Moran para o risco de edentulismo funcional gerado pelo Processo Analítico Hierárquico (AHP). Brasil, 2003.

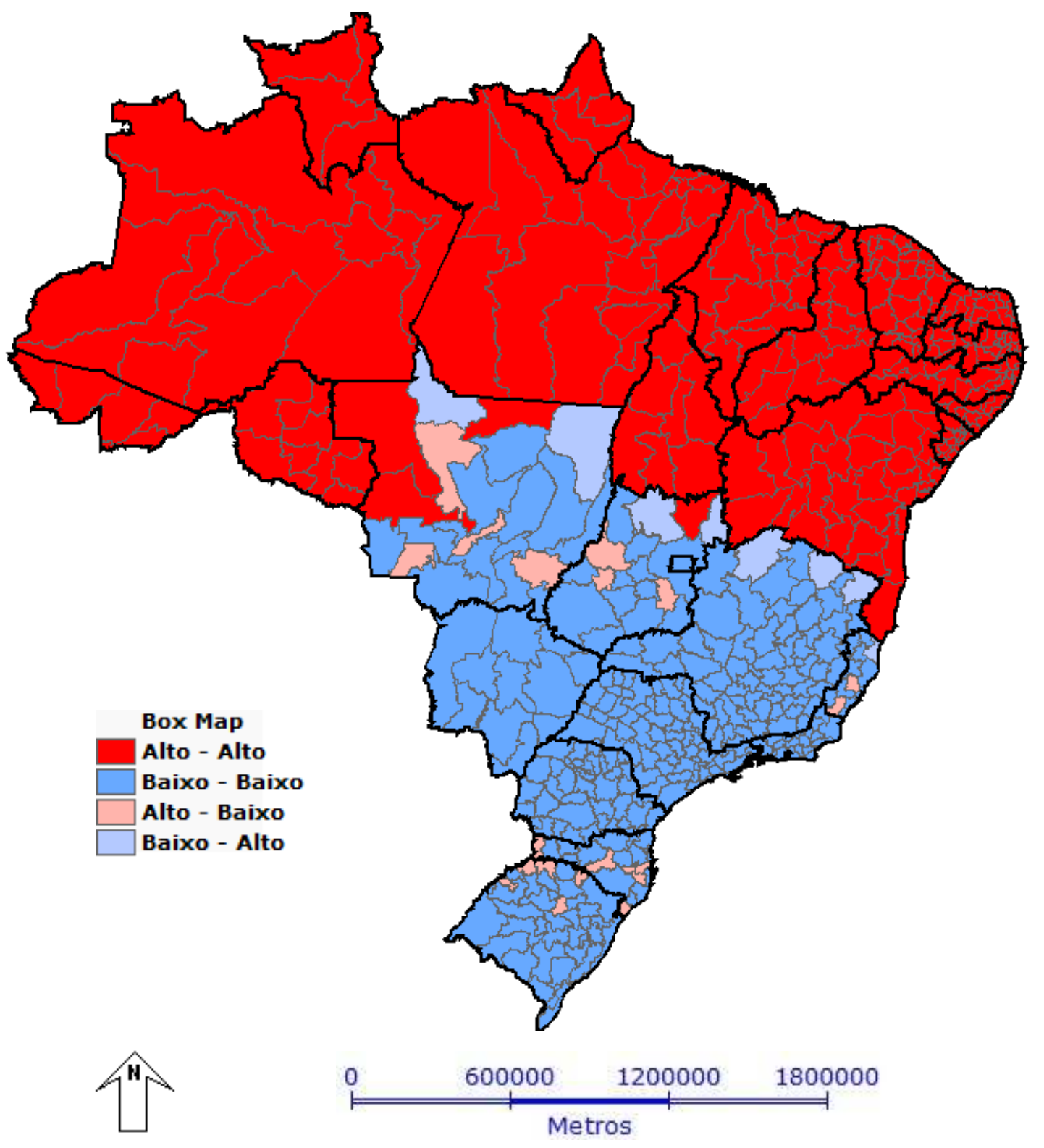


A Figura 19 mostra o LISA Map identificando as áreas de dependência espacial com significância estatística. Observa-se que boa parte das regiões Norte e Nordeste e a região Sudeste apresentaram significância estatística.

Figura 19 - LISA Map para o risco de edentulismo funcional gerado pelo Processo Analítico Hierárquico (AHP). Brasil, 2003.

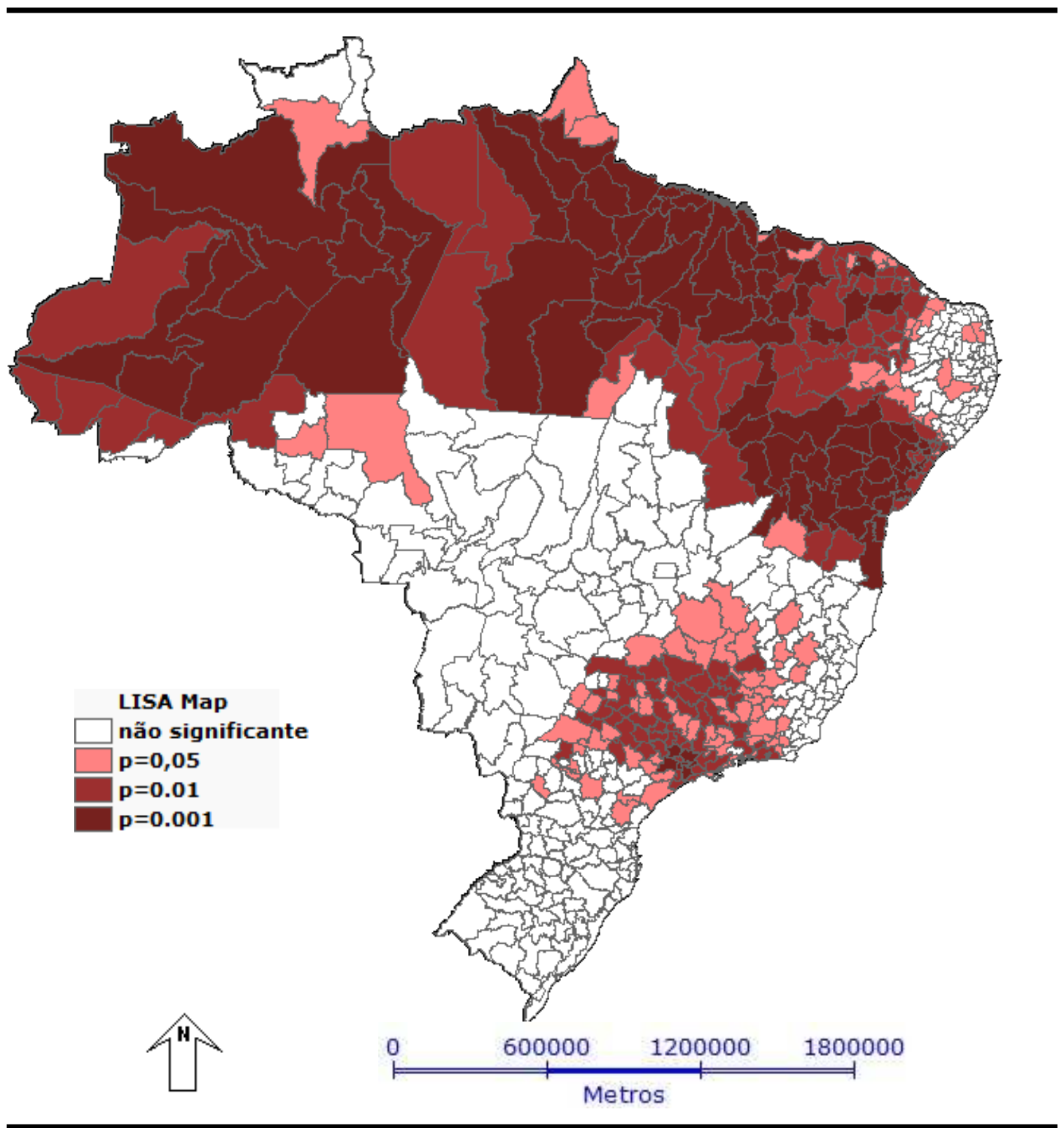


O Moran Map é apresentado na Figura 20 e discrimina as áreas já ilustradas no LISA Map segundo o diagrama de espalhamento de Moran. Constata-se que a dicotomia Norte/Nordeste - Sudeste se repete, porém, com áreas mais recortadas.

Figura 20 - Moran Map: Mapa de espalhamento de Moran para o risco de edentulismo funcional gerado pelo Processo Analítico Hierárquico (AHP). Brasil, 2003.

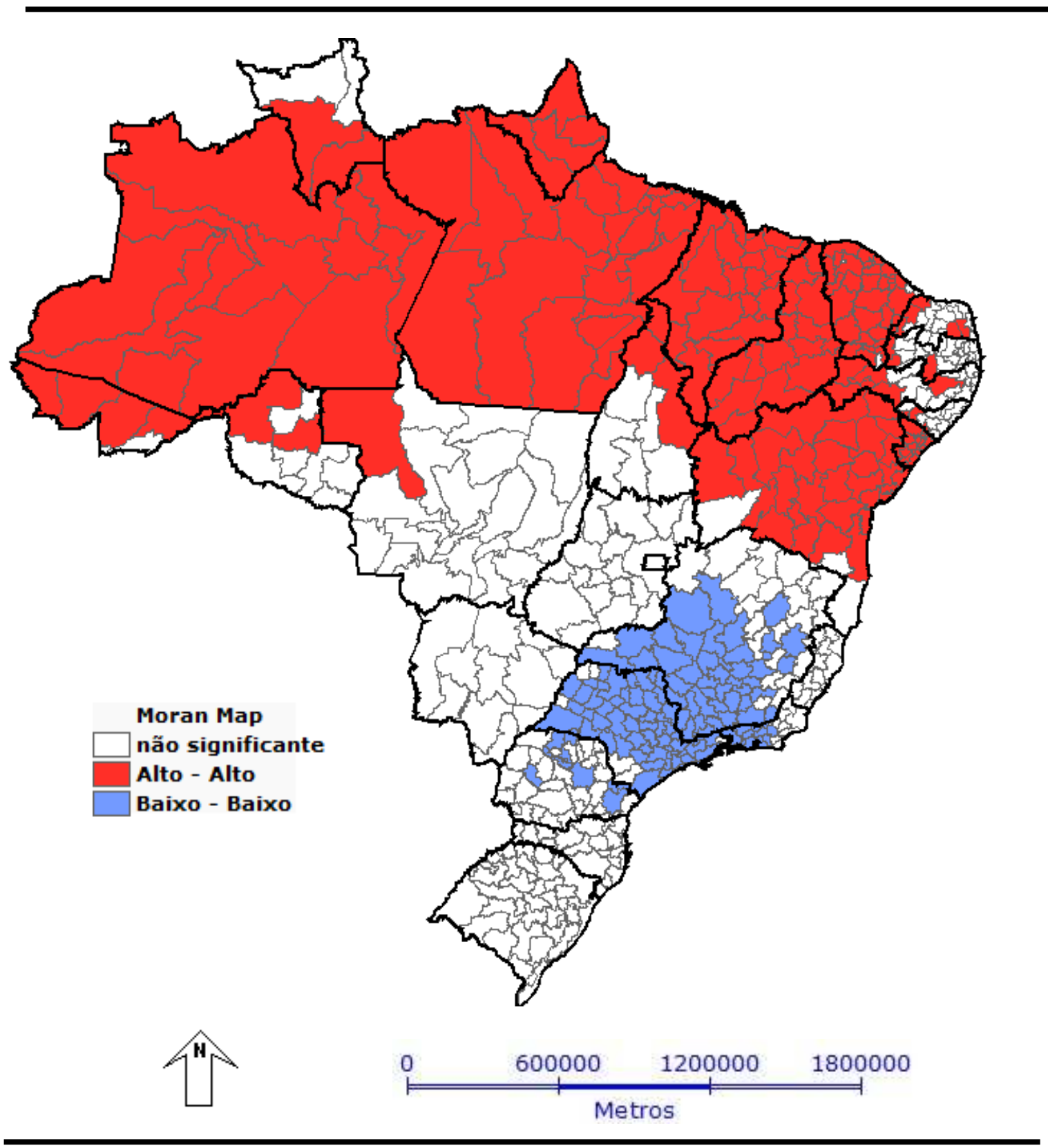




\subsection{Necessidade de prótese total em idosos}

A segunda análise foi feita com a intenção de avaliar os fatores associados à necessidade de prótese total em idosos edêntulos. Foram analisados 2931 idosos. A Tabela 7 apresenta a descrição deste desfecho segundo as variáveis independentes e os resultados da análise univariada. Com relação às variáveis contextuais, no nível regional, foi testada a associação do indicador Primeira Consulta Programática (é o percentual de pessoas que receberam uma primeira consulta odontológica programática, realizada com finalidade de diagnóstico e, necessariamente, elaboração de um plano preventivo-terapêutico, para atender as necessidades detectadas. Não se refere a atendimentos eventuais como os de urgência/emergência que não tem seguimento previsto), no nível estadual utilizou-se a variável Média de Anos de Estudo, e no nível municipal o porte populacional. Apenas as duas últimas variáveis foram significativas, ou seja, a maior média de anos de estudo nos estados e o maior porte municipal são fatores de proteção para a necessidade de prótese total em pelo menos um arco dentário em idosos.

Todas as variáveis do bloco 2, 3 e 4 foram significativas.

Analisando os resultados do modelo múltiplo (Tabela 8), segundo o modelo teórico apresentado na Figura $4(C)$, observa-se que as três variáveis contextuais apresentaram significância, adicionando o efeito da primeira consulta programática no papel protetor contra a necessidade de prótese total. 
No bloco 2 observou-se que residir em área rural e possuir maior número de pessoas por cômodo foram aspectos associados a maior necessidade de prótese total, enquanto possuir maior escolaridade e um automóvel foram fatores de proteção.

No bloco 3, constata-se que, diferentemente das outras análises, o fato de nunca ter ido ao dentista apresentou uma elevada Razão de Prevalência em relação a quem já foi ao dentista, aumentando 2,3 vezes o risco de necessidade de prótese total. Outras variáveis associadas a este desfecho foram ter realizado a última consulta odontológica em serviço público e por qualquer outro motivo que não fosse rotina. Ter realizado a última consulta odontológica entre um e dois anos foi fator de proteção.

Indo de encontro às outras análises, o sexo masculino apresentou maior risco para este desfecho, assim como pertencer ao grupo étnico não branco e possuir idade acima da mediana.

O teste de interações apresentado na Figura 21 mostra que apesar do fato de morar em municípios pequenos seja um fator de risco, quando interage com a escolaridade de 1 a 4 anos este fator passa a ser proteção. Apesar do fato de morar em área urbana seja, isoladamente, um fator protetor, na interação com o uso de serviço público esta relação passa a ser de risco. O sexo feminino foi fator protetor e teve seu efeito aumentado na interação com a posse de dois ou mais automóveis e com nove anos de estudo. Entretanto, ser do sexo feminino e interagir com idade acima da mediana representou um fator de risco. 
Tabela 7 - Razão de prevalência da necessidade de prótese total em pelo menos um arco em idosos segundo estimativas do modelo univariado de regressão de Poisson. Brasil, 2004.

\begin{tabular}{|c|c|c|c|c|c|c|}
\hline \multicolumn{2}{|c|}{$\begin{array}{l}\text { Variáveis do nível contextual } \\
\text { Bloco } 1\end{array}$} & $\mathbf{N}(\%)$ & $\begin{array}{l}\text { Prevalência } \\
\text { Nec. PT* }\end{array}$ & $\mathbf{R P}$ & IC 95\% & Valor-p \\
\hline Nível Regional & $\begin{array}{l}\text { Primeira consulta } \\
\text { programática }\end{array}$ & - & - & 0,856 & 0,$710 ; 1,034$ & 0,1061 \\
\hline $\begin{array}{l}\text { Nível Estadual } \\
\text { Nível municipal } \\
\text { Porte municipal }\end{array}$ & $\begin{array}{l}\text { Média de anos de estudo } \\
\text { Até } 100 \text { mil habitantes } \\
\text { Mais de } 100 \text { mil } \\
\text { habitantes }\end{array}$ & $\begin{array}{c}- \\
2370(81 \%) \\
554(19 \%)\end{array}$ & $\begin{array}{c}- \\
37,2 \% \\
29,2 \%\end{array}$ & $\begin{array}{l}0,768 \\
1,000 \\
0,820\end{array}$ & 0,$703 ; 0,839$ & $<0,0001$ \\
\hline \multicolumn{2}{|c|}{$\begin{array}{l}\text { Variáveis do nível individual } \\
\text { Bloco } 2\end{array}$} & $\mathbf{N}(\%)$ & $\begin{array}{l}\text { Prevalência } \\
\text { Nec. PT* }\end{array}$ & $\mathbf{R P}$ & IC 95\% & Valor-p \\
\hline \multirow[t]{2}{*}{ Local geográfico } & Urbano & $2533(87 \%)$ & $34,2 \%$ & 1,000 & & \\
\hline & Rural & 389 (13\%) & $45,5 \%$ & 1,224 & 1,$116 ; 1,342$ & $<0,0001$ \\
\hline \multirow[t]{4}{*}{ Escolaridade } & Sem estudo & $1114(39 \%)$ & $45,0 \%$ & 1,000 & & \\
\hline & Até quatro anos & $1334(46 \%)$ & $31,6 \%$ & 0,752 & 0,$715 ; 0,791$ & $<0,0001$ \\
\hline & Até oito anos & $322(11 \%)$ & $25,8 \%$ & 0,627 & 0,$482 ; 0,815$ & 0,0004 \\
\hline & Nove anos ou mais & $110(4 \%)$ & $14,5 \%$ & 0,344 & 0,$214 ; 0,552$ & $<0,0001$ \\
\hline \multirow[t]{2}{*}{ Moradia } & Casa própria & $2524(87 \%)$ & $35,2 \%$ & 1,000 & & \\
\hline & Casa não própria & 391 (13\%) & $38,6 \%$ & 1,133 & 1,$075 ; 1,195$ & $<0,0001$ \\
\hline \multirow{3}{*}{$\begin{array}{l}\text { Posse de } \\
\text { automóvel }\end{array}$} & Sem automóvel & $2492(85 \%)$ & $37,7 \%$ & 1,000 & & \\
\hline & Um automóvel & $381(13 \%)$ & $23,9 \%$ & 0,697 & 0,$633 ; 0,767$ & $<0,0001$ \\
\hline & Dois ou mais automóveis & $40(2 \%)$ & $22,5 \%$ & 0,606 & 0,$327 ; 1,123$ & 0,1122 \\
\hline \multirow{2}{*}{$\begin{array}{l}\text { Pessoas por } \\
\text { cômodo }\end{array}$} & Até a mediana & $1510(52 \%)$ & $30,5 \%$ & 1,000 & & \\
\hline & Acima da mediana & $1382(48 \%)$ & $41,1 \%$ & 1,301 & 1,217;1,390 & $<0,0001$ \\
\hline \multicolumn{2}{|c|}{$\begin{array}{l}\text { Variáveis do nível individual } \\
\text { Bloco } 3\end{array}$} & $\mathbf{N}(\%)$ & $\begin{array}{l}\text { Prevalência } \\
\text { Nec. } \text { PT }^{\star}\end{array}$ & $\mathbf{R P}$ & IC 95\% & Valor-p \\
\hline \multirow[t]{2}{*}{ Visita ao dentista } & Já foi ao dentista & $2802(96 \%)$ & $34,7 \%$ & 1,000 & & \\
\hline & Nunca foi ao dentista & $116(4 \%)$ & $59,5 \%$ & 1,527 & 1,$214 ; 1,920$ & 0,0003 \\
\hline \multirow{3}{*}{$\begin{array}{l}\text { Tempo da última } \\
\text { consulta }\end{array}$} & Menos de um ano & $286(10 \%)$ & $29,0 \%$ & 1,000 & & \\
\hline & De um a dois anos & 247 (8\%) & $20,6 \%$ & 0,678 & 0,$476 ; 0,967$ & 0,0321 \\
\hline & Há três anos ou mais & $2258(78 \%)$ & $36,8 \%$ & 1,147 & 0,$921 ; 1,428$ & 0,2197 \\
\hline \multirow{3}{*}{$\begin{array}{l}\text { Local da última } \\
\text { consulta }\end{array}$} & Serviço privado & $1450(50 \%)$ & $27,9 \%$ & 1,000 & & \\
\hline & Serviço público & $1166(40 \%)$ & $42,8 \%$ & 1,502 & 1,$312 ; 1,720$ & $<0,0001$ \\
\hline & Outros serviços & $178(6 \%)$ & $35,4 \%$ & 1,176 & 0,993;1,392 & 0,0607 \\
\hline \multirow{4}{*}{$\begin{array}{l}\text { Motivo da última } \\
\text { consulta }\end{array}$} & Rotina & $467(16 \%)$ & $19,3 \%$ & 1,000 & & \\
\hline & Dor & 1388 (48\%) & $42,6 \%$ & 2,010 & 1,$652 ; 2,445$ & $<0,0001$ \\
\hline & Cavidades nos dentes & $304(10 \%)$ & $33,6 \%$ & 1,576 & 1,$110 ; 2,239$ & 0,0110 \\
\hline & $\begin{array}{l}\text { Sangramento gengival, } \\
\text { rosto inchado ou feridas } \\
\text { na boca }\end{array}$ & $643(22 \%)$ & $29,2 \%$ & 1,448 & 1,$245 ; 1,684$ & $<0,0001$ \\
\hline
\end{tabular}


Tabela 7 - Razão de prevalência da necessidade de prótese total em pelo menos um arco em idosos segundo estimativas do modelo univariado de regressão de Poisson. Brasil, 2004.

continuação

\begin{tabular}{|c|c|c|c|c|c|c|}
\hline \multicolumn{2}{|c|}{$\begin{array}{l}\text { Variáveis do nível individual } \\
\text { Bloco } 3\end{array}$} & $\mathbf{N}(\%)$ & $\begin{array}{l}\text { Prevalência } \\
\text { Nec. } \text { PT }^{\star}\end{array}$ & RP & IC 95\% & Valor-p \\
\hline \multirow{2}{*}{$\begin{array}{l}\text { Informações } \\
\text { prevenção }\end{array}$} & Recebeu informações & $1068(37 \%)$ & $30,3 \%$ & 1,000 & & \\
\hline & Não recebeu informações & $1847(63 \%)$ & $38,7 \%$ & 1,170 & 1,$026 ; 1,334$ & 0,0185 \\
\hline \multicolumn{2}{|c|}{$\begin{array}{l}\text { Variáveis do nível individual } \\
\text { Bloco } 4\end{array}$} & $\mathbf{N}(\%)$ & $\begin{array}{l}\text { Prevalência } \\
\text { Nec. } \text { PT }^{\star}\end{array}$ & $\mathbf{R P}$ & IC 95\% & Valor-p \\
\hline \multirow[t]{2}{*}{ Sexo } & Feminino & $2060(70 \%)$ & $34,1 \%$ & 1,000 & & \\
\hline & Masculino & $864(30 \%)$ & $39,5 \%$ & 1,171 & 1,$091 ; 1,257$ & $<0,0001$ \\
\hline \multirow[t]{2}{*}{ Grupo étnico } & Branco & $1442(50 \%)$ & $28,8 \%$ & 1,000 & & \\
\hline & Não branco & $1472(50 \%)$ & $42,4 \%$ & 1,292 & 1,$230 ; 1,357$ & $<0,0001$ \\
\hline \multirow[t]{2}{*}{ Idade } & Até a mediana ( $\leq 69)$ & $1646(56 \%)$ & $32,6 \%$ & 1,000 & & \\
\hline & Acima da mediana $(>69)$ & $1278(44 \%)$ & $39,6 \%$ & 1,212 & 1,$071 ; 1,371$ & 0,0023 \\
\hline
\end{tabular}

* Prevalência de necessidade de prótese total em pelo menos um arco dentário EP: erro-padrão

RP: razão de prevalência

IC 95\%: intervalo de confiança de $95 \%$ 
Tabela 8 - Razão de prevalência da necessidade de prótese total em pelo menos um arco em idosos segundo estimativas do modelo hierárquico múltiplo de regressão de Poisson multinível. Brasil, 2004.

\begin{tabular}{|c|c|c|c|c|c|c|}
\hline \multicolumn{2}{|c|}{$\begin{array}{l}\text { Variáveis do nível contextual } \\
\text { Bloco } 1\end{array}$} & $\begin{array}{l}\text { Coeficiente } \\
\text { regressão }\end{array}$ & EP & $\mathbf{R P}^{*}$ & IC 95\% & Valor-p \\
\hline \multicolumn{7}{|l|}{ Nível Regional } \\
\hline & $\begin{array}{l}\text { Primeira consulta } \\
\text { programática }\end{array}$ & $-0,138$ & 0,063 & 0,871 & 0,$770 ; 0,986$ & 0,0268 \\
\hline \multicolumn{7}{|l|}{ Nível Estadual } \\
\hline & Média de anos de estudo & $-0,242$ & 0,035 & 0,785 & 0,$733 ; 0,841$ & $<0,0001$ \\
\hline \multicolumn{7}{|l|}{ Nível municipal } \\
\hline & Até 100 mil habitantes & & & 1,000 & & \\
\hline \multicolumn{7}{|l|}{ Porte municipal } \\
\hline & Mais de 100 mil habitantes & $-0,184$ & 0,084 & 0,832 & 0,$706 ; 0,981$ & 0,0285 \\
\hline \multicolumn{2}{|c|}{$\begin{array}{l}\text { Variáveis do nível individual } \\
\text { Bloco } 2\end{array}$} & $\begin{array}{l}\text { Coeficiente } \\
\text { regressão }\end{array}$ & EP & RPt & IC 95\% & Valor-p \\
\hline \multirow[t]{2}{*}{ Local geográfico } & Urbano & & & 1,000 & & \\
\hline & Rural & 0,150 & 0,029 & 1,162 & 1,$098 ; 1,230$ & $<0,0001$ \\
\hline \multirow[t]{4}{*}{ Escolaridade } & Sem estudo & & & 1,000 & & \\
\hline & Até quatro anos & $-0,239$ & 0,033 & 0,787 & 0,$738 ; 0,840$ & $<0,0001$ \\
\hline & Até oito anos & $-0,400$ & 0,138 & 0,670 & 0,$511 ; 0,879$ & 0,0036 \\
\hline & Nove anos ou mais & $-0,901$ & 0,260 & 0,406 & 0,$244 ; 0,676$ & 0,0005 \\
\hline \multirow{3}{*}{$\begin{array}{l}\text { Posse de } \\
\text { automóvel }\end{array}$} & Sem automóvel & & & 1,000 & & \\
\hline & Um automóvel & $-0,229$ & 0,086 & 0,795 & 0,$672 ; 0,941$ & 0,0081 \\
\hline & Dois ou mais automóveis & $-0,369$ & 0,318 & 0,691 & 0,$371 ; 1,290$ & 0,2461 \\
\hline \multirow{2}{*}{$\begin{array}{l}\text { Pessoas por } \\
\text { cômodo }\end{array}$} & Até a mediana & & & 1,000 & & \\
\hline & Acima da mediana & 0,252 & 0,031 & 1,287 & 1,$211 ; 1,367$ & $<0,0001$ \\
\hline \multicolumn{2}{|c|}{$\begin{array}{c}\text { Variáveis do nível individual } \\
\text { Bloco } 3\end{array}$} & $\begin{array}{l}\text { Coeficiente } \\
\text { regressão }\end{array}$ & EP & RP¥ & IC 95\% & Valor-p \\
\hline \multirow[t]{2}{*}{ Visita ao dentista } & Já foi ao dentista & & & 1,000 & & \\
\hline & Nunca foi ao dentista & 0,841 & 0,176 & 2,319 & 1,$642 ; 3,274$ & $<0,0001$ \\
\hline \multirow{3}{*}{$\begin{array}{l}\text { Tempo da última } \\
\text { consulta }\end{array}$} & Menos de um ano & & & 1,000 & & \\
\hline & De um a dois anos & $-0,367$ & 0,154 & 0,693 & 0,$512 ; 0,937$ & 0,0168 \\
\hline & Há três anos ou mais & 0,024 & 0,071 & 1,024 & 0,$891 ; 1,177$ & 0,7290 \\
\hline \multirow{3}{*}{$\begin{array}{l}\text { Local da última } \\
\text { consulta }\end{array}$} & Serviço privado & & & 1,000 & & \\
\hline & Serviço público & 0,277 & 0,067 & 1,319 & 1,$157 ; 1,504$ & $<0,0001$ \\
\hline & Outros serviços & 0,038 & 0,073 & 1,039 & 0,$900 ; 1,199$ & 0,6060 \\
\hline \multirow{4}{*}{$\begin{array}{l}\text { Motivo da última } \\
\text { consulta }\end{array}$} & Rotina & & & 1,000 & & \\
\hline & Dor & 0,475 & 0,102 & 1,608 & 1,$317 ; 1,964$ & $<0,0001$ \\
\hline & Cavidades nos dentes & 0,279 & 0,170 & 1,322 & 0,$947 ; 1,844$ & 0,1001 \\
\hline & $\begin{array}{l}\text { Sangramento gengival, } \\
\text { rosto inchado ou feridas na } \\
\text { boca }\end{array}$ & 0,259 & 0,065 & 1,296 & 1,$141 ; 1,472$ & $<0,0001$ \\
\hline
\end{tabular}


Tabela 8 - Razão de prevalência da necessidade de prótese total em pelo menos um arco em idosos segundo estimativas do modelo hierárquico múltiplo de regressão de Poisson multinível. Brasil, 2004.

continuação

\begin{tabular}{|c|c|c|c|c|c|c|}
\hline Variéc & $\begin{array}{l}\text { do nível individual } \\
\text { Bloco } 4\end{array}$ & $\begin{array}{l}\text { Coeficiente } \\
\text { regressão }\end{array}$ & EP & RP§ & IC 95\% & Valor-p \\
\hline \multirow[t]{2}{*}{ Sexo } & Feminino & & & 1,000 & & \\
\hline & Masculino & 0,115 & 0,023 & 1,122 & 1,$072 ; 1,174$ & $<0,0001$ \\
\hline \multirow[t]{2}{*}{ Grupo étnico } & Branco & & & 1,000 & & \\
\hline & Não branco & 0,146 & 0,021 & 1,157 & 1,$111 ; 1,206$ & $<0,0001$ \\
\hline \multirow[t]{2}{*}{ Idade } & Até a mediana $(\leq 69)$ & & & 1,000 & & \\
\hline & Acima da mediana $(>69)$ & 0,154 & 0,046 & 1,166 & 1,$066 ; 1,277$ & 0,0007 \\
\hline
\end{tabular}

EP: erro-padrão

RP: razão de prevalência

IC 95\%: intervalo de confiança de $95 \%$

**ajustado pelas variáveis contextuais

fajustado pelas variáveis contextuais e do bloco 2 .

łajustado pelas variáveis contextuais e dos blocos 2 e 3

§ajustado pelas variáveis contextuais e dos blocos 2, 3 e 4

Figura 21 - Razão de Prevalência (RP) e intervalo de 95\% para as variáveis contextuais e individuais que apresentaram interações, para a necessidade prótese total em idosos. Brasil, 2004.

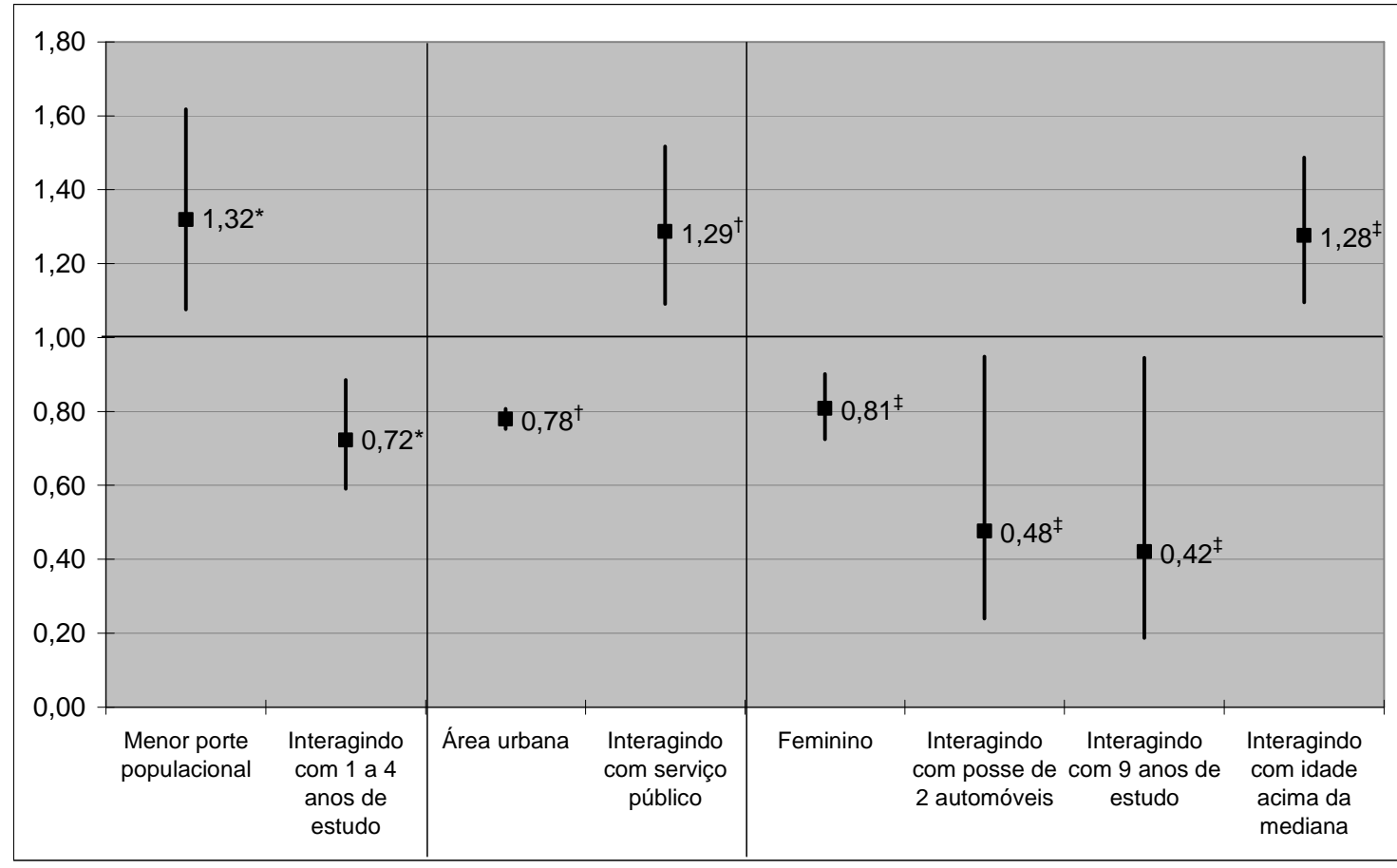

* RP para as variáveis contextuais e do bloco 2

† RP para as variáveis contextuais e dos blocos 2 e 3

‡ RP para as variáveis contextuais e dos blocos 2,3 e 4 


\subsubsection{Análise espacial da necessidade de prótese total em idosos}

As três variáveis contextuais que apresentaram associação com a necessidade de prótese total em pelo menos um arco (Tabela 8) foram submetidas à análise espacial do risco por meio do Processo Analítico Hierárquico (AHP). A variável porte populacional já foi mapeada e está ilustrada na Figura 8. As demais variáveis (primeira consulta odontológica programática e média de anos de estudo) se encontram nas figuras 22 e 23 , respectivamente.

Figura 22 - Taxa de primeira consulta odontológica programática segundo quintis, por microrregião, Brasil, 2003.

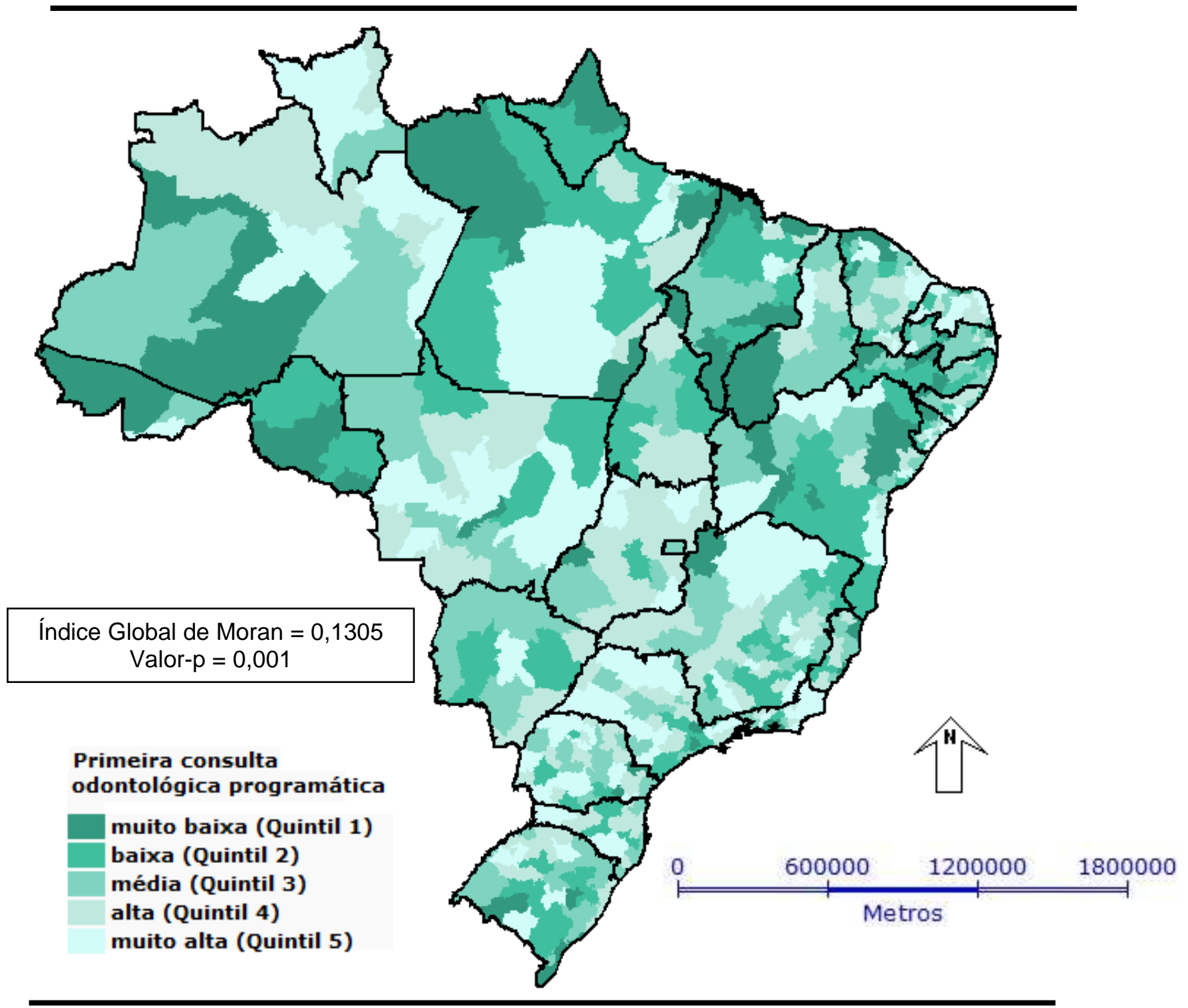


Figura 23 - Média de anos de estudo da população de 25 anos ou mais de idade segundo quintis, por microrregião, Brasil, 2000.

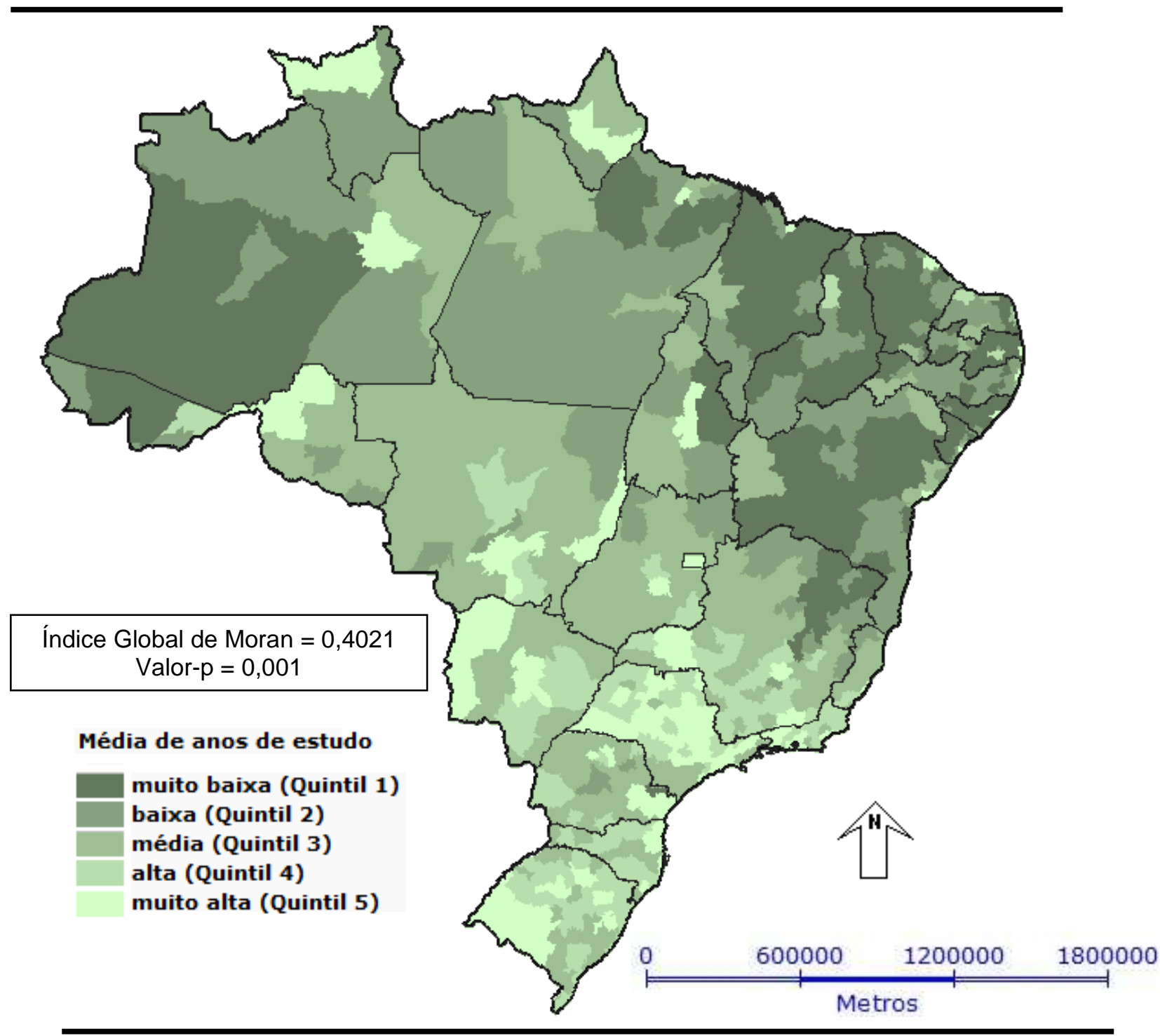

Observou-se que a distribuição espacial tanto da taxa de primeira consulta odontológica quanto da média de anos de estudo apresentaram dependência espacial significante. A dependência foi mais forte na média de anos de estudo, em que grande parte da Região Nordeste e a porção oeste da Região Norte apresentaram os menores valores nesta variável. A melhor 
situação foi observada em maior quantidade de áreas nos estados de São Paulo e Rio Grande do Sul.

Já com relação à taxa da primeira consulta odontológica programática, constatou-se que, apesar de ter apresentado dependência espacial significante, seus valores se encontram espacialmente distribuídos de forma mais difusa, permitindo visualizar alguns pontos com piores taxas em basicamente todas as cinco macrorregiões.

O mapa de risco para a necessidade de prótese total em pelo menos um arco, em idosos, segundo a técnica AHP, pode ser observado na Figura 24. O mesmo mapa gerado após o procedimento de suavização por krigeagem se encontra na Figura 25.

Pode-se observar uma maior área de risco em basicamente todos os estados da Região Nordeste e também no extremo oeste da Região Norte. Parte do norte de Goiás, Mato Grosso e de Minas Gerais também apresentaram maior risco para o desfecho em análise. Os estados com menores áreas de risco foram São Paulo, Santa Catarina, Mato Grosso do Sul e Rio Grande do Sul.

As figuras que aparecem na seqüência (figuras 26 a 28) ilustram o Box map, Lisa map e Moran map, respectivamente. Podemos observar na Figura 28 uma dependência espacial significativa de áreas com maior risco na Região Nordeste e oeste da Região Norte, conforme já mostrado na Figura 25 (Krigeagem). 
Figura 24 - Mapa de risco para necessidade de prótese total em idosos gerado pelo Processo Analítico Hierárquico (AHP). Brasil, 2003.

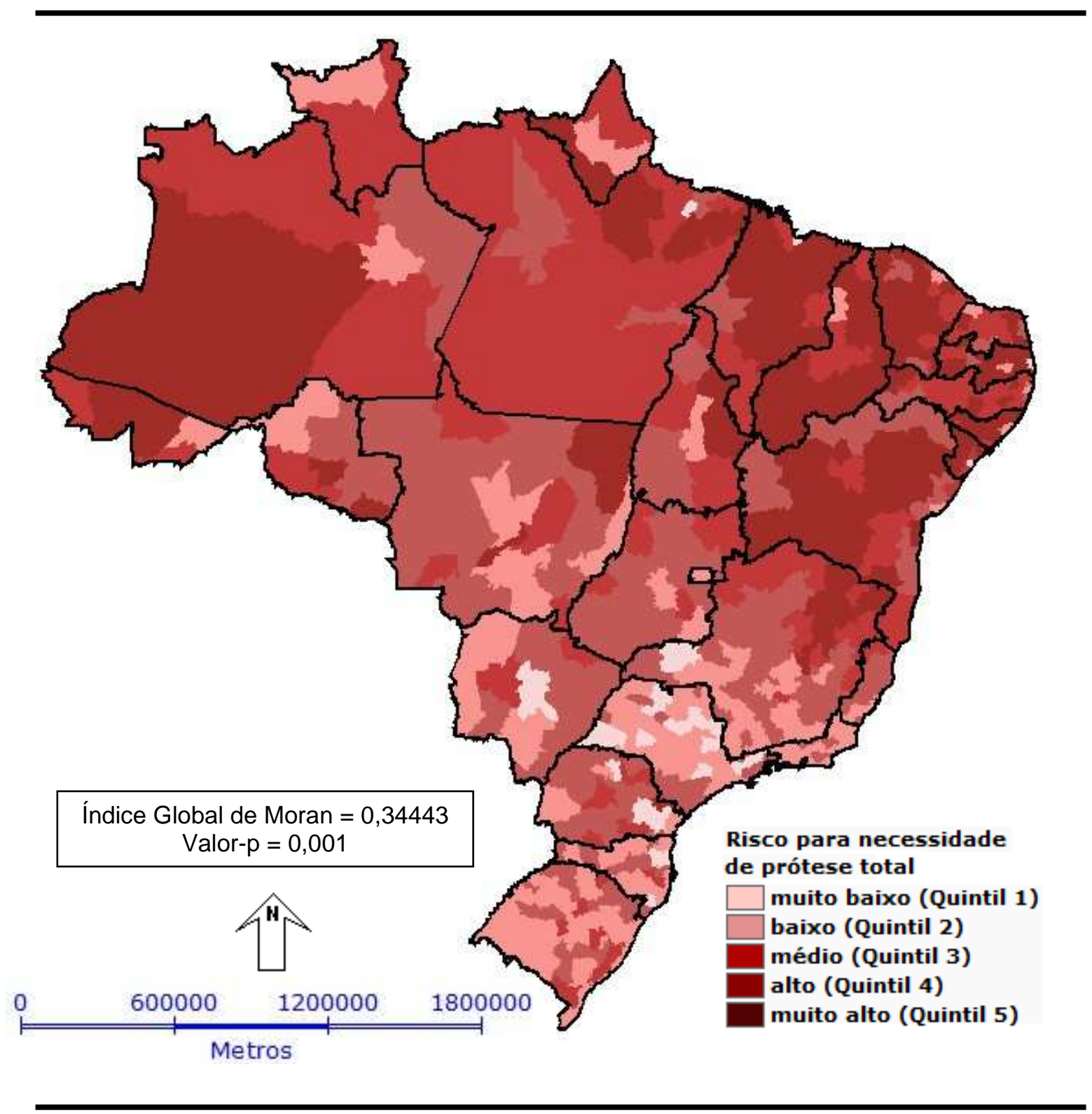


Figura 25 - Mapa de risco para necessidade de prótese total em idosos gerado pelo Processo Analítico Hierárquico (AHP). Brasil, 2003.

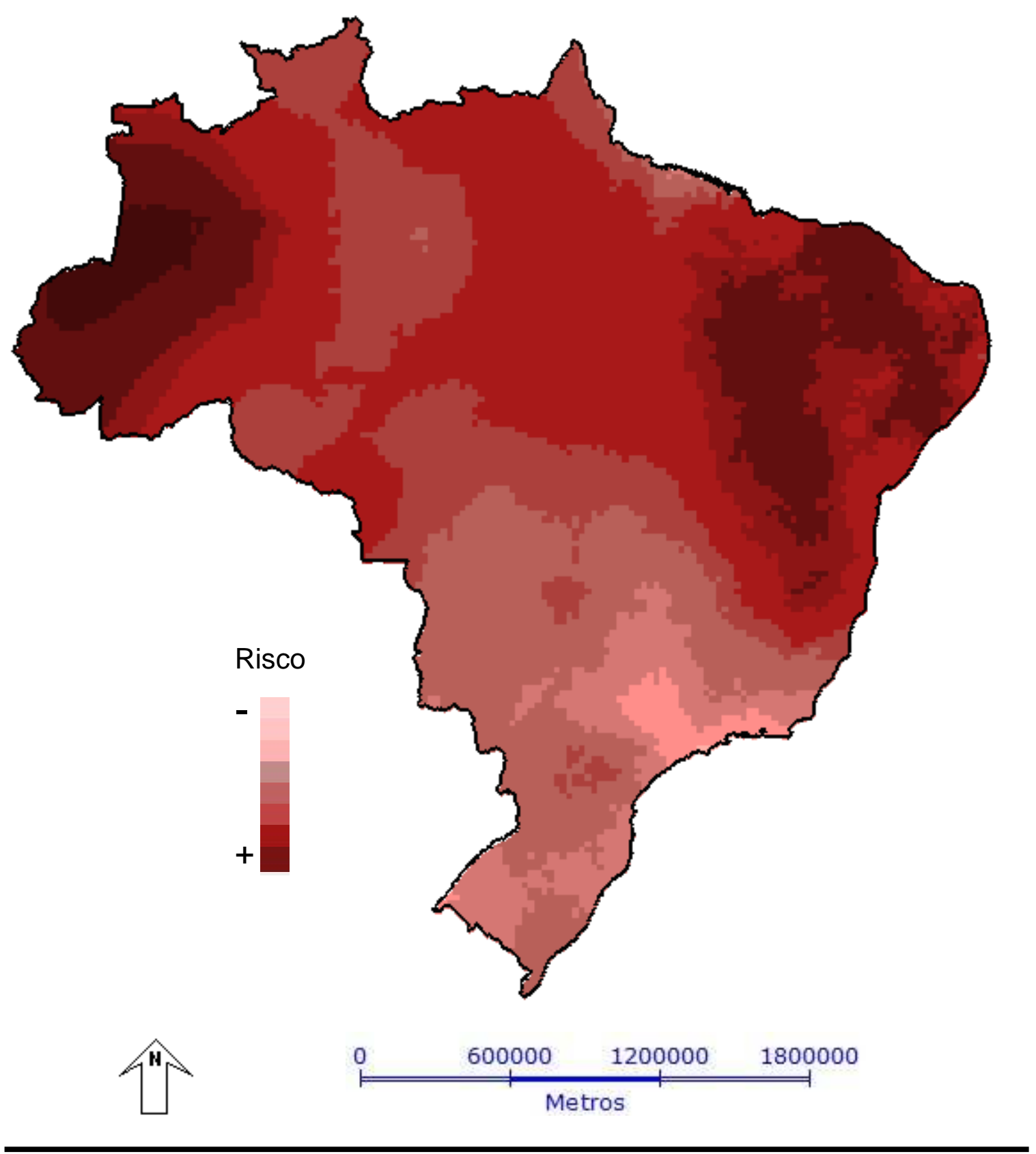


Figura 26 - Box Map: Mapa de espalhamento de Moran para o risco de necessidade de prótese total em pelo menos um arco dentário. Brasil, 2003.

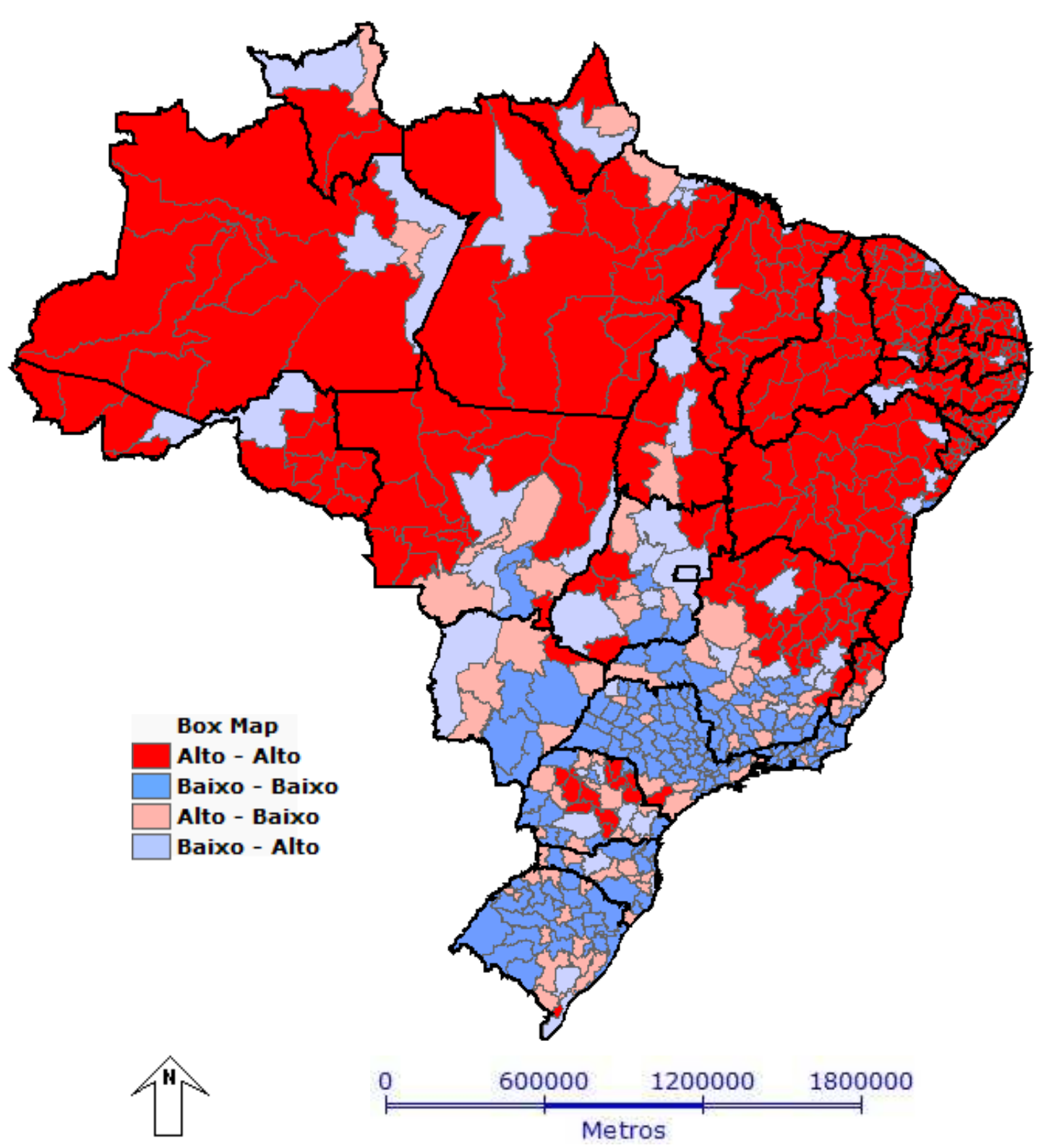


Figura 27 - LISA Map para o risco de necessidade de prótese total em pelo menos um arco dentário. Brasil, 2003.

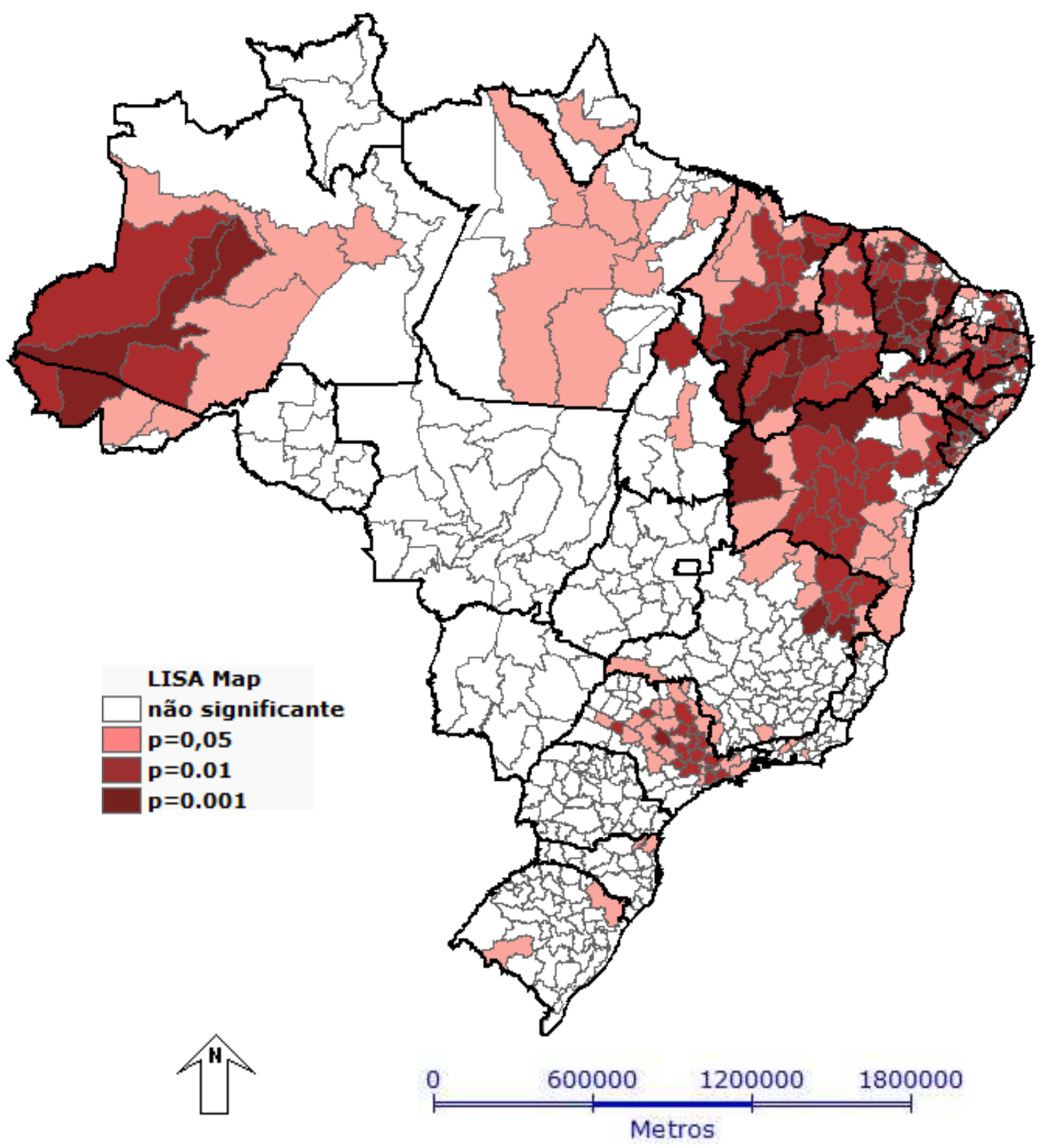


Figura 28 - Moran Map: Mapa de espalhamento de Moran para o risco de necessidade de prótese total em pelo menos um arco dentário gerado pelo Processo Analítico Hierárquico (AHP). Brasil, 2003.

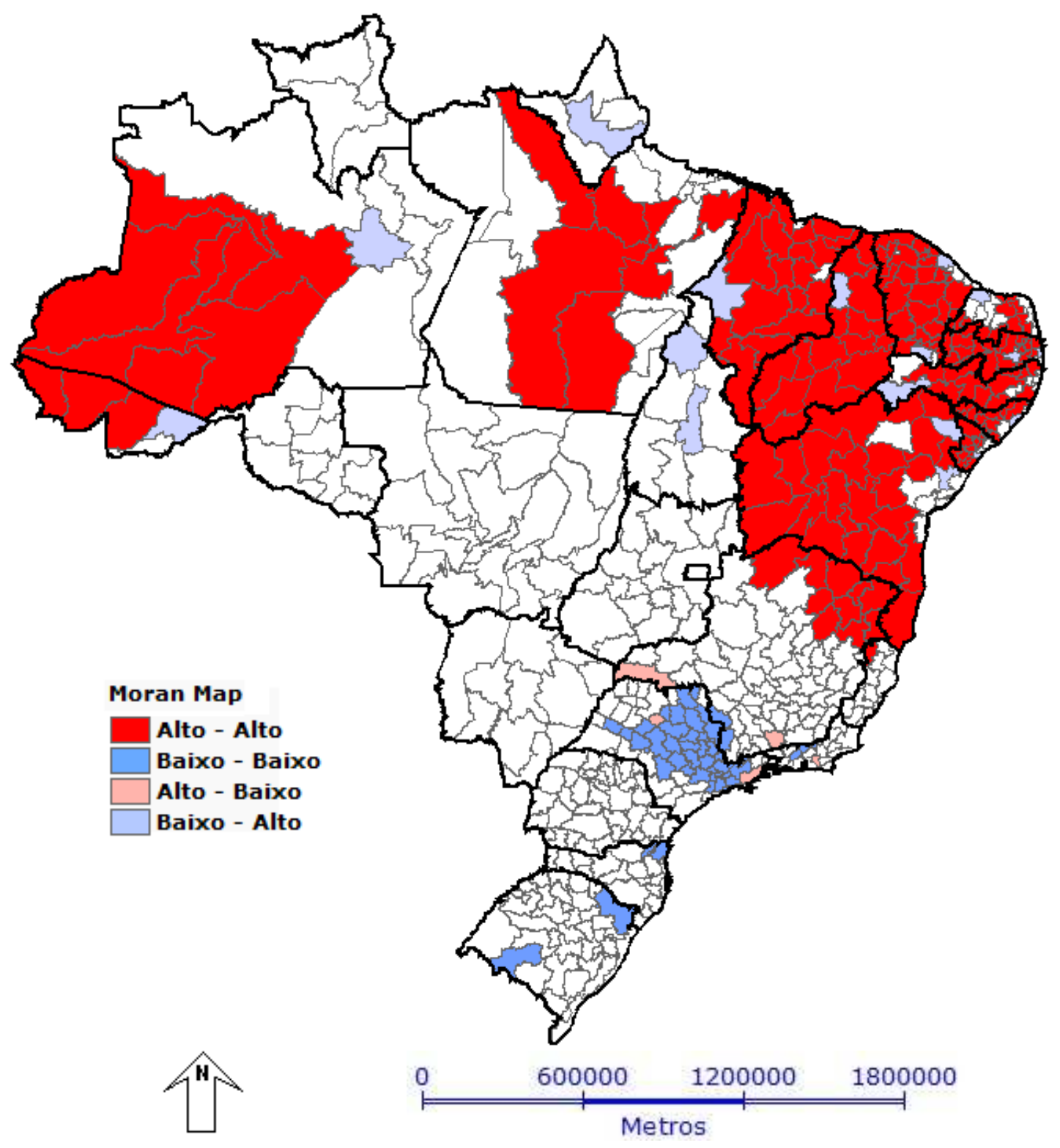


Entretanto, não houve dependência significativa de valores elevados de risco nos estados do Mato Grosso e de Goiás, exceto no norte do Estado de Minas Gerais. Áreas com maior proteção contra a necessidade de prótese total em pelo menos um arco dentário foram os estados de São Paulo, e pequenas áreas em Santa Catarina e no Rio Grande do Sul. 


\section{DISCUSSÃO}

O inquérito epidemiológico analisado neste estudo representou uma importante contribuição no conhecimento das condições de saúde bucal das populações adulta e idosa no Brasil. Tradicionalmente, os inquéritos anteriores tanto nacionais quanto regionais se limitaram, em sua maioria, aos escolares e à descrição do índice de cárie aos 12 anos de idade, excluindo os indivíduos adultos e idosos de suas abordagens. Adicionalmente, a coleta de informações em nível individual sobre os aspectos sociodemográficos e o acesso aos serviços odontológicos, realizada nesse inquérito, representou excelente oportunidade de conhecer o perfil da saúde bucal segundo diferentes fatores individuais.

A disponibilidade de dados secundários por Sistemas de Informação de instituições governamentais, em cada nível analisado, possibilitou conhecer a influência de variáveis contextuais sobre o desfecho. A análise multinível, além de considerar o desenho amostral ao particionar as variâncias de cada nível, tornou possível contemplar parte da complexidade inerente ao processo saúde-doença. Esta possibilidade garantiu a abordagem simultânea de fatores contextuais e individuais na análise. O modelo hierárquico adotado ultrapassou as variáveis de nível individual e suas diferentes camadas de mediação, e considerou aspectos do nível contextual como mediadores de toda a rede de determinação individual. 
A análise de resíduos, realizada por inspeção de gráficos de diagnóstico do tipo QQ-plot (standardised residual versus normal score) e Residual plot (standardised residual versus fixed part prediction), sugeriu um bom ajuste dos modelos. O modelo de regressão log-linear binomial negativa se mostrou como uma útil ferramenta metodológica na análise de variáveis dependentes quantitativas discretas que não possuem distribuição normal para serem ajustadas em um modelo de regressão linear ou que possuem a variância maior do que a média, prejudicando o uso de um modelo de regressão log-linear de Poisson devido ao fenômeno da superdispersão ${ }^{33}$. Entretanto, a recomendação para o uso da regressão binomial negativa na presença de superdispersão atende mais aos princípios formais da técnica, muitas vezes não sendo suficiente para alterar a força, a direção e a interpretação da medida de efeito em julgamento.

Adicionalmente, o modelo de regressão binomial negativa prescindiu da imposição de um ponto de corte sobre a variável dependente "perda dentária em adultos", favorecendo sua abordagem no formato natural, ou seja, na forma como ela se apresenta nos indivíduos (contagem de dentes perdidos).

O estudo dos determinantes sociais da perda dentária é um tema complexo e divergente entre vários países. Principalmente devido às diferentes variáveis preditoras presentes na literatura. GILBERT et al. ${ }^{30}$ estudaram a influência da raça e da condição socioeconômica (CSE) sobre a incidência de perda dentária em adultos na Flórida (EUA). Os autores sugerem que os determinantes sociais da perda dentária podem agir em 
direções opostas. Considerando que o único caminho de experimentar a perda dentária é a entrada no sistema de assistência odontológica (com pequena exceção das auto-extrações), os indivíduos afro-americanos e com baixa CSE teriam menor risco de perdas porque têm menos chance de entrar no sistema. Porém, uma vez tendo acesso ao sistema, eles terão maior risco de perda dentária. Com efeito, os autores demonstraram que a raça e a CSE perdem a significância na presença de doenças e sintomas dentários, mas passam a ter novamente efeito quando a análise se limita aos indivíduos que tiveram pelo menos uma visita ao dentista durante o período analisado. Os autores sugerem que estas diferenças sociais na perda dentária também se manifestam no uso dos serviços odontológicos e que indivíduos em desvantagem recebem menos alternativas de tratamento em relação à extração dentária.

No nosso estudo, isto talvez explique o risco de perda dentária encontrado nos adultos que já foram ao dentista, resultado também encontrado em adultos coreanos ${ }^{40}$. Entretanto, devido à maior parte dos indivíduos adultos do nosso estudo já terem ido ao dentista alguma vez na vida $(97 \%)$, principalmente no serviço público, diferenças sociais no acesso ao dentista não puderam ser captadas. Da mesma forma, o grupo étnico não teve efeito sobre a perda dentária quando ajustado pelas variáveis dos blocos superiores (modelo final). Este resultado sugere que o grupo étnico seja um marcador de risco presente em alguma variável socioeconômica, confundindo seu efeito independente. Entretanto, outros estudos confirmam um maior risco de perda dentária entre indivíduos da raça negra ${ }^{31,23,36}$. 
O teste de interações (Figura 5) mostrou relações significantes entre as variáveis contextuais e individuais. As interações sugeriram que mesmo indivíduos com maior escolaridade ou que receberam informações sobre prevenção tiveram aumento no risco quando associados aos Estados com alta taxa de exodontia. Este resultado mostra a influência de uma variável contextual relacionada ao serviço de assistência odontológica sobre o efeito dos fatores individuais, independente das demais variáveis ajustadas no modelo final. Nesse sentido, quem já foi ao dentista, mas possui dois ou mais automóveis apresentou diminuição de $64 \%$ no risco de perda dentária. Este achado fornece evidência de que, dependendo do nível socioeconômico, ir ao dentista pode representar risco ou proteção da perda dentária. Em outras palavras, a privação de determinados bens aliada ao prestígio social que estes bens agregam aos seus detentores, revelam também uma maior privação de saúde bucal ou mesmo uma idéia de que ter um tratamento odontológico adequado seja não só uma medida de prestígio, mas um privilégio social.

Conforme argumentado na introdução, a taxa de exodontia realizada pelo SUS pode não representar a realidade de alguns idosos que não freqüentam ou freqüentaram o serviço público, entretanto, como se trata de uma variável contextual, seu efeito deve ser analisado dentro dos limites da falácia ecológica ou do efeito de conglomerado.

Da mesma forma, o maior porte populacional representou proteção para a perda dentária em adultos e necessidade de prótese total em idosos, apontando para uma melhor oportunidade de acesso nestes 
municípios. Tal fenômeno pode ser explicado por uma série de fatores tais como pela melhor estrutura e organização dos serviços de saúde, maior concentração de cirurgiões-dentistas e maior oferta de tratamentos alternativos à exodontia.

GILBERT et al. ${ }^{31}$ realizaram um estudo longitudinal da incidência de perda dentária e empregaram um modelo de regressão logística multinível. Porém, os dois níveis avaliados foram os indivíduos e os dentes. As variáveis do nível dentário associadas à incidência de perda dentária foram o aumento na perda de inserção periodontal, no número de superfícies coronais e radiculares cariadas, a mobilidade dentária e fratura na restauração. No nível individual foram o relato de dor dentária, de cavidades dentárias, de necessidade percebida de tratamento odontológico, de fratura dentária, frustração com o atendimento odontológico, preferência pela extração no lugar de tratamento alternativo, grupo etário mais avançado, raça negra e sexo feminino.

Um estudo realizado em adultos da área urbana de Porto Alegre, região sul do Brasil, encontrou uma média de 11,2 dentes perdidos ${ }^{73}$. A análise múltipla ajustada pela idade mostrou o sexo feminino, o baixo nível socioeconômico e o tabagismo como os principais fatores de risco para a perda dos dentes. Entretanto, as variáveis relacionadas às condições de saúde bucal (perda de inserção periodontal, dentes cariados ou restaurados) apresentaram maior efeito sobre a perda dentária. Porém, diferente do trabalho anteriormente citado, este estudo foi transversal, o que limita as inferências sobre a causalidade entre as doenças bucais e a perda dentária. 
O efeito de variáveis odontológicas, tais como a presença de cárie e de doença periodontal, é o principal preditor da perda de dentes ${ }^{17,31,73,23,36}$. Isto ocorre porque estas doenças (com exceção da pequena participação de outros motivos) agem como marcadores de risco e acabam assumindo uma relação de identidade com a perda dentária, mostrando uma correlação quase perfeita. A inclusão destas variáveis pode mascarar o efeito de outras variáveis não odontológicas, como mostrado por GILBERT et. al. ${ }^{31}$, e estas se apresentam como preditores simultâneos tanto das doenças quanto das perdas de dentes. Este último fato ocorre, na maioria das vezes, devido ao surgimento de cárie e da doença periodontal. Dessa forma, a perda dentária torna-se uma medida indireta das doenças bucais e partilha os mesmos fatores de risco.

Embora o inquérito não tenha coletado informações específicas sobre as condições dentárias antes da perda dos dentes, o motivo da última consulta odontológica, representado pela presença de sangramento gengival, mostrou alto risco para a perda dentária $(R M=1,387)$. Esta condição representa um importante marcador da doença periodontal que, juntamente com a cárie, são importantes preditores da perda dentária em adultos e idosos 27,11 .

Contudo, a ausência de uma abordagem longitudinal que provesse detalhe sobre os motivos da extração abre espaço para duas hipóteses segundo GILBERT et al. ${ }^{31}$ : por um lado, as pessoas primeiro decidem remover um dente devido a um problema específico e vão ao dentista extraílo ou, por outro lado, primeiro decidem procurar um dentista devido a um 
problema específico e vão ao dentista ver o que pode ser feito. No primeiro caso, os sintomas e problemas específicos determinam a perda de dentes. No segundo caso, o atendimento odontológico determina a perda dentária e os problemas e sintomas teriam um efeito direto sobre o uso dos serviços odontológicos e indireto sobre a perda de dentes.

A análise do modelo final possibilita identificar o perfil de acesso ao serviço odontológico e a influência contextual das extrações dos dentes. Apesar de o serviço público ter perdido a significância como fator de risco no modelo múltiplo, a maior taxa de exodontia realizada pelos serviços públicos dos estados brasileiros foi fator de risco contextual para a perda dentária. Adicionalmente, o fato de não receber informações sobre prevenções de doenças bucais também representou risco para o desfecho analisado. Esse resultado chama a atenção para o papel do serviço público na mutilação dentária, principalmente quando consideramos que é a população desfavorecida quem mais acessa este serviço. Vale ressaltar que deve ser papel dos serviços públicos de saúde bucal incentivar e realizar ações de promoção e educação em saúde bucal, e não somente ações curativas de caráter mutilador.

Um aspecto interessante, que pode parecer de início paradoxal, é o efeito protetor das regiões que possuem maior número de dentistas/1000 habitantes. Apesar de ser fator de risco o fato de ter consultado um dentista, este risco deve estar ocorrendo pelo motivo apresentado anteriormente (realização de extrações em detrimento de opções alternativas de tratamento). A maior quantidade de dentistas, além de refletir uma possível 
melhor estrutura e desenvolvimento urbano da região (regiões com maior grau de urbanização tendem a apresentar maior oferta de recursos humanos) também refletem maiores possibilidades de alternativas de tratamento odontológico, de um acesso mais regular e de oferta de procedimentos preventivos. Ressalta-se que o risco de quem visitou 0 dentista entre 1 e 2 anos é bem menor comparado a quem a realizou há 3 anos ou mais. Nesse mesmo sentido, cidades de grande porte (mais de 100 mil habitantes) apresentaram efeito protetor contra a perda dentária.

CUNHA-CRUZ et al. ${ }^{21}$ avaliaram a influência da visita odontológica de rotina sobre a retenção de dentes em adultos do Rio de Janeiro (Brasil). Indivíduos que visitaram o dentista apenas quando estavam com algum problema dentário tiveram maior chance de perda dentária, independente do sexo, idade, raça, renda e nível educacional. Entretanto, o intervalo de tempo da visita de rotina não foi significante. Em nosso estudo, a alta escolaridade e a posse de pelo menos um automóvel mostraram efeito protetor contra a perda dentária. SUOMINEN-TAIPALE et al. ${ }^{72}$, examinando os fatores de risco para o edentulismo em adultos na Finlândia encontraram uma chance cinco vezes maior em indivíduos com nove anos ou menos de estudo em comparação àqueles com 13 anos ou mais de estudo. Em grande parte dos estudos analisados, o baixo nível educacional e a baixa renda foram importantes preditores da perda dentária ${ }^{73,21,75,34,35}$. Indivíduos pobres e com baixa escolaridade experimentam alta incidência de doenças bucais e de perda dentária, tendendo a visitar o dentista apenas quando sentem algum problema e não para visitas de rotina. No sentido oposto, indivíduos 
ricos e com maior escolaridade apresentam menos incidência de perda dos dentes e visitam o dentista com maior freqüência e para check-up de rotina $^{21,75}$.

HAMASHA et al. ${ }^{34}$ investigaram os fatores de risco para perda dentária em adultos na Jordânia. O número médio de dentes perdidos foi 11 , menor que o encontrado no Brasil $(14 \pm 9,5)$. De modo semelhante ao presente estudo, a localização geográfica (urbana ou rural) não foi associada à perda dentária, enquanto a maior idade, a baixa escolaridade, a baixa renda, o gênero masculino, escovação dentária com freqüência inferior a uma vez por dia e consulta odontológica para limpeza dentária realizada há um ano ou mais aumentaram o risco e explicaram $75 \%$ da variação da perda de dentes. Em adultos da Noruega, apenas o baixo nível educacional foi associado a este fato. Idade, sexo, local de residência, número de dentes presentes e a crença de que os dentes devem ser mantidos por toda a vida não apresentaram associação com o mesmo. ${ }^{35}$.

O sexo feminino apresentou risco para a perda dentária. Este achado corrobora resultados encontrados em vários estudos ${ }^{31,73,75,44}$. Porém, este tema é controverso e existem estudos que concluíram que o sexo não é um preditor significante ${ }^{17,35,41}$, ou que o sexo masculino apresenta maior risco ${ }^{40,34}$. Possivelmente, tais divergências representam mais uma diferença de gênero do que de sexo, tendo em vista os aspectos mais culturais (estilo de vida, uso de serviços de saúde, entre outros) e menos biológicos envolvidos no processo saúde-doença bucal. Em nosso estudo, apesar de as variáveis do bloco 4 não serem diretamente determinadas pelos blocos 
superiores (por serem variáveis imutáveis nos indivíduos), preferiu-se deixálas no bloco proximal ao desfecho para que pudessem ser controladas pelo efeito dos outros níveis. Verificamos que mesmo assim o efeito do sexo feminino foi altamente significante.

Entretanto, o aumento da idade aparece como fator de risco para a perda dentária em vários estudos ${ }^{31,72,34}$. $\mathrm{O}$ aspecto cumulativo típico das duas principais doenças bucais, cárie e doença periodontal, faz com que as suas conseqüências máximas, expressas pela perda dentária, ocorram em indivíduos mais velhos, na maior parte dos casos.

Com relação à análise da saúde bucal dos idosos, a maioria dos estudos epidemiológicos internacionais, principalmente nos Estados Unidos e na Europa, aborda a saúde bucal dos idosos focalizando seus resultados na tríade: prevalência de edentulismo, uso e necessidade de prótese, e uso de serviços odontológicos como reparador da saúde bucal. Dessa forma, a prevalência de edentulismo parece ser o índice mais indicado para mensurar as condições de saúde bucal dos idosos, principalmente com relação à severidade de cárie, enquanto que os dois últimos componentes da tríade revelam as respostas sociais a esse grave problema de saúde bucal, ou seja, o nível de reparação do dano estabelecido.

No presente estudo optou-se em investigar a prevalência de edentulismo funcional entre aqueles idosos dentados. Esta condição é caracterizada pela ausência de no mínimo 20 dentes permanentes em condições funcionais. Esta opção favoreceu a abordagem de fatores de risco diferenciados haja vista se tratar de idosos não edêntulos. Sendo assim, os 
resultados apontaram para os fatores associados à perda dentária em indivíduos idosos que ainda possuem dentes permanentes, aspecto ainda pouco explorado na literatura.

A prevalência de edentulismo funcional foi elevada (78,7\%). Entretanto, a maioria dos estudos relata a prevalência de edentulismo "total". Dentre eles podemos destacar uma baixa prevalência deste agravo como em Hong Kong ${ }^{18}$, apenas $12 \%$ eram edêntulos. No sul da China, a prevalência de edentulismo foi ainda menor: apenas $4,4 \%$ dos idosos residentes em área urbana apresentaram essa condição ${ }^{44}$; na Lituânia, também considerando apenas o grupo índice da OMS, $11 \%$ eram edêntulos $^{68}$; na Índia, $15 \%$ eram edêntulos ${ }^{65}$; na França $^{7}$ esse porcentual foi de 16,3\%; em Ontário (Canadá) $)^{45}$, foi de 24,4\%; na Suécia ${ }^{59}$, foi de $31,5 \%$, e em Adelaide ${ }^{70}$, a prevalência de edentulismo foi de $47,7 \%$.

O aumento do edentulismo com a idade parece ser uma tendência universal, criando no imaginário social a velha figura do idoso desdentado e a aceitação da perda dentária como uma evolução natural da dentição humana, mais ou menos no sentido de "nascemos sem dentes e morremos sem dentes". A maior prevalência de edentulismo entre as mulheres revela a existência de alguns fenômenos relacionados aos diferenciais de gênero em saúde. Dentre esses fenômenos, a maior expectativa de vida das mulheres estaria prolongando o tempo de exposição aos fatores determinantes do edentulismo, resultando maior número de idosas edêntulas e que alcançam uma idade mais avançada em relação aos homens, devendo-se ressaltar que essas diferenças ocorrem em números absolutos e relativos. Em razão 
desse fenômeno, devemos considerar o maior cuidado que a mulher despende com a própria saúde. Neste caso, tal cuidado pode gerar dados surpreendentes, pois o maior uso de serviços odontológicos, quando estes adotam uma prática mutiladora, poderia representar um acréscimo na prevalência de edentulismo entre as mulheres.

CALDAS JUNIOR et al. ${ }^{11}$ observaram uma forte associação estatística entre extrações dentárias por causa da cárie e o número de vezes que o dente extraído foi restaurado. Constataram que dentre 284 pacientes que extraíram um dente em razão da cárie, $77,8 \%$ haviam recebido tratamento restaurador nesse dente. Os autores destacam que "é errônea a crença de que a perda dentária pode ser prevenida na população simplesmente pela restauração do dente". Uma vez que a restauração dentária ocorre nos serviços odontológicos, podemos inferir que apenas o uso desses serviços não garante a redução das perdas de dentes e, conseqüentemente, a redução na prevalência do edentulismo. Considerando que as mulheres procuram mais os serviços de saúde em comparação com os homens, fica mais fácil compreender a paradoxal maior prevalência de edentulismo entre as mulheres.

De modo geral, a contribuição do estudo dos fatores associados ao edentulismo funcional em idosos no Brasil merece ser destacada pelo fato de que o maior número de dentistas por habitante e a maior taxa de exodontia, ambos efeitos contextuais, representaram proteção e risco para este desfecho, respectivamente. Nesta mesma direção, o fato de morar na área rural, ter tido a última consulta odontológica há três anos ou mais, no 
serviço público e por motivo de dor, e ser do sexo masculino constituíram características associadas à maior prevalência de edentulismo funcional.

Já a análise da necessidade de prótese total em idosos revelou a ausência da resposta social à mutilação dentária, assim como os fatores associados a tal ausência. O menor uso desse tipo de prótese no arco inferior associado à sua maior necessidade também nesse arco é um padrão congruente com a maior parte dos estudos nacionais, revelando que o uso de prótese total inferior está relacionado a aspectos que transcendem a oferta dos serviços de reabilitação, sugerindo a presença de outros fatores determinantes, tais como o desconforto, a falta de adaptação e 0 não comprometimento estético. Todos esses aspectos formam obstáculos para o uso desse tipo de prótese.

Conforme mencionado por FERNANDES et al. ${ }^{26}$, o simples uso de prótese não garante uma saúde bucal adequada, uma vez que muitas dessas necessitariam de substituição, notadamente em razão dos desgastes (longo tempo de uso) e falhas na sua confecção. Considerando-se tal aspecto, pode-se afirmar que a necessidade de prótese, principalmente a total, aferida neste estudo, encontra-se subestimada, haja vista que essa condição foi determinada apenas pela presença ou ausência de espaços dentários não substituídos por aparelhos protéticos. Nesse sentido, a necessidade de prótese total seria ainda maior, pois seriam incluídos os casos que necessitariam de substituição, realidade bastante comum entre a maior parte dos idosos. FRARE et al. ${ }^{28}$ relataram que a última consulta odontológica coincidia, na maioria dos casos, com a instalação das próteses 
que, em média, apresentavam um tempo de 20 anos de uso. Apesar do fato de o edentulismo ser o problema de saúde bucal de maior prevalência entre os idosos, poucos estudos divulgam o uso e a necessidade de prótese de forma padronizada, obedecendo aos códigos e critérios recomendados pela OMS, o que dificulta a comparação dos achados.

Percebe-se que, de modo geral, a escolaridade representa um papel determinante na necessidade de aparelhos protéticos. Apesar de as mulheres apresentarem maiores perdas dentárias, os homens apresentaram maior necessidade de prótese. Um aspecto interessante observado no presente estudo foi o aumento do risco de perda dentária e de edentulismo funcional em adultos e em idosos, respectivamente, que freqüentaram o dentista pelo menos uma vez na vida, ao passo em que esse aspecto foi fator de proteção para a necessidade de prótese total em idosos. Este fato sugere de um lado que ir ao dentista aumenta o risco de perder os dentes e por outro lado não ir ao dentista aumenta o risco de necessitar de prótese total. Sendo o dentista o mesmo ator responsável tanto pela perda de dentes quanto pela instalação da prótese total, pode-se destacá-lo como um ator decisivo para o desfecho da saúde bucal desses indivíduos. Dessa forma, o acesso à consulta odontológica torna-se um aspecto positivo ou negativo dependendo do estado dentário do paciente e de seu nível socioeconômico, conforme mostrado e discutido nos achados sobre os testes de interações.

Na Índia, 17,6\% dos idosos não usavam próteses por possuírem dentes naturais. Apenas $8,3 \%$ utilizavam a total em um ou em ambos os arcos, e 7,8\% usavam a removível. Dentre os 222 idosos desdentados 
parciais ou totais, 103 utilizavam prótese total em um ou em ambos os arcos, sendo que o maior uso foi encontrado no sexo masculino ${ }^{65}$, diferente do presente estudo.

Em Guangdong (China), 51,4\% dos idosos de 65 a 74 anos, residentes na área urbana, utilizavam algum tipo de aparelho protético. Porém, somente $10,2 \%$ utilizavam prótese total ${ }^{44}$. Em Hong Kong, 53\% e $62 \%$ não usavam prótese no arco superior e inferior, respectivamente. Esse resultado não revela uma alta necessidade de seu uso, mas, sim, uma baixa prevalência de edentulismo (12\%). Apenas $21 \%$ e $17 \%$ utilizavam prótese total superior e inferior, respectivamente ${ }^{18}$. Em Adelaide, $83,9 \%$ dos idosos utilizavam algum tipo de prótese, sendo que $45,3 \%$ usavam próteses totais superiores e inferiores ${ }^{70}$.

Revisando estudos sobre a saúde bucal de idosos na América Latina, MARIÑO ${ }^{46}$ observou que na Costa Rica $33 \%$ da população idosa necessitavam de reabilitação protética, total ou parcial. No Chile, dentre os idosos que necessitavam de prótese parcial superior, $85 \%$ as usavam, enquanto que dos que necessitavam de prótese total inferior, apenas $21 \%$ as usavam.

Com relação aos estudos locais, apesar de vários artigos se preocuparem em abordar o uso e a necessidade de aparelhos protéticos, a falta de padronização na apresentação dos achados é emblemática. Não há um consenso sobre a determinação dos critérios para se definir a necessidade de uso dos mesmos (alguns trabalhos citam critérios para 
reparos e substituição) ou sobre a divisão dos resultados por arcadas, deficiências observadas nos próprios manuais da OMS ${ }^{16}$.

Entre os usuários de grupos de Terceira Idade na cidade de Piracicaba (SP), $80,3 \%$ e $57,3 \%$ usavam prótese total superior e inferior, respectivamente. Não usavam esses aparelhos no arco superior $11,4 \%$ e, no arco inferior, 31,1\%. Houve apenas necessidade de prótese total inferior, representando 4,9\% ${ }^{66}$. PEREIRA et al. ${ }^{60}$, pesquisando idosos institucionalizados na mesma cidade, encontraram em idosos com mais de 75 anos um percentual de $55,7 \%$ e $31,5 \%$ utilizando prótese total superior e inferior, respectivamente. Não usavam prótese no arco superior $44,3 \%$ e, no arco inferior, $67,1 \%$. A necessidade de aparelho protético total foi de $68,6 \%$ no arco superior e $74,3 \%$ no inferior.

Em pesquisa realizada em idosos de instituições públicas e privadas de longa permanência na cidade de Goiânia (GO), REIS et al. ${ }^{64}$ encontraram menores porcentagens de idosos que usavam próteses. A prótese total foi o tipo de prótese mais usado, principalmente no arco superior. A maioria dos idosos necessitava de prótese em proporções semelhantes nos dois arcos, porém houve maior necessidade de prótese total superior.

Na cidade de Rio Claro (SP), SILVA et al. ${ }^{67}$ observaram o uso de prótese total superior e inferior em $52,4 \%$ e $35,6 \%$ dos idosos examinados, respectivamente. Houve maior necessidade de prótese total superior $(48,5 \%)$ em relação à inferior (45,5\%), embora seja leve essa diferença. Em Biguaçu (SC), 31,8\% dos idosos não usavam prótese no arco superior e 
$65,7 \%$ no inferior. Para o arco superior e inferior, respectivamente, 36,1\% e 20,2\% não necessitavam de aparelhos protéticos e 47,7\% e 42,6\% necessitavam de prótese total ${ }^{15}$.

Diferente dos países analisados, especialmente a Índia e a China, no Brasil existe um quadro caracterizado por uma população idosa com muitos usuários de prótese total, e, ao, mesmo tempo, ainda com um grande contingente necessitando desse tipo de aparelho. Tal aspecto configura um cenário polarizado, em que o pano de fundo é a elevada prevalência de edentulismo, ocupando a cena de um lado os usuários de prótese total e, do outro lado, os que ainda necessitam desse tipo de reabilitação.

Com relação à análise espacial dos dados, em Geografia, admitese a possibilidade de que atributos espaciais próximos entre si possuam características semelhantes. À medida que se distanciam, tornam-se cada vez mais diferentes. Esta dependência espacial é chamada por Tobler de primeira lei da geografia que afirma que todas as coisas são parecidas, mas coisas mais próximas se parecem mais que coisas mais distantes ${ }^{24}$. Tal relação de "vizinhança", apesar de ser observada mais em atributos naturais, como, por exemplo, as características do solo também podem estar presentes em fenômenos sociais, principalmente quando aceitamos o território como um espaço socialmente construído. Porém, em virtude da própria complexidade dos processos sociais, principalmente nas grandes metrópoles brasileiras, é comum encontrarmos "ilhas" com características totalmente diferentes de seu entorno, tais como as favelas e os bolsões de pobreza ou, no sentido oposto, condomínios de luxo em regiões periféricas 
envoltos por áreas de intensa pobreza. Tais situações não são explicadas por leis funcionalistas que insistem em explicar fenômenos sociais utilizando leis naturais.

Além de descrever padrões espaciais de distribuição das condições de saúde bucal e de fatores relacionados a estas condições, em nível individual, a abordagem ecológica permitiu uma ampliação na apreensão da realidade na medida em que possibilitou a inclusão de variáveis contextuais coletivas. Esta propriedade dos estudos ecológicos favorece a predição dos resultados para regiões não amostradas pelo inquérito domiciliar, conquanto seja respeitada a representatividade populacional da amostra, à parte as flutuações aleatórias e o erro amostral.

Em termos gerais, poucos são os estudos que procuraram abordar a relação entre o espaço geográfico e a saúde bucal. A preocupação em localizar geograficamente as condições de saúde bucal iniciou-se paralelamente com a preocupação em gerar informações epidemiológicas que pudessem ser padronizadas e que permitissem comparações entre diferentes regiões do mundo. Por meio de ferramentas da Cartografia e com a ascensão da "Geografia das Patologias" iniciada na década de 1940, os estudos epidemiológicos em saúde bucal se reduziam ao mapeamento da cárie em várias partes do mundo, apenas como uma forma descritiva e gráfica de apresentação dos dados disponíveis sobre a cárie ${ }^{48}$. A idéia era de somente "colorir" os mapas de acordo com um ranking estabelecido sobre a cárie em diferentes países. 
As descrições sobre a variação geográfica da cárie nessa época eram carregadas de conotações políticas e ideológicas que elegiam como fatores determinantes a latitude, aspectos climáticos e socioeconômicos, sustentando a inferioridade dos países localizados abaixo da linha do equador em comparação aos países das zonas temperadas.

No entanto, a idéia de sobreposição, embora manual, de mapas transparentes, contendo diferentes informações geográficas já estava presente naquela época. Esta mesma idéia é hoje empregada em um ambiente computacional - Sistemas de Informação Geográfica (SIG) - na forma de sobreposição de camadas ou layers, porém com maior complexidade e variedade de camadas, ampliando as opções de análises.

As evidências revelam o grande potencial das análises espaciais em saúde bucal. Apesar de ainda serem poucos os estudos que abordam o espaço e o seu papel na saúde bucal da população, as experiências citadas apontam a importância do uso dos SIG nos estudos epidemiológicos em saúde bucal, principalmente na relação entre o acesso aos serviços odontológicos e as condições de saúde bucal, expressas pelas necessidades de tratamento.

Porém, torna-se imprescindível destacar a relação temporal da experiência do indivíduo com seu território. A simples descrição das condições de saúde bucal de uma pessoa e sua relação com sua posição geográfica não é, isoladamente, determinante no processo saúde-doença. Principalmente quando consideramos que a cárie e a doença periodontal, especialmente em idosos, são resultados cumulativos de vários anos em 
que cada indivíduo foi submetido a diferentes níveis de exposição, tanto a fatores de risco quanto a fatores de proteção, não necessariamente tendo ocorrido em um mesmo ambiente ao longo da vida. Em contrapartida, reconhecemos uma reprodução, de expressão espacial, das condições de vida e saúde da população na medida em que o local de moradia do indivíduo reflete sua própria condição socioeconômica. Dessa maneira, o território, como reflexo das condições econômicas de seus habitantes e sujeito às iniqüidades sociais e políticas, poderia influenciar negativamente as condições de vida de seus ocupantes. Percebe-se, então, que o território passa a gerar (e gerir) a pobreza de forma sustentável.

Contudo, o presente estudo apresenta algumas limitações. Apesar de o modelo multinível ter corrigido o efeito de conglomerado (representado pela dependência dos indivíduos nos níveis amostrais) e de ter gerado estimativas mais precisas dos erros-padrão pelo particionamento das variâncias, o inquérito epidemiológico analisado não apresenta informação sobre a taxa de não resposta, dificultando tanto a definição dos pesos amostrais para a análise descritiva dos dados quanto à verificação de potenciais vieses devido às recusas. Como destacado por QUEIROZ et al. ${ }^{62}$, o procedimento de amostragem do Projeto SB Brasil 2003 não apresenta informações adicionais que favoreceriam uma análise mais detalhada, alertando seus potenciais usuários de que estimativas produzidas não são representativas da população brasileira, além de apontar para as possibilidades de correção dos problemas identificados. Entretanto, o artigo não avança na solução dos problemas indicados. Para tanto, seria 
necessário o resgate de informações constantes dos relatórios das equipes de campo, o que necessariamente passa pelo apoio do Ministério da Saúde e das coordenações estaduais e municipais do Projeto SB Brasil 2003. Todavia, tal fato não é suficiente para justificar a renúncia em trabalhar com os dados do referido inquérito como uma possível e disponível descrição do cenário epidemiológico da saúde bucal da população brasileira, mesmo com todas suas limitações.

Outro aspecto foi que o presente estudo, no que diz respeito à saúde bucal dos adultos, analisou a perda dentária incluindo todos os indivíduos, inclusive aqueles com a perda de todos os dentes. Apesar de esta estratégia evitar pontos de corte e possibilitar uma abordagem pluralista da perda dentária, COPELAND et al. ${ }^{17}$ sugerem a presença de diferentes preditores para a perda dentária e para o edentulismo (perda de todos os dentes). Futuras abordagens devem contemplar esta possibilidade.

Embora estudos tenham sugerido a maior influência de aspectos dentários sobre a incidência de perda de dentes ${ }^{17,31,73,23,36}$, eles são privilégios de estudos longitudinais em que é possível a obtenção da informação da condição dentária antes da extração. Fatores do dente (toothlevel) não foram considerados, pois, além de não termos informações anteriores sobre as condições dentárias, os indivíduos edêntulos (sem dentes) foram incluídos na análise da perda de dentes em adultos e estes fatores poderiam ter efeitos contrários sobre este desfecho. Por exemplo, as doenças dentárias seriam associadas à presença de dentes, pois seria necessário ter dentes para se ter a doença, e tais doenças seriam 
consideradas proteção para a perda dentária, pois não estariam presentes nos edêntulos. Outras análises incluindo apenas indivíduos dentados e um recorte longitudinal poderiam considerar a influência dos fatores dentários. Porém, não teríamos idéia dos fatores responsáveis pela perda de todos os dentes de uma forma global. Todavia, o motivo da última consulta odontológica poderia sugerir uma aproximação da condição não apenas dos dentes, mas de toda a cavidade oral. 


\section{CONCLUSÕES}

A perda dentária em adultos brasileiros foi elevada quando comparada com outros países. Mesmo com uma grande variabilidade $( \pm 9,5)$ em torno da média de 14 dentes perdidos, metade dos indivíduos havia perdido 12 dentes. Os fatores de risco envolvidos neste fenômeno apresentaram efeitos em múltiplos níveis, correspondendo aos referenciais teóricos sobre a determinação do processo saúde-doença apresentados na introdução deste estudo.

Nesse sentido, fica evidente a participação independente dos fatores contextuais abordados sobre a perda dentária. Além desses fatores controlarem o efeito das variáveis individuais, foi possível identificar interações interníveis. Este resultado evidencia o papel importante dos aspectos contextuais sobre perfis individuais de exposição. Independente do sexo, da idade, dos aspectos socioeconômicos, representados pela escolaridade e pela posse de automóvel, e do perfil de acesso aos serviços odontológicos, a maior taxa de exodontia representou um forte efeito contextual no maior risco de perda dentária além de alterar o efeito de variáveis protetoras.

Embora o estudo não apresente poder de inferência sobre a causalidade da perda dentária (característica inerente ao desenho utilizado), os resultados mostraram que são necessárias mudanças nos atributos individuais, como a redução das desigualdades entre gênero e idade, diminuição das disparidades socioeconômicas e mudanças no perfil de 
acesso ao serviço odontológico, objetivando a prevenção das doenças bucais. Entretanto, ações sobre os diferentes contextos que modulam a dinâmica social nos perfis de saúde da população são necessárias para a redução das desigualdades em saúde. A compreensão do efeito do nível contextual sobre a saúde bucal representa uma ótima oportunidade para uma ação indireta sobre os determinantes individuais das doenças bucais e da perda dentária.

A análise da saúde bucal dos idosos mostrou duas faces importantes que estão presentes nesses indivíduos: a prevalência de edentulismo funcional e a ausência de resposta social a este agravo, ou seja, a prevalência de necessidade de prótese total em pelo menos um arco dentário. O estudo apresentou não apenas associações em um contexto multinível, mas importantes interações presentes intra e interníveis. Tais associações e interações apontam para caminhos que devemos de um lado prevenir a perda dentária e de outro lado tratar este gravo presente nos idosos que apresentaram necessidade de prótese total. Dessa forma, o estudo fornece subsídios para a estruturação de ações de promoção de saúde bucal que considere os fatores de risco e de proteção explorados na presente análise. Um bom exemplo de ações de promoção da saúde bucal, especificamente para a prevenção da cárie, utilizando abordagens populacionais é a fluoretação das águas de abastecimento público. Embora esta informação estivesse presente no banco de dados com relação aos municípios que possuem água fluoretada, ela não foi trabalhada devido às características da população abordada neste estudo. Acredita-se que os 
efeitos benéficos do flúor podem não ter alcançado os idosos e em menor parte os adultos pela relação temporal entre a implementação desta medida de proteção específica (bastante variada de município para município) e o seu efeito protetor.

Com efeito, as análises estatísticas e espaciais empregadas no presente estudo devem contribuir para o fortalecimento do planejamento e da atuação dos serviços locais de saúde, fornecendo uma resposta social às precárias condições bucais encontradas na população adulta e idosa brasileira. Tais condições, notoriamente mais desfavoráveis nos indivíduos com piores condições de vida, possuem não só uma distribuição coletiva, mas também geográfica, fatos estes que devem ser levados em conta no direcionamento das ações de saúde. Neste sentido, o estudo avançou ao apontar as áreas geográficas com maior possibilidade de ocorrências dos agravos estudados, devido à maior presença dos fatores de risco contextuais nestas áreas. Além disso, foi possível encontrar áreas com risco estatisticamente significantes, ou seja, espaços de risco que não se manifestam por obra do simples acaso.

A associação de modelos matemáticos (necessariamente reducionistas) à interpretação (necessariamente subjetiva) do especialista ${ }^{24}$ aproxima as análises espaciais de outras correntes filosóficas e de metodologias qualitativas, repugnando qualquer caráter positivista que tradicionalmente estereotipa os trabalhos quantitativos. Independente do recorte teórico e metodológico utilizado, a ausência da neutralidade científica deve ser uma premissa presente nos modelos explicativos da realidade, 
principalmente quando consideramos que a estatística mensura justamente a incerteza dessa realidade. Não conseguimos alcançar a perfeição de nossos modelos, mas podemos conhecer a incerteza de nossas elaborações da realidade.

Concordando com BREILH e GRANDA ${ }^{10}$, é necessário não corromper os achados epidemiológicos, reduzindo-os a instrumentos neopositivistas para a sustentação do "projeto de dominação política das classes dominantes, que apoiou e continua apoiando o maior obscurecimento da visão do processo saúde-doença e o desenvolvimento de alternativas de verdadeira transformação".

O uso de modelos estatísticos, tendo em vista a sua tendente submissão às leis funcionais e probabilísticas ${ }^{10}$, não deve ser tomado como o único caminho para a revelação das iniqüidades em saúde. Tal postura resultaria em uma total indiferença quanto aos aspectos sócio-ideológicos impossíveis de serem quantificados em freqüências ou médias. Assumir este equívoco contribuiria para uma explicação funcionalista, colaborando para a manutenção do status quo, sem que haja nem sequer uma aproximação das verdadeiras origens das desigualdades sociais. Ainda assim, geraria uma falsa idéia de descoberta dos fatores determinantes das doenças ou agravos à saúde, mascarando os reais interesses do modo de produção capitalista e criando intelectuais orgânicos desse processo.

É no sentido contrário a essa tendência, que a modelagem estatística deve ser um instrumento identificador do lócus da doença socialmente determinada, não de forma atomizada, mas apontando os 
grupos sociais que expressam em suas condições de vida e saúde o fruto do modo de produção vigente em nossa sociedade. Dessa forma, acredita-se que a informação gerada pelos modelos estatísticos fortaleceria a denúncia contra as injustiças sociais, uma vez que geraria não apenas uma explicação, mas antes uma indignação e uma busca pela superação de tais iniqüidades.

Por fim, conclui-se que a perda dentária em adultos, a prevalência de edentulismo funcional e a necessidade de prótese total em idosos no Brasil possuem importantes associações com determinantes sociais da saúde. Estes determinantes, representados neste estudo pelos fatores contextuais, serviram de mediadores para os determinantes individuais intermediários e proximais ao desfecho. A localização espacial destes determinantes sociais apontam áreas críticas onde ações que favoreçam maior equidade em saúde devem ser implementadas. O conjunto de reflexões apoiadas no exercício empírico que este trabalho apresentou aponta para a importância do efeito do contexto como a "causas das causas" dos agravos em saúde bucal sofridos por grande parte da população adulta e idosa brasileira. 


\section{Referências}

1. Almeida Filho N. A ciência da saúde. São Paulo: Hucitec; 2000.

2. Barata RB. Epidemiologia Social. Rev Bras Epidemiol 2005; 8(1): 717.

3. Barcellos C, Bastos FI. Geoprocessamento, ambiente e saúde: uma união possível? Cad Saúde Pública 1996; 12(3): 389-97.

4. Barcellos C. A saúde nos sistemas de informação geográfica: apenas uma camada a mais? Cad Prudentino Geogr 2003; 25: 29-43.

5. Barros AJD, Hirakata VN. Alternatives for logistic regression in crosssectional studies: an empirical comparison of models that directly estimate the prevalence ratio. BMC Medical Research Methodology 2003; 3(21): 21.

6. Bourgeois D, Nihtila A, Mersel A. Prevalence of caries and edentulousness among 65-74-years-old in Europe. Bull World Health Org 1998;76: 413-7.

7. Bourgeois DM, Doury J. Periodontal conditions in 65-74 year old adults in France, 1995. Int Dent Journal 1999; 49: 182-6.

8. Brasil. Departamento de Informática do SUS - DATASUS. 2007 [citado em 3 de Março de 2007]; Disponível em: www.datasus.gov.br.

9. Brasil. Ministério da Saúde. Projeto SB Brasil 2003: condições de saúde bucal da população brasileira 2002-2003: resultados principais. Brasília: Ministério da Saúde; 2004. 
10. Breilh L, Granda E. Investigação da saúde na sociedade: guia pedagógico sobre um novo enfoque do método epidemiológico. São Paulo: Abrasco; 1986.

11. Caldas Junior AF, Silveira RCJ, Marcenes W. The impact of restorative treatment on tooth loss prevention. Pesqui Odontol Bras 2003; 17(2): 166-70.

12. Camargo ECG, Fucks SD, Câmara G. Análise espacial de superfícies. In: Druck, S. Carvalho MS Câmara G, Monteiro AVM, eds. Análise espacial de dados geográficos. Brasília: EMBRAPA; 2004.

13. Carvalho MS, Câmara G, Cruz OG, Correa V. Análise de dados de área. In: Druck, S. Carvalho MS Câmara G, Monteiro AVM. Análise espacial de dados geográficos. Brasília: EMBRAPA; 2004.

14. Chaimovickz F. A saúde dos idosos brasileiros às vésperas do século XXI: problemas, projeções e alternativas. Rev Saúde Pública 1997; 31(2): 184-200.

15. Colussi CF, Freitas SFT, Calvo MCM. Perfil epidemiológico da cárie e do uso e necessidade de prótese na população idosa de Biguaçu, Santa Catarina. Rev Bras Epidemiol 2004; 7(1): 88-97.

16. Colussi CF, Freitas SFT. Aspectos epidemiológicos da saúde bucal do idoso no Brasil. Cad Saude Publica 2002; 18: 1313-1320.

17. Copeland LB, Krall EA, Brown LJ, Garcia RI, Streckfus CF. Predictors of tooth loss in two US adult populations. Journal of Public Health Dentistry 2004;64: 31-7. 
18. Corbet EF, Lo ECM. Tooth spaces in and prosthetic treatment received by the middle-aged and the elderly in Hong Kong. Community Dent Oral Epidemiol 1994; 22: 386-91.

19. Costa JFR, Chagas LD, Silvestre RM (org,). A política nacional de saúde bucal no Brasil: registro de uma conquista histórica. Brasília: OPAS 2006.

20. Costa MCN, Teixeira MGLC. A concepção de "espaço" na investigação epidemiológica. Cad Saúde Pública 1999; 15(2): 271279.

21. Cunha-Cruz J, Nadanovsky P, Faerstein E, Lopes CS. Routine dental visits are associated with tooth retention in Brazilian adults: the PróSaúde Study. Journal of Public Health Dentistry 2004;64: 216-22.

22. Dahlgren G, Whitehead M. European strategies for tackling social inequities in health: Levelling up Part 2. Copenhagen 2007, WHO Regional Office for Europe (Studies on social and economic determinants of population health, No. 3).

23. Drake CW, Hunt RJ, Koch GG. Three-year tooth loss among black and white older adults in North Carolina. J Dent Res 1995;74: 675-80.

24. Druck S, Carvalho MS, Câmara G, Monteiro AMV, organizadores. Análise espacial de dados geográficos. Planaltina: Empresa Brasileira de Pesquisa Agropecuária; 2004.

25. Fedération Dentaire Internacionale. Global goals for oral health in the year 2000. Int Dent J, 32 (1): 74-7, 1982. 
26. Fernandes RAC, Silva SRC, Watanabe MGC, Pereira AC, Martildes, MLR. Uso e necessidade de prótese dentária em idosos que demandam um centro de saúde. Rev Brasileira Odontol 1997; 54(2): 107-10.

27. Franks AST, Hedegárd B. Odontologia geriátrica. Rio de Janeiro: Editorial Labor do Brasil; 1977.

28. Frare SM, Limas PA, Albarello FJ, Pedot G, Régio RAS. Terceira Idade: Quais os problemas bucais existentes? Rev Assoc Paul Cir Dent 1997; 51(6): 573-6.

29. Frazão P, Antunes JLF, Narvai PC. Perda dentária precoce em adultos de 35 a 44 anos de idade: estado de São Paulo, Brasil, 1998. Rev Bras Epidemiol.2003; 6(1): 49-57.

30. Gilbert GH, Duncan RP, Shelton BJ. Social determinants of tooth loss. Health Service Research 2003;38: 1843-62.

31. Gilbert GH, Miller MK, Duncan RP, Ringelberg ML, Dolan TA, Foerster U. Tooth-specific and person-level predictors of 24-month tooth loss among older adults. Community Dent Oral Epidemiol 1999;27: 372-85.

32. Goldstein H. Multilevel Statistical Models. London: Arnold; 2003.

33. GschlößI S, Czado C. Modelling count data with overdispersion and spatial effects. Statistical papers (online first) [cited 19 nov 2007]; Available from: www.springerlink.com.

34. Hamasha AA, Sasa I, Qudah MA. Risk indicators associated with tooth loss in Jordanian adults. Community Dent Oral Epidemiol 2000;28: 67-72. 
35. Haugejorden O, Klock KS, Trovik TA. Incidence and predictors of selfreported tooth loss in a representative sample of Norwegian adults. Community Dent Oral Epidemiol 2003;31: 261-8.

36. Hunt RJ, Drake CW, Beck JD. Eighteen-month incidence of tooth loss among older adults in North Carolina. American Journal of Public Health 1995;85: 561-3.

37. Instituto Brasileiro de Geografia e Estatística. Pesquisa nacional por amostra de domicílio 1998: análise dos resultados, 1998 [acessado em 2004 Abr 14]. Disponível em: http://www.ibge.gov.br

38. Karlsson G, Teiwik A, Lundström A, Ravald N. Costs of periodontal and prosthodontic treatment and evaluation of oral health in patients after treatment of advanced peridontal disease. Community Dent Oral Epidemiol 1995;23: 159-64.

39. Kayser AF. Shortened dental arches and oral function. J Oral Rehabil 1981; 8(5): 457-62.

40. Kim H, Lee S, Cho S, Patton LL, Ku Y. Associations between missing teeth with unmet needs and socioeconomic status among south Korean dentate government employees. Journal of Public Health Dentistry 2007;67: 174-8.

41. Klein BEK, Klein R, Knudston MD. Life-style correlates of tooth loss in an adult Midwestern population. Journal of Public Health Dentistry 2004;64: 145-50.

42. Krieger N. Epidemiology and the web of causation: has anyone seen the spiders? Soc Sci Med 1994;39: 887-903. 
43. Last JM. A dictionary of epidemiology. Oxford: Oxford University Press; 1995.

44. Lin HC, Corbet EF, Lo ECM, Zhang FG. Tooth loss, occluding pairs, and prosthetic status of Chinese adults. J Dent Res 2001; 80(5): 14915.

45. Locker D, Slade GD, Leake JL. Prevalence of and factors associated with root decay in older adults in Canadá. J Dent Res 1989; 68(5): 768-72.

46. Mariño R. La salud bucodental de los ancianos: realidad, mitos y posibilidades. Bol Oficina Sanit Panam 1994; 116(5): 419-26.

47. Marques E, Torres $H$. São Paulo: segregação, pobreza e desigualdades sociais. São Paulo: Senac; 2005.

48. McPhail CWB, Grainger RM. A mapping procedure for the geographic pathology of dental caries. International Dental Journal 1969; 19(3): 380-92.

49. Medronho RA, Perez MA. Distribuição das doenças no espaço e no tempo. In: Medronho RA, Carvalho DM, Bloch KV, Luiz RR, Werneck GL. Epidemiologia. São Paulo: Atheneu; 2004. p. 57-71.

50. Minayo MCS, organizadora. Os muitos Brasis: saúde e população na década de 80. São Paulo-Rio de Janeiro: Hucitec-Abrasco; 1999.

51. Monken $\mathrm{M}$, Barcellos $\mathrm{C}$. Vigilância em saúde e território utilizado: possibilidades teóricas e metodológicas. Cad Saúde Pública 2005; 21(3): 898-906. 
52. Moreira FR, Barbosa C, Câmara G, Almeida-Filho R. Inferência geográfica e suporte à decisão. In: Câmara G, Davis C, Monteiro AMV. Introdução à ciência da geoinformação. [acesso em 25 de março de 2009]. Disponível em: http://www.dpi.inpe.br/gillberto/livro/introd/

53. Moreira RS, Nico LS, Tomita NE, Ruiz T. A saúde bucal do idoso brasileiro: revisão sistemática sobre o quadro epidemiológico e acesso aos serviços de saúde bucal. Cad Saude Publica 2005; 21(6): 1665-75.

54. Moreira RS, Nico LS, Tomita NE. A relação entre o espaço e a saúde bucal coletiva: por uma epidemiologia georreferenciada. Ciênc. saúde coletiva 2007 ; $12(1)$ : 275-84.

55. Moysés SJ, Sheiham A. Saúde Bucal Coletiva: personagens, autores ou ... Pirandello de novo? In: Kriger L, organizador. ABOPREV: promoção de saúde bucal. São Paulo: Artes Médicas; 2003. p. 387442.

56. Musacchio E, Perissinotto E, Binotto P, et al. Tooth loss in the elderly and its association with nutritional status, socio-economic and lifestyle factors. Acta Odontol Scand 2007;65: 78-86.

57. Nadanovsky P, Luiz RR, Costa AJL. Causalidade em saúde bucal. In: Costa AJL, Nadanovsky P, Luiz RR. Epidemiologia e bioestatística na pesquisa odontológica. São Paulo: Atheneu; 2005. p. 71-87.

58. Palloni A, Peláez M. Histórico e natureza do estudo. In: Lebrão ML, Duarte YAO, organizadores. SABE - Saúde, Bem-estar e Envelhecimento: O projeto SABE no município de São Paulo: uma 
abordagem inicial. Brasília: Organização Pan-Americana de Saúde; 2003. p.15-32.

59. Palmqvist S. Treatment need and received in an elderly Swedish county population. Gerodontics 1988; 4: 272-6.

60. Pereira AC, Silva FRB, Meneghim MC. Prevalência de cárie e necessidade de prótese em uma população geriátrica institucionalizada da cidade de Piracicaba-SP. Rev Odont Brasil Central 1999; 8(26): 17-21.

61. Petersen PE. The World Oral Health Report 2003: continuous improvement of oral health in the 21st century - the approach of the WHO Global Oral Health Programme. Community Dent Oral Epidemiol 2003;31(Suppl. 1): 3-24.

62. Queiroz RCS, Portela MC, Vasconcellos MTL. Pesquisa sobre as Condições de Saúde Bucal da População Brasileira (SB Brasil 2003): seus dados não produzem estimativas populacionais, mas há possibilidade de correção. Cad Saúde Pública 2009; 25:47-58.

63. Rasbash J, Browne W, Healy M, Cameron B, Charlton C. MLwiN. 2.02 ed: Institute of Education; 2005.

64. Reis SCGB, Higino MASP, Melo HMD, Freire MCM. Condição de saúde bucal de idosos institucionalizados em Goiânia-GO, 2003. Rev Bras Epidemiol 2005; 8(1): 67-73.

65. Shah N. Gender issues and oral health in elderly Indians. Int Dent Journal 2003; 53: 475-84. 
66. Silva DD, Souza MLR, Toledo R, Lisboa CM, Taglietta MF. Condições de saúde bucal em idosos na cidade de Piracicaba. Rev Assoc Paulista Cirurgião Dentista 2002; 56(3).

67. Silva DD, Souza MLR, Wada RS. Saúde bucal em adultos e idosos na cidade de Rio Claro, São Paulo, Brasil. Cad Saúde Pública 2004; 20(2): 626-31.

68. Skudutyte R, Aleksejuniene J, Eriksen HM. Dental caries in adult Lithuanians. Acta Odontol Scand 2000; 58: 143-7.

69. Slade GD, Nuttall N, Sanders AE, Steele JG, Allen PF, Lahti S. Impacts of oral disorders in the United Kingdom and Australia. British Dental Journal 2005;198: 489-93.

70. Slade GD, Spencer AJ, Gorkic E, Andrews G. Oral health status and treatment needs of non-institutionalized persons aged $60_{+}$in Adelaide, South Australia. Australian Dent Journal 1993; 38(5): 37380.

71. Steele JG, Sanders AE, Slade GD, et al. How do age and tooth loss affect oral health impacts and quality of life? A study comparing two national samples. Community Dent Oral Epidemiol 2004;32: 107-14.

72. Suominen-Taipale A, Alanen P, Helenius $H$, Nordblad A, Uutela A. Edentulism among Finnish adults of working age, 1978-1997. Community Dent Oral Epidemiol 1999;27: 353-65.

73. Susin C, Oppermann RV, Haugejorden O, Albandar JM. Tooth loss and associated risk indicators in an adult urban population from south Brazil. Acta Odontol Scand 2005;63: 85-93. 
74. Susser M, Susser E. Choosing a future for Epidemiology: II. From black box to Chinese boxes and eco-epidemiology. Am J Public Health 1996;86: 674-7.

75. Treasure E, Kelly M, Nuttall N, Nunn J, Bradnock G, White D. Factors associated with oral health: a multivariate analysis of results from the 1998 Adult Dental Health survey. British Dental Journal 2001;190: 608.

76. Vermelho LL, Monteiro FG. Transição demográfica e epidemiológica. In: Medronho RA et al. Epidemiologia. São Paulo: Ed. Atheneu; 2004. p. 91-103.

77. Victora CG, Huttly SR, Fuchs SC, Olinto MT. The role of conceptual frameworks in epidemiological analysis: a hierarchical approach. Int $\mathrm{J}$ Epidemiol 1997;26: 224-7.

78. World Health Organization. Oral health surveys: basic methods. $4^{\text {th }}$ ed. Geneva: ORH/EPID; 1997. 


\section{Anexos}


ANEXO A

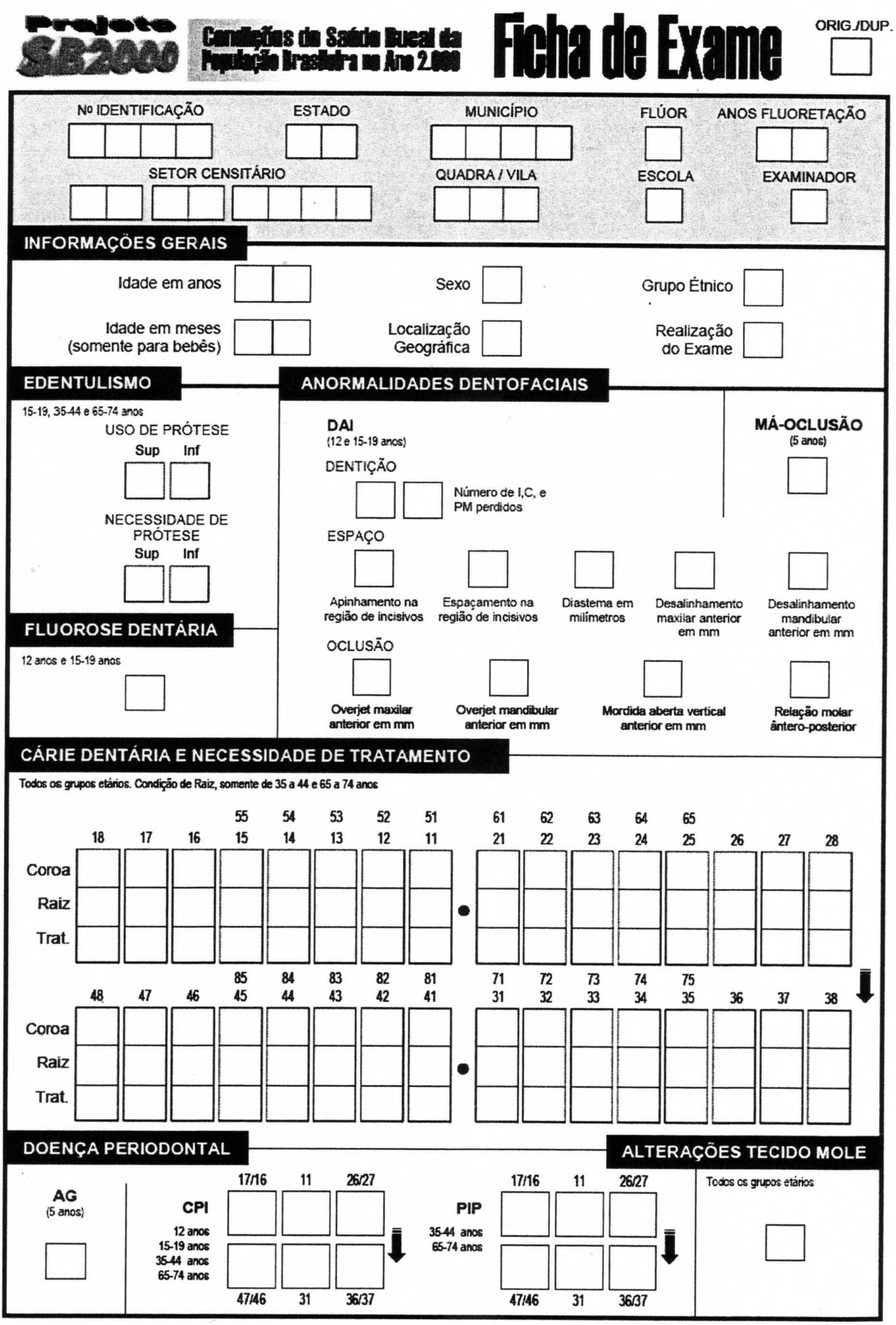




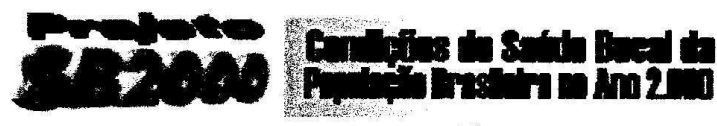

\section{Formulário de avaliação sócioeconômica, acesso e autopercepção em saúde bucal}

\section{CARACTERIZAÇÄO SÓCIOECONÓMICA}

(1) Número de pessoas

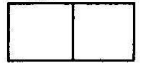

(4) Tipo de Escola

0. Hö́o é estudante 1- Píblica 3- Outos

(7) Renda Familiar (em reais)

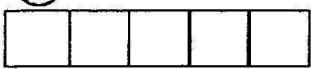

(2) Escolaridade (anos de estuso)

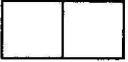

(5) Moradia

1- Própia

3 - Alugada

4- Cedid

(8) Renda Pessoal (em rezic)

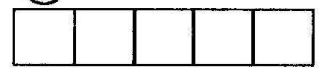

(3) Estudante

0. $\sin$

6) Nủmero de cómodos da casa

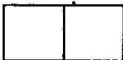

(9) Posse de automóvel

0 - Mto possti

1 - Possui um autombives

2. Possui dois ou mais automóveis

\section{ACESSO A SERVIÇOS ODONTOLÓGICOS}

(10) Jả foi ao dentista ałgurna vez na vida? O-sim

(12) Onde?

1 - Nunca for a do denticta

2-Senigo Priwado L beral

3- Senvipo Privado (danos e coménioc)

4 - Senvipo flartripico

5-outro:

(11) Há quanto tempo?

0. Nunca toi as denbista

1 - Menos de 1 ano

2-De 1 a 2 anoc

(14) Como avalia o atendimento?

D- Munca foi ao dentizte

1- Pétrimo

2-Ruim

3- Regatur

(13) Por quê?

5- Óंín

1- Conca for an do

2-Dor

3- Sangrarrento gengiva

5 - Ferites, erocosos ou manchas na boca

6-Oatros

(15) Recebeu informaçōes sobre como evitar problemas bucais?

]$_{1-5 m}^{0-5 m}$

16 Considera que necessita de tratamento atualmente? $0-\operatorname{sim}$

\section{AUTOPERCEPÇÄO EM SAÚDE BUCAL}

(17) Como classificaria sua saúde bucal?

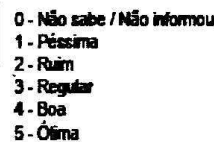

(19) Como classificaria sua mastigaçäo?

O- Niso abe i Nio informou

1. Ptaxina

2-Puin

3-Reguia

4-Boa

5- Óina

(21) De que forma a sua saude bucal afeta o seu elacionamento com outras pessoas?

O- NGo vabe i Niä intomou

1 - Nö ateta

3. Afta mis ou neno:

4. Asta milo

(18) Como classificaria a aparência de seus dentes e gengivas?

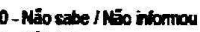

1. Péscina

2-Ruin

3-Regut

4-Boa

5- Óinin

20) Como classificaria a sua fala devido aos seus dentes e gengivas?

o-Nï sate I Itio informow

1-Pexsina

2-Rum

3-Reguar

1- Ban

(22) O quanto de dor seus dentes e gengivas causaram nos últimos 6 meses?

0 - Nerhuma Dor

1- Pouca Dor

2- Média Dor

- Inita Da 

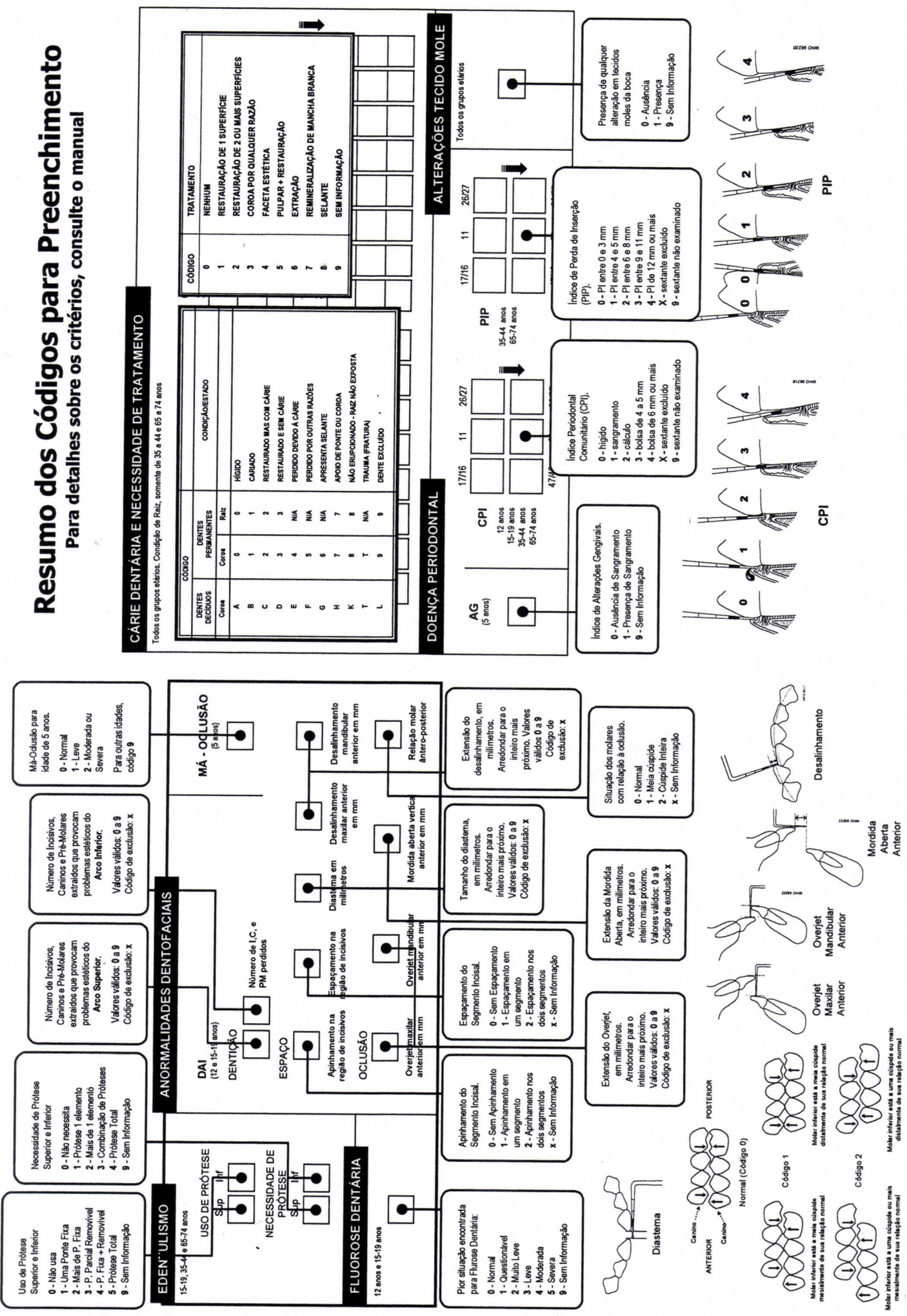
ANEXO B

\section{Universidade de São Paulo}

Faculdade de Saúde Pública

\section{COMITÊ DE ÉTICA - COEP}

Av. Dr. Arnaldo, 715 - Assessoria Acadêmica - CEP 01246-904 - São Paulo - Brasil Telefones: (55-11) 3066-7779 - e-mail: coep@ifsp.usp.br

\section{Of.COEP/236/05}

Pelo presente, informo que o Comitê de Ética em Pesquisa da Faculdade de Saúde Pública da Universidade de São Paulo-COEP analisou de acordo com os requisitos da Resolução CNS/196/96 e suas complementares, o Protocolo de Pesquisa n. ${ }^{\circ}$ 1417, intitulado: "A SAÚDE BUCAL NO TERRITÓRIO BRASILEIRO: A DESIGUALDADE EM DIFERENTES ESCALAS GEOGRÁFICAS", apresentado pelo pesquisador Rafael da Silveira Moreira, tendo em vista que se trata de pesquisa baseada em banco de dados de domínio público, näo há necessidade de emissão de parecer deste Comitê.

Atenciosamente,

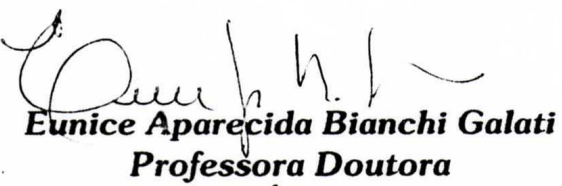

Coordenadora do Comitê de Ética em Pesquisa da FSP-COEP 


\section{Currículo Lattes do autor}

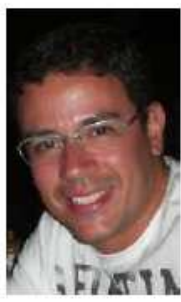

Rafael da Silveira Moreira

possui graduaçấo em Odontologia pela Faculdade de Odontologia da Universidade Federal

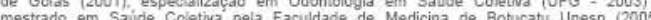
Conciviu doutorado em Saúde Pública na Faculdade de Saúde Pübica da Universidade de Săo Paulo (FSP-USP), área de concentraçăo em Epidemiologia (2009). Tem expereñncia na

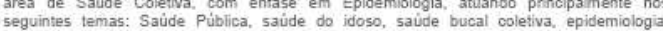

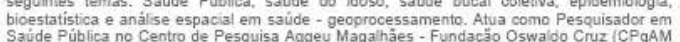
-Fiocruz)
(Texto informado pelo autor)

Ûltima atualização do curriculo em 11/12/2009

Enóereço para acessar este $C V$ :

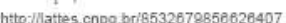

Cortificado

$11 / 12 / 09$
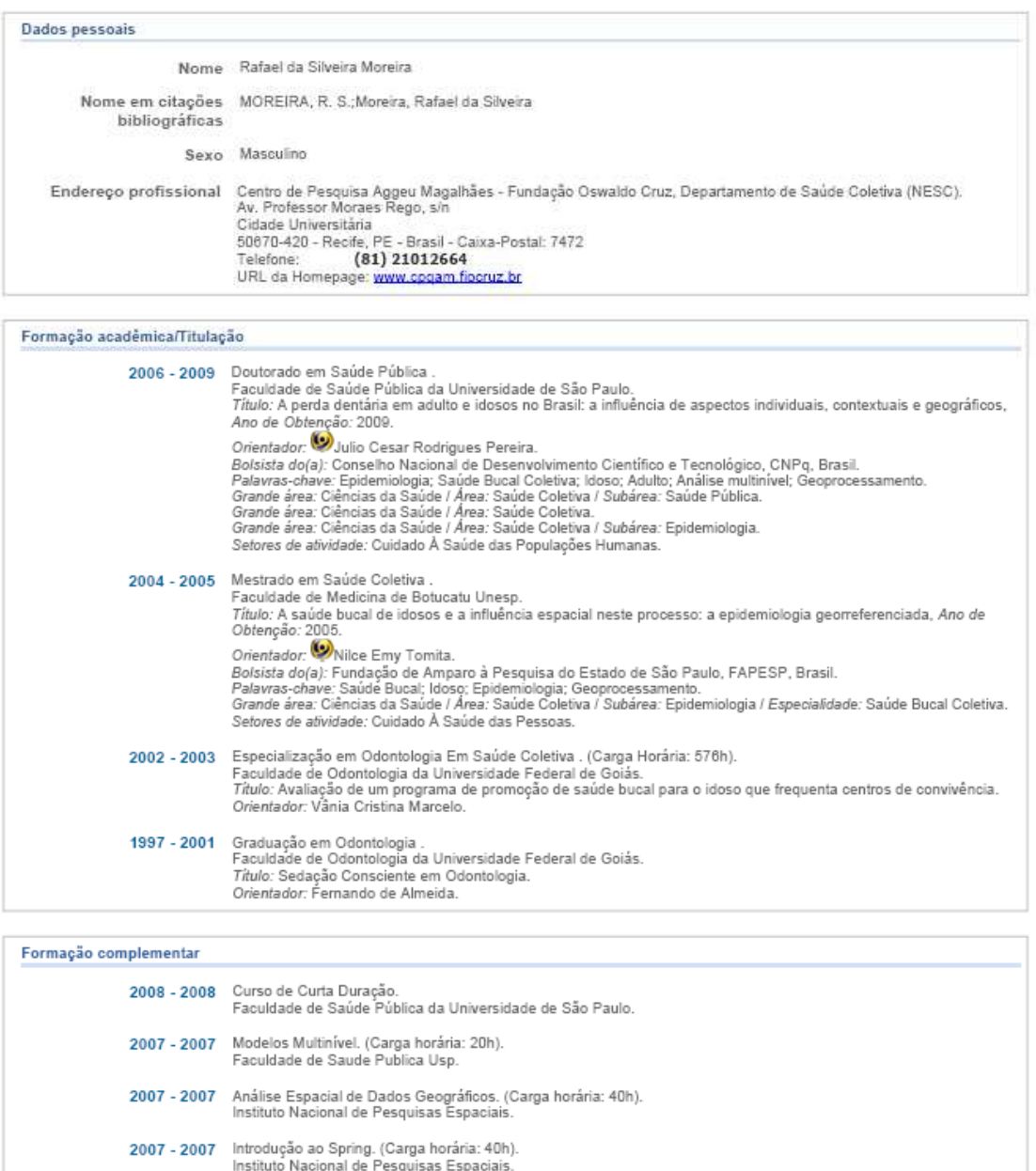
